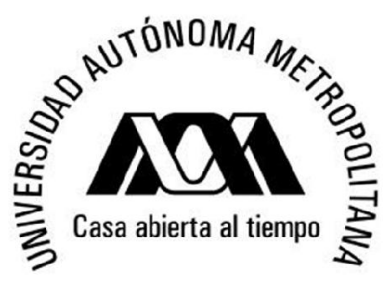

UNIVERSIDAD AUTÓNOMA METROPOLITANA

Tztapalapa

\title{
“RELACIÓN DEL ESTRÉS OXIDANTE CON LA BIOSÍNTESIS DE LOVASTATINA POR Aspergillus terreus EN FERMENTACIÓN SÓLIDA Y LÍQUIDA"
}

\author{
TESIS \\ PARA OBTENER EL GRADO DE \\ DOCTORA EN BIOTECNOLOGÍA \\ PRESENTA
}

M. en B. Roxana Uri Miranda Labra

COMITÉ TUTORIAL

Director de Tesis

Dr. Javier Barrios González

Asesores

Dr. Luis Enrique Gómez Quiroz

Dr. Francisco Fierro Fierro 
El presente proyecto se realizó en el Laboratorio de Ingeniería Genética y Metabolitos Secundarios del Departamento de Biotecnología de la División de Ciencias Básicas y de la Salud, Universidad Autónoma Metropolitana, unidad Iztapalapa.

El Doctorado en Biotecnología de la Universidad Autónoma Metropolitana, está incluido en el Programa Nacional de Posgrados de Calidad (PNPC) del Consejo Nacional de Ciencia y Tecnología (CONACyT), con la referencia 001466.

Así mismo, se contó con el Apoyo de CONACyT, con el otorgamiento de la Beca para Estudios Doctorales No. 202349.
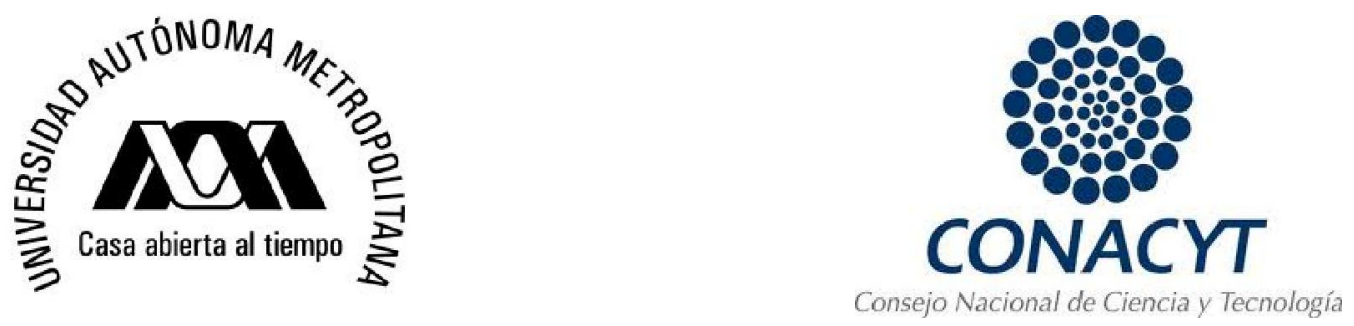
El jurado designado por la

División de Ciencias Biológicas y de la Salud de la Unidad Iztapalapa aprobó la tesis

\section{"RELACIÓN DEL ESTRÉS OXIDANTE CON LA BIOSÍNTESIS DE LOVASTATINA POR Aspergillus terreus EN FERMENTACIÓN SÓLIDA Y LÍQUIDA"}

que presentó la

M. en B. Roxana Uri Miranda Labra

Comité Tutoral:

Director: Dr. Javier Barrios González

Asesor: Dr. Francisco Fierro Fierro

Asesor: Dr. Luis Enrique Gómez Quiroz

Jurado:

Presidente: Dr. Francisco Fierro Fierro

Secretario: Dr. Armando Mejía Álvarez

Vocal: Dr. Luis Enrique Gómez Quiroz

Vocal: Dr. Armando Luna López 
"Mira que te mando que te esfuerces y seas valiente; no temas ni desmayes. Porque el Eterno estará contigo a dondequiera que vayas" Josué 1:7 
Y sentía que nunca llegaría este momento... pero el tiempo llegó y deseo aprovechar este espacio para DED $\mathcal{C A R}$ este trabajo a...

\section{A mis padres Mary y Sacil:}

Sabiendo que no existirá una forma de agradecer toda una vida de sacrificios y esfuerzos, quiero que sientan que el objetivo logrado también es suyo y que la fuerza que me ayudó a conseguirlo fue su apoyo. LOS AMO, son los mejores padres de este mundo.

\section{A mis hermanos Gersam. Mare y Yhadin:}

Por todo el amor que me han demostrado siempre, no sé que hubiera hecho sin ustedes en mi vida, ¡son mi adoración!

\section{A mi espasa Vicente:}

A ti que te conocí cuando inicié este proyecto importante y te volviste mi apoyo incondicional para lograr este objetivo. Gracias por todo ese apoyo, pero sobretodo, gracias por ese pequeño gran regalo que me diste durante el transcurso de esta gran aventura...

\section{A mi hija Joab Emiliana...}

Cuanto te amo mi hijo hermoso, tu sonrisa, tu belleza, tu inocencia, todo tú, me cautivaste desde que supe de tu existencia, volviéndote la más grande de mis alegrías y mis motivaciones y en los momentos más difíciles, fuiste tu quien me dio la fuerza para seguir adelante en todo, particularmente, me diste esa chispa para poder culminar este proyecto.

\section{Y coma alvidarte mi princesa Zirel...}

¡Esa sonrisa hermosa que me hacía recordar que la vida es tan bella como tu! Gracias por tantas travesuras y momentos maravillosos a tu lado, te adoro mucho mi pequeña princesa de caramelo. 
Pero en especial, quiero DED $\mathcal{C}$ AR este proyecto a unas personas maravillosas en particular, porque es gracias a ellos que estoy aquí, y porque además son mi ejemplo de trabajo, esfuerzo y dedicación...

A mis abuelos...

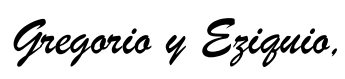

a quienes el Eterno me los ha bendecido con muchos años de vida y aún los puedo disfrutar.

Pero sobretodo, a dos mujeres maravillosas, fuertes e inteligentes, a quienes hoy la nostalgia trae a mi memoria porque ya no están con nosotros, a mis hermosas abuelas que partieron de este mundo durante el tiempo en el que desarrollaba este proyecto, a mi Criss y a mi Zlower, tu grandota por fin terminó...

Esta tesis se las dedica a ustedes con toda mi amor... 
Agradezea enormemente a...

Al Dr. Zacier por su paciencia, por todas sus enseñanzas, sus pláticas, pero sobretodo sus consejos, he aprendido mucho de usted y créame, es un gran ejemplo para mí, en lo personal como en lo profesional. Gracias por adoptarme como hija estos más de 7 añitos...

Al Dr. Luis Eurique, porque aparte de ser mi asesor, es mi paisano, una gran persona, le estoy y le estaré muy agradecida por todo lo que me ayudó, tanto en el ámbito profesional como en lo personal...y nos queda un camino por delante! Sólo espero no se arrepienta ;)

A la Dra. Conchita, gracias por todo su apoyo, ayuda y sobretodo comprensión para poder salir adelante en los momentos más difíciles que he enfrentado en la vida hasta el momento. Es usted una mujer maravillosa, mi respeto y admiración para usted siempre!

A los Doctores Paca Peke. Paca Fierra. Armanda y Aracely, porque me hicieron sentir parte de una familia en el laboratorio y me apoyaron cuando lo requerí, gracias por todo!

A todos mis compañeros del laboratorio de Ingeniería Genética y Metabalitas Secundarias, por hacer más ameno el trabajo, en especial a Hugo, Jessy, Jaime, Omar, Vicky, Ana, Marisol, por todos los momentos compartidos.

A mis amigas Maura. Diana, Jey. Tati, Tere, Paa, Oli no sé que hubiera hecho sin ustedes! Son una bendición en mi vida. 
Un especial agradecimiento a Ailed Pérez y Mariel Mendoza, por su invaluable apoyo y aportación en la parte del silenciamiento del gen Atyapl y Northern-blot de srrA respectivamente, pero sobretodo, gracias por su amistad.

Y sobretodo, gracias a CONACyT por la beca otorgada para poder cumplir con este objetivo, y a la UAM por darme la oportunidad para lograrlo.

Y a todos aquellos que de alguna manera estuvieron siempre conmigo y que creyeron en mí, y que son tantos que no cabrían en este pequeño espacio.

A todos ustedes... Gracias! 


\section{INDICES}

Índice de Tablas y Figuras ....................................................................................................

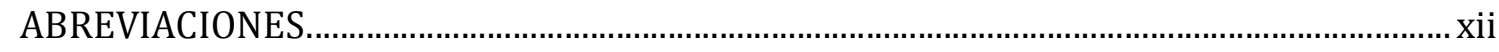

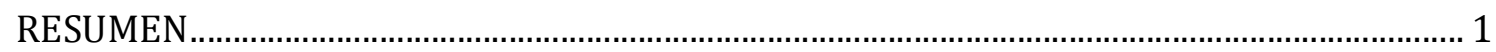

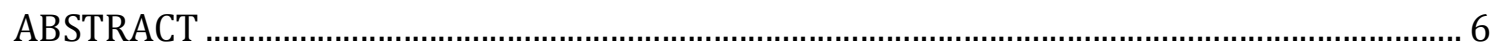

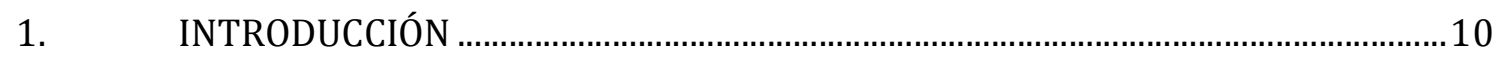

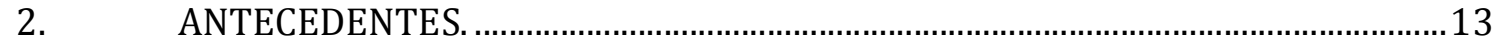

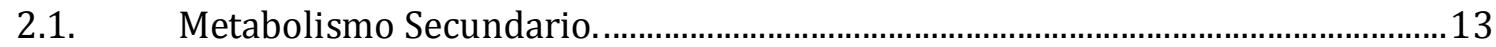

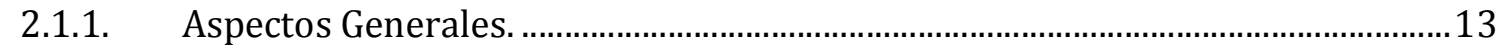

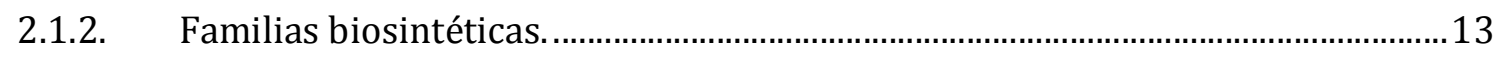

2.2. MS derivados del Acetil-CoA: LAS ESTATINAS..................................................14

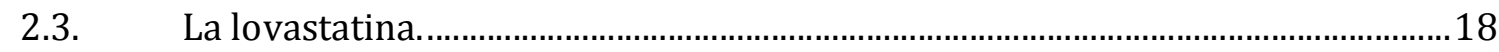

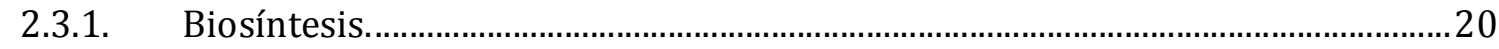

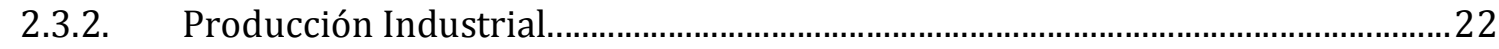

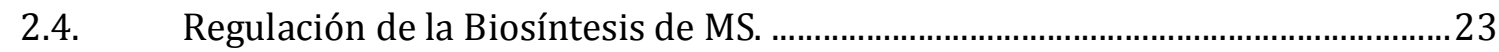

2.4.1. Factores Transcripcionales que regulan la Biosíntesis de MS. ............................24

2.4.2. Manipulación de la Regulación de la Biosíntesis de Lovastatina para mejorar su

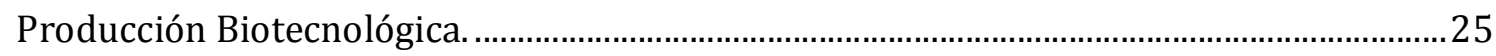

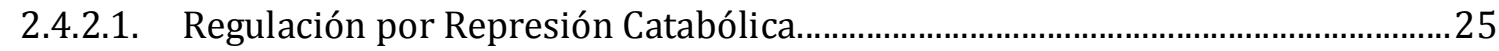

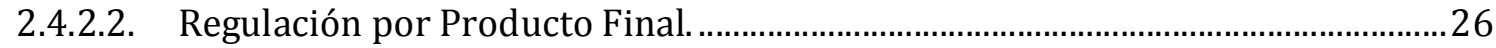

2.4.2.3. Regulador Global del Metabolismo Secundario: LaeA...........................................26

2.4.2.4. Fisiología Especial del Medio Sólido...................................................................26

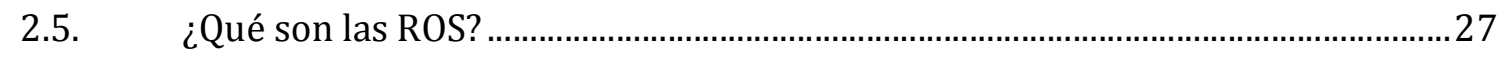

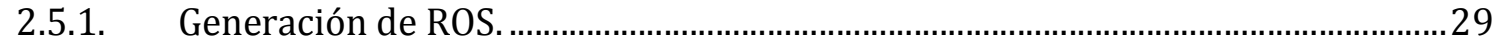

2.5.1.1. Generación de ROS en hongos. .................................................................................32

2.5.2. Las ROS como moléculas señalizadoras. ............................................................... 32

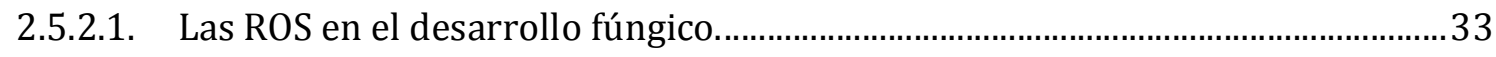

2.5.2.2. Enzimas Antioxidantes como Indicadores de ROS en el Desarrollo Celular.......35

2.5.2.3. Percepción de las ROS y las respuestas antioxidantes en hongos. ........................38

2.6. Relación del Metabolismo Secundario, Desarrollo Fúngico y EOX.......................44

2.6.1. Metabolismo Secundario y Desarrollo Fúngico.........................................................44

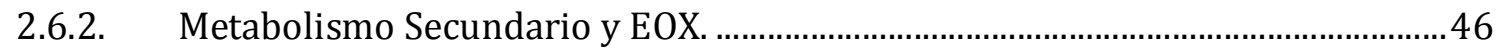

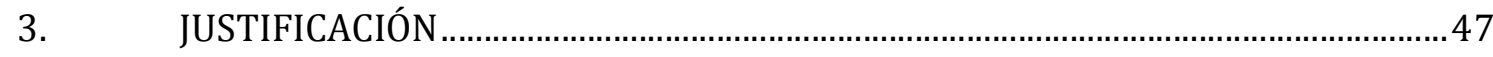




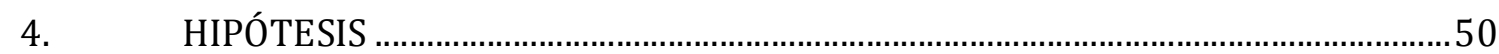

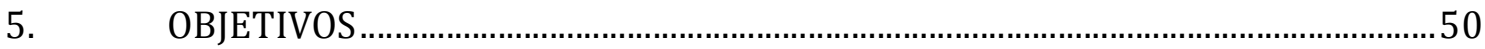

5.1. OBJETIVO GENERAL …………………………................................................50

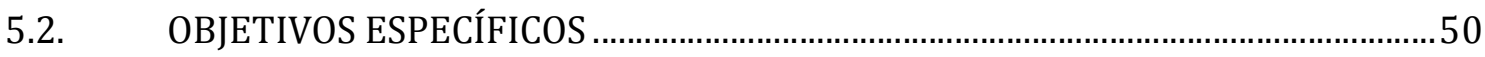

6. MATERIALES Y MÉTODOS...........................................................................

6.1. Cepas, medio de cultivo y condiciones de cultivo..................................................51

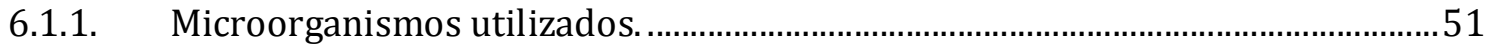

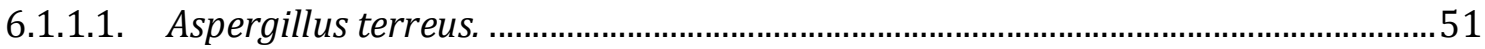

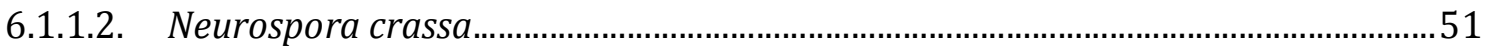

6.1.2. Propagación de esporas para FL y FS................................................................51

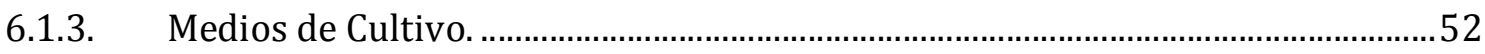

6.1.3.1. Medio de propagación de esporas y conservación de cepas.................................52

6.1.3.2. Producción de Lovastatina. ……………………………………………………...52

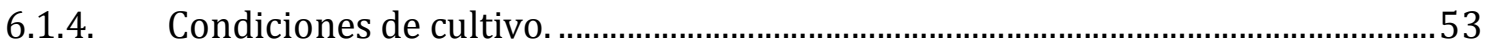

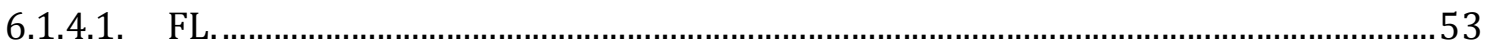

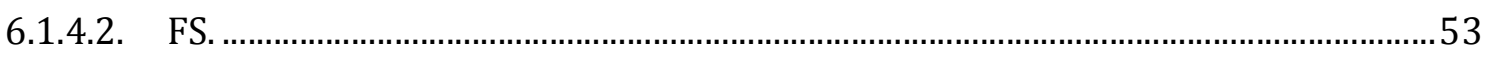

6.1.4.3. CAJA DE PETRI................................................................................................53

6.1.4.4. Empleo de Antioxidantes y Oxidantes exógenos......................................................53

6.2. Técnicas analíticas............................................................................................54

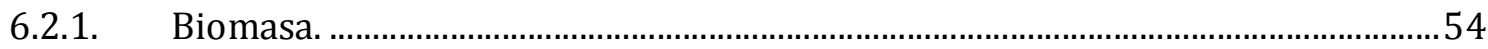

6.2.2. Extracción y cuantificación de Lovastatina.........................................................54

6.2.2.1. Conversión de la lovastatina de su forma Lactona a su forma $\beta$-hidroxiácida. 55

6.2.3. Extracción y cuantificación de azucares.................................................................55

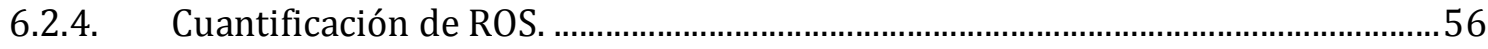

6.2.5. Determinación de GSH/GSSG (balance redox)......................................................56

6.3. Técnicas Moleculares..........................................................................................57

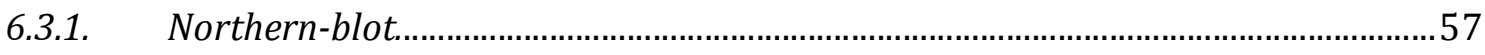

6.3.1.1. Extracción de RNA........................................................................................57

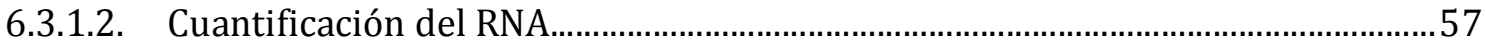

6.3.1.3. Electroforesis en geles con Formaldehído...........................................................58

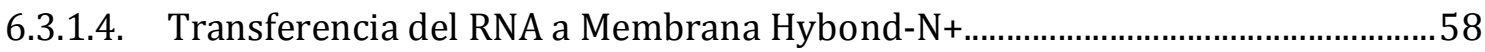

6.3.1.5. Fijación del RNA a la membrana. .......................................................................59

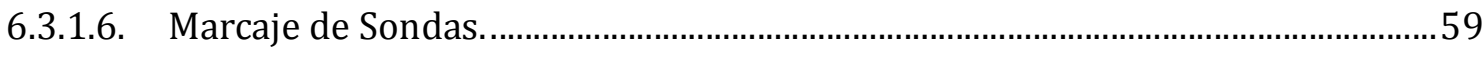




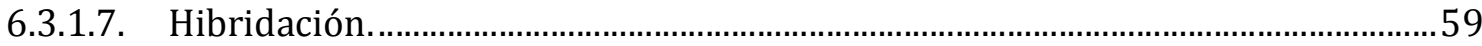

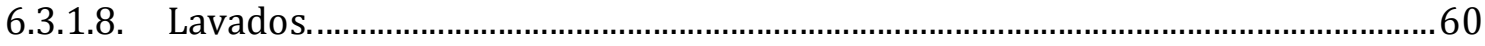

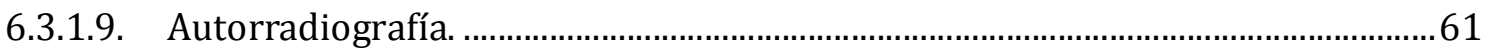

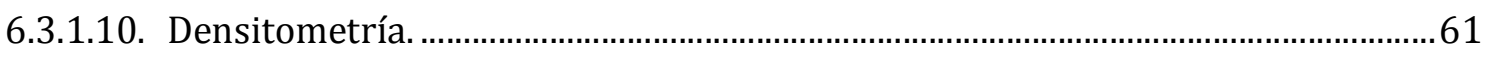

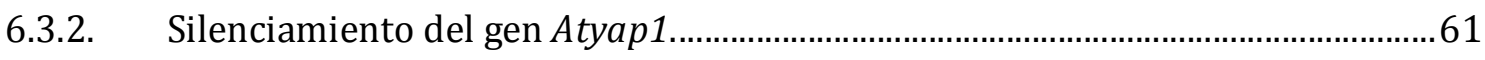

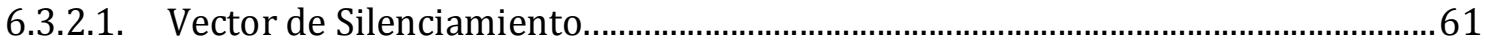

6.3.2.2. Condiciones para la obtención del fragmento del gen Atyap1 para

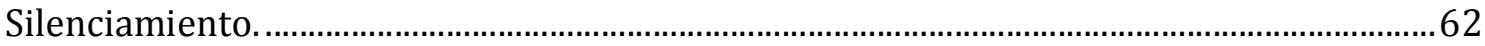

6.3.3. Lisis Alcalina: Técnica para obtener ADN plasmídico.............................................63

6.3.4. PCR de colonia para identificación de clonas..........................................................64

6.3.5. Purificación de productos de PCR y vectores............................................................64

6.3.6. Digestiones con enzimas de restricción.........................................................................64

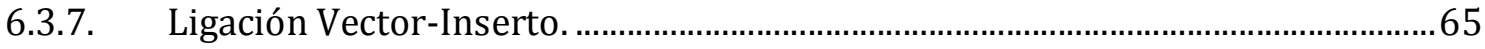

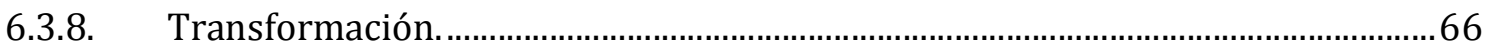

6.3.9. Análisis in silico del promotor.............................................................................66

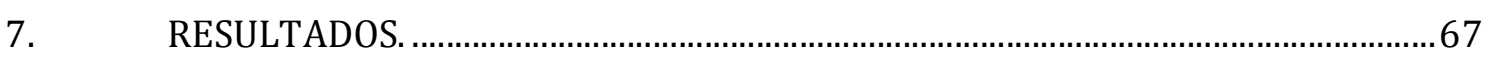

7.1. Cinéticas de producción en FS y FL de lovastatina...............................................67

7.2. Perfil de acumulación de ROS durante la trofofase e idiofase de producción en FS y FL. 68

7.3. Estado redox de trofo- e idiofase de FS y FL........................................................69

7.4. Efecto de antioxidantes exógenos sobre la producción de lovastatina...............70

7.4.1. Efecto de antioxidantes en caja de Petri..................................................................... 70

7.4.2. Efecto del antioxidante TMTU en cultivo en caja de Petri......................................72

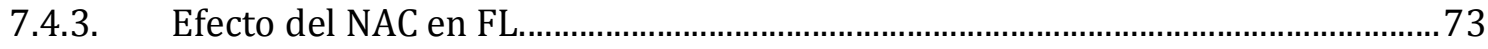

7.4.3.1. Efecto de diferentes concentraciones de NAC. ......................................................73

7.4.3.2. Efecto del tiempo de adición del NAC.......................................................................75

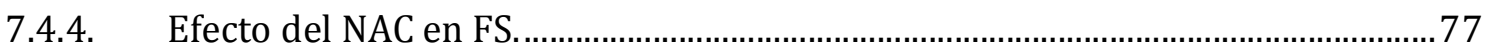

7.4.5. Efecto del NAC sobre la expresión de los genes de la ruta biosintética: $l o v E$ y lovF. $\quad 79$

7.4.5.1. Análisis de Northern de los genes $\operatorname{lov} E$ y lovF en FS............................................79

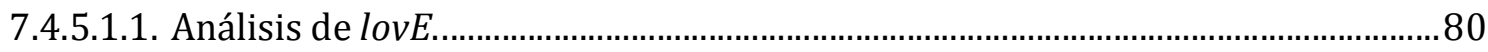

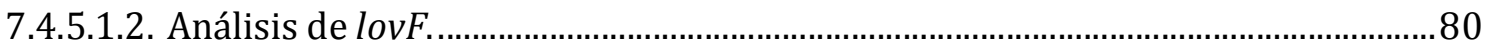

7.4.5.2. Análisis de Northern de los genes lovE y lovF para FL..........................................81 


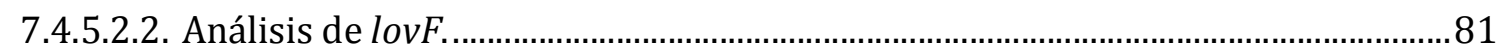

7.5. Efecto de oxidantes exógenos sobre la producción de lovastatina. .....................82

7.5.1. Efecto de oxidantes en cultivo en caja de Petri......................................................82

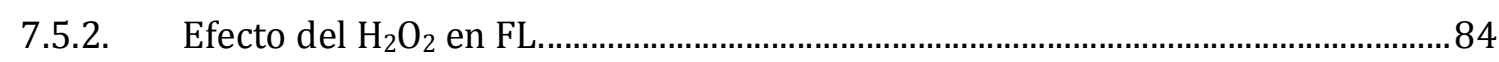

7.5.3. Efecto del $\mathrm{H}_{2} \mathrm{O}_{2}$ sobre la biosíntesis de lovastatina en FS......................................85

7.6. Mecanismo que pueden regular la biosíntesis de lovastatina...............................86

7.6.1. Análisis in silico del promotor del gen lovE ......................................................86

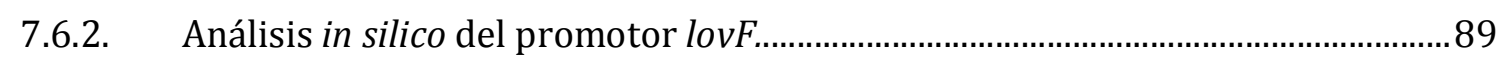

7.6.3. Perfiles de expresión de genes que codifican para los Factores

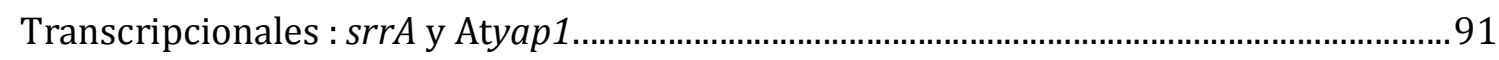

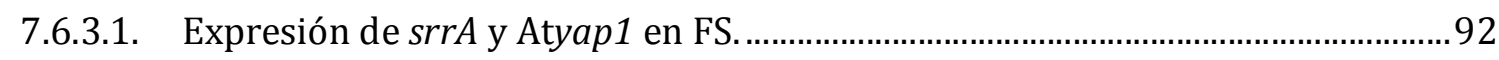

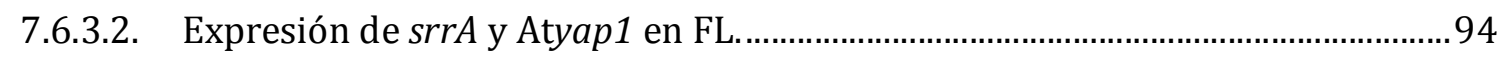

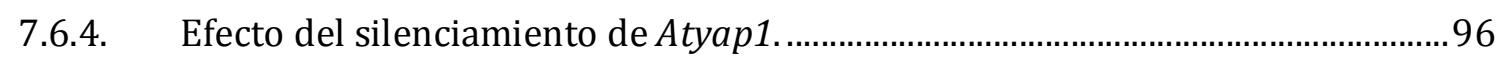

7.6.4.1. Construcción del vector pGdpPkiRNAi-Atyap1....................................................96

7.6.4.2. Caracterización de las transformantes de A. terreus con la construcción

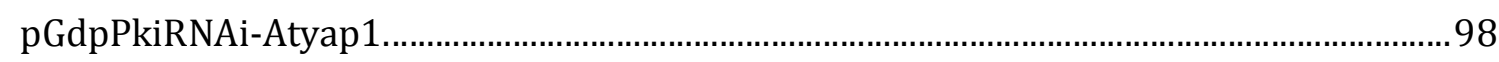

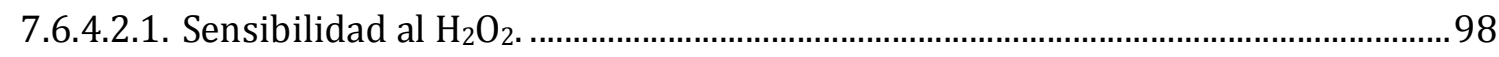

7.6.4.2.2. Esporulación y producción de lovastatina de las transformantes de A.terreus. 99

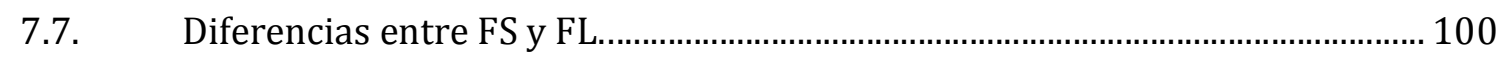

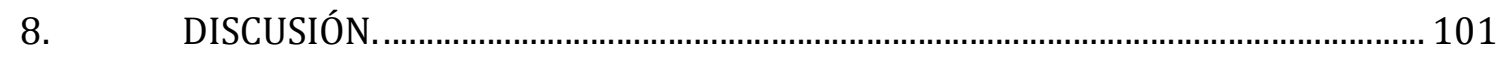

8.1. Diferencias de producción de lovastatina en FS y FL: Fisiología especial del

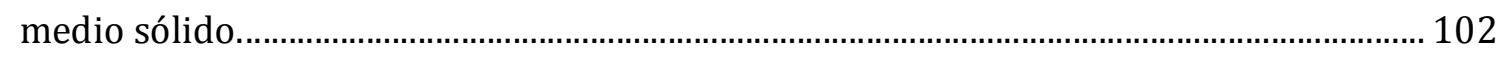

8.2. Caracterización del PEO: Cuantificación de ROS y balance redox. ..................... 103

8.3. Las ROS son necesarias para la biosíntesis de lovastatina.................................. 105

8.4. El mecanismo de regulación de ROS sobre la biosíntesis de lovastatina, puede ser a través de Factores Transcripcionales que responden a EOX..................................... 106 8.5. Diferencias en el control de ROS en FS y FL: ¿Causa de una mayor producción

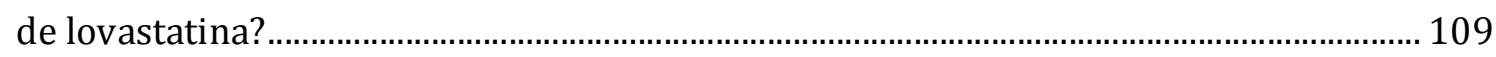

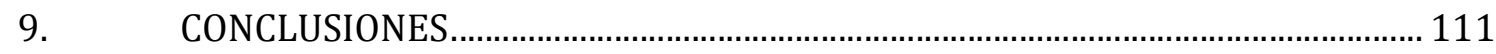

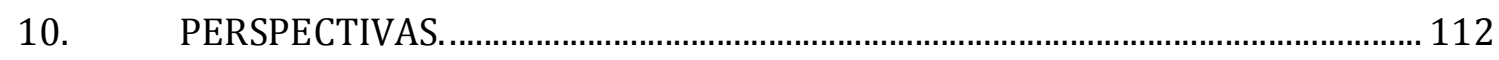

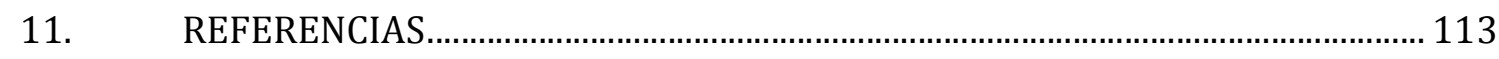




\section{Índice de Tablas y Figuras...}

Fig. 1Ruta biosintética del colesterol. La HMG-CoA reductasa es la enzima limitante de la biosíntesis de esta molécula.

Fig. 2 Estructuras químicas de las estatinas naturales y sus derivados: simvastatina y pravastatina (Barrios-González \& R. Miranda 2010).

Fig. 3 Modelo que explica la gran variedad de efectos biológicos de las estatinas; y por tanto, los usos actuales y potenciales. La inhibición de la HGM-CoA reductasa, no solamente reduce los niveles de colesterol, sino también los intermediarios isoprenoides, afectando la prenilación de las proteínas G (i.e., Ras). Esto puede resultar en la modulación de la transducción de señales de los receptores hacia la expresión de los genes, que directa o indirectamente afectan el balance proliferación/apoptosis, quimiosinas inflamatorias, y mensajeros citogenéticos, todos mediados por proteínas G (Barrios-González \& R. Miranda 2010). 18

Fig. 4 Estructura química de la lovastatina (Rollini 2002).

Fig. 5 Clúster biosintético de la lovastatina: $\operatorname{lov} B$ y $\operatorname{lov} F$ biosíntesis de policétidos; lov $C$ enoil reductasa; lov $D$ transesterasa; lovE y lovH genes reguladores; ORF2 y ORF17 genes del citocromo P-450; ORF1 y ORF10 genes potenciales de resistencia; ORF12 y ORF16 genes de transporte; lovG, ORF12, ORF15 y ORF18 función desconocida) (BarriosGonzález \& R. Miranda 2010). 20

Fig. 6 Ruta biosintética de lovastatina, mostrando las enzimas involucradas y los genes que lo codifican (Barrios-González \& R. Miranda 2010).

Fig. 7 Las especies reactivas del oxígeno (ROS), superóxido $\left(\mathrm{O}_{2}^{\bullet}-\right)$, peróxido de hidrógeno $\left(\mathrm{H}_{2} \mathrm{O}_{2}\right)$, y radical hidroxilo $(\mathrm{HO} \bullet)$, se generan a partir de la reducción parcial del oxígeno molecular $\left(\mathrm{O}_{2}\right)$. 28

Fig. 8 Estructura electrónica de las ROS generadas a partir de la molécula de dioxígeno (Folch-Mallol et al. 2004).

Fig. 9 Producción y detoxificación de ROS en las células eucariotas 31

Fig. 10 Modelo de regulación de la diferenciación celular por ROS (Aguirre et al. 2005). ... 34 
Fig. 11 Regulación por oxidantes de Yap1p. A) Condiciones de no estrés y B) Condiciones de EOX por diamida o por $\mathrm{H}_{2} \mathrm{O}_{2}$ (Moye-Rowley 2003). 40

Fig. 12 Ruta responsable de la respuesta a $\mathrm{H}_{2} \mathrm{O}_{2}$ en Schizosaccharomyces pombe (Aguirre et al. 2005) 44

Fig. 13 Controles integrados en la transducción de señales en la producción de esporas (conidiación) y el metabolismo secundario en Aspergillus nidulans. Las líneas continuas, muestran las rutas conocidas, y las líneas punteadas indican una ruta hipotética. FadA, subunidad $\alpha$ de una proteína $\mathrm{G}$, heterotrimérica; FlbA, una proteína regulatoria que tiene un motivo RGS (regulador de la señalización de proteína G); PkaA, subunidad catalítica de una proteína quinasa $\mathrm{A}$; BrlA, factor de transcripción, producto del primer gen de la vía reguladora central de la conidiogénesis; AflR (regulador de aflatoxinas), un factor de la transcripción específica de la biosíntesis de esterigmatocistina/aflatoxina (Keller et al. 2005). 45

Tabla 1 Composición del medio Power (mantenimiento y propagación de esporas) ............ 52

Tabla 2 Composición del Medio de Producción de Lovastatina para FL y FS...................... 52

Tabla 3 Secuencias de oligos diseñados y empleados en este trabajo 60

Fig. 14 Vector pGdpPki-RNAi empleado para silenciar Atyapl de A. terreus (Marcial et al. 2011).

Fig. 15 Cinética de producción de lovastatina en A)FS y B)FL. También se presenta la cinética de producción de biomasa en ambos sistemas de cultivo. Nótese que el comportamiento del pH fue similar en ambos sistemas de producción.

Fig. 16 Perfil de acumulación de ROS durante la trofofase e idiofase de A)FS y B)FL. Nótese la diferencia de escalas en la concentración de ROS entre los paneles A y B, debido a bajos niveles en FS. El contenido de ROS con diferentes letras indica diferencias significativas del resto, esto de acuerdo a la prueba de comparación LSD $(\mathrm{p}<0.05)$. $\mathrm{URF}=$ Unidades Relativas de Fluorescencia 68

Fig. 17 Balance redox (GSH/GSSG) durante la trofo- e idiofase de la fermentación de lovastatina en FS y FL. Nótese la diferencia de escalas en el cociente GSH/GSSG entre FS y FL 69

Fig. 18 Molécula de N-Acetil-L-cisteina. 70 
Fig. 19 Efecto de diferentes concentraciones del NAC sobre la morfología de Aspergillus terreus al día 10. 71

Fig. 20 Efecto sobre la biosíntesis de lovastatina al emplear diferentes concentraciones de NAC en cultivo sólido en caja de Petri al día 10. Los datos originalmente se obtuvieron en unidades de $\mathrm{ug} / \mathrm{ml}$, pero se representaron en \% para efectos de comparación. Se observaron diferencias significativas con respecto al control, de acuerdo a la prueba de Dunnet $(\mathrm{p}<0.05)$ 71

Fig. 21 Molécula de Tetrametiltiourea 72

Fig. 22 Efecto del antioxidante TMTU sobre la biosíntesis de lovastatina al día 10 de cultivo en caja de Petri . Se observó un efecto negativo significativo $(\mathrm{p}<0.05)$ de acuerdo a la prueba de comparación de Dunnet. 73

Fig. 23 Relación entre la producción de lovastatina ( $\square)$ y acumulación de ROS $(\diamond)$ a las $72 \mathrm{~h}$ de la FL. La letra "a” indica diferencia significativa con respecto al control en relación a la producción de lovastatina, mientras que el signo "\#” indica diferencias significativas en la acumulación de ROS, según la prueba de comparaciones múltiples de Dunnet $(\mathrm{p}<0.05)$. En la parte superior, se muestran los datos de biomasa ( $\square)$ y el comportamiento del $\mathrm{pH}(\odot)$ donde no hubo diferencias significativas con respecto al control de acuerdo a la prueba de Dunnet $(\mathrm{p}<0.05)$. 74

Tabla 4 Reducción de lovastatina (\%), y ROS por el empleo de diferentes concentraciones de NAC en FL. La letra “a” y el signo “\#” indican diferencias significativas con respecto a sus controles, de acuerdo a la prueba de Dunnet $(\mathrm{p}<0.05)$. 74

Fig. 24 Efecto de la adición de 10mM de NAC sobre la producción de lovastatina (ם) al final de las $72 \mathrm{~h}$ en FL. La adición se realizó independientemente a diferentes tiempos durante la trofofase $(0,15$ y $20 \mathrm{~h})$ e idiofase $(36$ y $48 \mathrm{~h})$. El CONTROL, es al que no se le adicionó NAC. En la parte superior, se muestra la producción final de biomasa ( $\square$ ) y el $\mathrm{pH}(\diamond)$ al final de las $72 \mathrm{~h}$ después de cada tratamiento. El símbolo “*” muestra diferencias significativas respecto al control de acuerdo a la prueba de Dunnet $(\mathrm{p}<0.05)$.

Tabla 5 Producción Específica de lovastatina en FL y \% de reducción debido a la adición del antioxidante NAC (10mM) a diferentes tiempos . La letra "a" indica diferencias significativas de acuerdo a la prueba de comparaciones múltiples Dunnet $(\mathrm{p}<0.05) \ldots \ldots .76$ 
Fig. 25 Relación producción de lovastatina ( $\square)$ vs acumulación de ROS $(\diamond)$ a las $72 \mathrm{~h}$ de la FS. La letra "a" indica diferencia significativa con respecto al control en relación a la producción de lovastatina, y el signo “\#”en la acumulación de ROS, según la prueba de comparaciones múltiples Dunnet $(\mathrm{p}<0.05)$. En la parte superior, se muestran los datos de biomasa ( $\square$ ) y el comportamiento del $\mathrm{pH}(0)$ donde no hubo diferencias significativas con respecto al control de acuerdo a la prueba de Dunnet $(\mathrm{p}<0.05) \ldots \ldots \ldots \ldots \ldots \ldots \ldots \ldots \ldots . . . . . . . . . . . . . . . .77$

Tabla 6 Reducción (\%) en la producción de lovastatina y ROS al emplear diferentes concentraciones de NAC. La letra "a" indica diferencias significativas según la prueba de comparaciones múltiples de Dunnet. 78

Fig. 26 Northern-blot de los genes $l o v E$ y $l o v F$ en FS. La intensidad de las bandas (señales) fueron cuantificadas por densitometría empleando el software ImageJ (versión 1.43u) y los resultados se normalizaron con la carga de rRNA (teñido con bromuro de etidio). A) Los resultados de la normalización de los tratamientos se presentan como fracción, considerando que la banda correspondiente a la muestra control (0) es 1 (es decir, el $100 \%$ ), se muestran los promedios de las densitometrías de 2 réplicas independientes. B) Se muestra el resultado de uno de los Northerns obtenidos de los genes lovE y lovF... 79

Fig. 27 Northern-blot de los genes $l o v E$ y lovF en FL. La intensidad de las bandas (señales) fueron cuantificadas por densitometría empleando el software ImageJ (versión 1.43u) y los resultados se normalizaron con la carga de rRNA (teñido con bromuro de etidio). Los resultados de la normalización de los tratamientos se presentan como fracción, considerando que la banda correspondiente a la muestra control (0) es 1 (es decir, el 100\%). A) Los resultados de la normalización de los tratamientos se presentan como fracción, considerando que la banda correspondiente a la muestra control (0) es 1 (es decir, el 100\%), se muestran los promedios de las densitometrías de dos réplicas independientes. B) Se muestra el resultado de uno de los Northerns obtenidos de los genes $l o v E$ y $l o v F$.

Fig. 28 Producción de lovastatina (en \%) en cultivo sólido en caja de Petri al día 10 al suplementar diferentes concentraciones de $\mathrm{H}_{2} \mathrm{O}_{2}$ y paraquat (PQT). Los símbolos “*” y “\#”, muestran diferencias significativas de muestras tratadas con $\mathrm{H}_{2} \mathrm{O}_{2}$ y paraquat respectivamente, comparado contra el control, esto de acuerdo a la prueba de

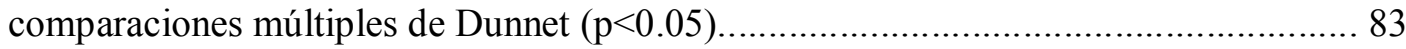


Fig. 29 Efecto de los oxidantes $\mathrm{H}_{2} \mathrm{O}_{2}$ y paraquat (PQT) sobre la morfología de Aspergillus terreus al día 10 en caja de Petri.... 83

Fig. 30 Efecto de diferentes concentraciones de $\mathrm{H}_{2} \mathrm{O}_{2}$ al día 3 de la FL, sobre la producción específica de lovastatina $(\square)$ y sobre la producción de biomasa $(\diamond)$. En ambos parámetros, no se observaron cambios significativos. 84

Fig. 31 Efecto de la adición de $\mathrm{H}_{2} \mathrm{O}_{2} 50 \mathrm{mM}$ a diferentes tiempos de la $\mathrm{FL}$ al día 3 sobre la producción específica de lovastatina $(\square)$ y sobre la producción de biomasa $(\diamond)$. En ambos parámetros, no se detectaron diferencias significativas al aplicar el Análisis de Varianza. 85

Fig. 32 Efecto de varias concentraciones de $\mathrm{H}_{2} \mathrm{O}_{2}$ sobre la biosíntesis de lovastatina y biomasa, al final del día 3 (72h) de FS. El análisis de ANOVA mostró que existen diferencias, y el análisis de Dunnet encontró diferencias significativas $(p<0.05)$ en la producción de lovastatina con 10 y $50 \mathrm{mM}$ (\#) y la biomasa (a)................................ 86

Tabla 7 Posición del gen lovE en el genoma de Aspergillus terreus obtenido del Broad Institute. 87

Fig. 33 Promotor (en gris) junto con la secuencia codificadora del gen $l o v E$, ubicado en el supercontig 16: 56546-59057 (+). 88

Fig. 34 Motivos conservados encontrados por el programa MEME en el promotor del gen lovE. 88

Fig. 35 Posibles sitios de unión de Factores Transcripcionales (que responden a diferentes tipos de estímulos. Nótese que en su mayoría, son Factores Transcripcionales que responden a EOX (Skn7, Nrf2, Msn2/4, AtfB, Ap-1, Aft2 y NF-kB) y algunos más que responden a estrés nutricional (CreA, Adr1, Rpn4). Algunos sitios de unión se encontraron sobre la cadena principal $(+$, sobre la línea) y algunos otros, se encontraron en la cadena antisentido (-, debajo de la cadena). 89

Tabla 8 Localización del gen lov $F$ dentro del genoma de $A$. terreus (Broad Institue)..... 89

Fig. 36 Promotor (en gris) junto con la secuencia codificadora del gen $l o v F$, ubicado en el supercontig 16: 63664-71705(+) 90

Fig. 37 Posibles sitios de unión a Factores Transcripcionales que responden a EOX en el promotor de lovF. Nótese que en su mayoría son sitios de unión a $\mathrm{Skn} 7$ (en levadura),

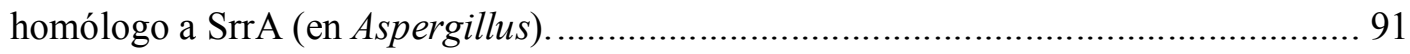


Fig. 38 Análisis de Northern de los genes $\operatorname{sr} A$, Atyap1, fadA, sod1, brlA, lovE y lovF, a diferentes tiempos de trofo- $(15,18,21$ y $23 \mathrm{~h})$ y de idiofase (24h en adelante) de la FS. Para cada uno de los genes se muestra su rRNA empleado como control de carga para cada gen en particular. La flecha en la parte superior indica que las $24 \mathrm{~h}$ es el inicio de la idiofase, observado por el inicio de expresión de $l o v E$ y por medio de una cinética de producción de lovastatina. 93

Fig. 39 Análisis de Northern de los genes srrA, Atyap1, fadA, sod1, lovE y lovF, a diferentes tiempos de la trofo-(de 15 a 23h) y de la idiofase (de $24 \mathrm{~h}$ en adelante) de la FL. Para cada uno de los genes se muestra el rRNA como control de carga empleado para cada gen en particular. La flecha en la parte superior indica que las $24 \mathrm{~h}$ es el inicio de la idiofase, observado por el inicio de expresión de $l o v E$ y por medio de una cinética de producción de lovastatina. 95

Fig. 40 Caracterización del plásmido pGpdPki-RNAi. Carril 1: plásmido sin digerir. Carril 2: plásmido digerido con $\mathrm{NcoI}$. 96

Fig. 41 A) Obtención del fragmento de 553 pb de Atyapl empleando un gradiente de temperaturas de hibridación; B) Caracterización de una de las clonas de E. coli DH5a transformadas con la construcción pJET-Atyap1RNAi seleccionadas, tras una digestión con la enzima de restricción NcoI

Fig. 42 Caracterización de las clonas que poseen la construcción pGdpPkiRNAi-Atyap1 tras la digestión con la enzima $N c o I$.

Fig. 43 Sensibilidad de las esporas de A. terreus a $\mathrm{H}_{2} \mathrm{O}_{2}$ : $\mathrm{P}$, cepa parental; $\mathrm{T} 1$ a $\mathrm{T} 8$, transformantes (con la construcción pGdpPkiRNAi-Atyap1) obtenidas de A. terreus... 98

Fig. 44 Cinética de esporulación de las cepas transformantes y la parental (P) de A. terreus. 99

Tabla 9 Diferencias fisiológicas y a nivel de expresión de genes encontradas entre FS y FL 100

Tabla 10 Posición y valor del p-value de cada uno de los motivos encontrados en el promotor del gen lovE por el programa MEME. Los motivos o sitios de unión señalados en color VERDE, muestra las secuencias consenso conservadas pertenecientes al motivo 1, en ROSA, se presentan las secuencias consenso para el motivo 2 y en AMARILLO las secuencias consenso para el motivo 3 (ubicadas en Fig. 45) 
Fig. 45 Distribución de los motivos o posibles sitios de unión de factores transcripcionales en el promotor del gen $l o v E$. En verde el motivo1, en rosa el motivo2, en amarillo el motivo 3, en azul rey, sitios encontrados por NSITE o por búsqueda dirigida, en verde agua sitio de unión compartido por motivo 3 y AtfB y en la secuencia 3-A (amarillo y subrayado) es el mismo sitio probable para el factor CreA.

Tabla 11 Posibles Factores Transcripcionales que pueden unirse a los motivos encontrados.

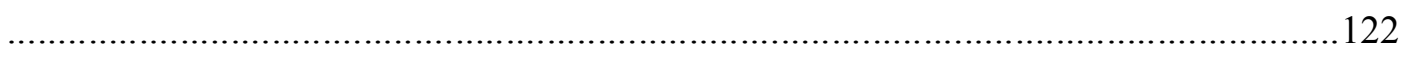

Fig. 46 Análisis in silico del promotor del gen lovF de Aspergillus terreus.........................123

Tabla 12 Factores Transcripcionales encontrados y sus probables sitios de unión en el promotor del gen lovF de Aspergillus terreus. .124 


\title{
ABREVIACIONES
}

\author{
AT Aflatoxinas \\ EOX Estrés Oxidante \\ FL Fermentación Líquida \\ FS Fermentación Sólida \\ MS Metabolito o Metabolitos Secundarios (según el contexto) \\ PEO Periodo de estrés oxidante \\ ROS Especies Reactivas de Oxígeno \\ GSH Glutatión en su forma reducida $\left(\mathrm{C}_{10} \mathrm{H}_{17} \mathrm{~N}_{3} \mathrm{O}_{6} \mathrm{~S}\right)$ \\ GSSG Glutatión en su forma oxidada $\left(\mathrm{C}_{20} \mathrm{H}_{32} \mathrm{~N}_{6} \mathrm{O}_{12} \mathrm{~S}_{2}\right)$
}




\section{RESUMEN}

La presente tesis es el primer trabajo que establece la existencia de una relación entre la biosíntesis de lovastatina y el estrés oxidante (EOX) a través de la generación de Especies

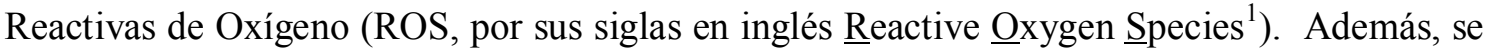
hizo un esfuerzo en tratar de establecer el posible mecanismo por el cual las ROS pueden regular la biosíntesis de este metabolito secundario.

La lovastatina, metabolito secundario producido por el hongo Aspergillus terreus, es de gran importancia comercial y farmacéutica por sus propiedades anticolesterolémicas. Comúnmente se produce en Fermentación Líquida (FL), pero la Fermentación Sólida (FS) se ha convertido en un proceso alternativo para producción industrial

Se sabe que la biosíntesis de lovastatina es regulada por represión catabólica, sin embargo, fue en FS donde se hicieron evidentes la existencia de otros mecanismos de regulación, ya que mostraba una mayor producción de lovastatina, y que ha dado lugar a lo que se ha denominado como la "Fisiología Especial del Medio Sólido".

Actualmente se conoce que las ROS juegan un papel importante en procesos celulares y de diferenciación en hongos. Bajo este supuesto, y asumiendo que el cambio de trofofase a idiofase es un proceso de diferenciación (metabólica), estudios anteriores de maestría (Miranda et al., 2008) mostraron que durante la trofofase o fase de crecimiento rápida, el gen sod1 (enzima antioxidante) se expresó fuertemente durante la trofofase, lo que denominamos en su momento como Periodo de Estrés Oxidante o PEO, justo antes de iniciarse la idiofase (fase de producción) de lovastatina. Estos hallazgos hicieron proponer la hipótesis de la existencia de un PEO donde existían elevadas cantidades de ROS justo antes de iniciarse la idiofase.

Bajo esta premisa, se decidió caracterizar el estado redox de ambas fases (trofo- e idiofase) tanto de FS y FL, a través de cinéticas de cuantificación de ROS y del estado redox (medido por el cociente glutatión reducido/glutatión oxidado: GSH/GSSG).

\footnotetext{
${ }^{1}$ En el área del Estrés Oxidante, es muy común emplear el término ROS para llamar a las para llamar a las especies reactivas de oxígeno tanto en inglés como en español, por lo que en esta tesis se empleará este término.
} 
Los resultados mostraron una elevación en la concentración de ROS (justo al iniciarse la biosíntesis de lovastatina) y que se mantuvo durante toda la idiofase. Esto sugirió una relación entre dicha acumulación de ROS y la biosíntesis de lovastatina, en ambos sistemas de producción.

Además, se encontró que el nivel de ROS fue 10 veces mayor en FL con respecto a los niveles de ROS en FS. Otra de las diferencias encontradas entre FS y FL, fue que los niveles de ROS en idiofase, fueron constantes en el primer sistema, a diferencia de lo encontrado en FL donde los niveles de ROS mostraron muchas fluctuaciones durante el desarrollo del cultivo.

Esto sugiere que niveles bajos de ROS y controlados, como lo encontrado en FS, son adecuados para lograr una buena función fisiológica, en particular, una buena producción de lovastatina.

En ambos sistemas de cultivo, el cociente GSH/GSSG indicó que fue en trofofase donde se encontró un estado más reductor que en idiofase. Además, el cociente GSH/GSSG fue 4 veces mayor en FS que en FL durante la trofofase, lo cual es coherente con el hecho de que se hayan encontrado menores cantidades de ROS en FS.

Estos hallazgos contradijeron la existencia de un PEO durante la trofofase, ya que los niveles de ROS fueron relativamente bajos en esta etapa, pero se mostró una coincidencia entre el inicio de la acumulación de ROS y la biosíntesis de lovastatina. Estos resultados sugieren que la alta expresión del gen sodl regula a la baja la producción de ROS, manteniendo así un estado redox adecuado (reductor) para llevar a cabo las funciones celulares del crecimiento. También sugiere que la alta concentración de ROS en idiofase, es importante para señalizar el metabolismo secundario.

Para tratar de establecer la existencia del vínculo entre la producción de ROS y lovastatina, se decidió emplear antioxidantes y oxidantes exógenos y observar su influencia sobre la biosíntesis del metabolito. El empleo del antioxidante NAC (N-acetilcisteína), redujo significativamente la biosíntesis de lovastatina en ambos sistemas de cultivo. En FL, concentraciones iguales o mayores a $10 \mathrm{mM}$ de NAC lograron decrementos significativos de hasta del 62\% $(\mathrm{p}<0.05)$ en el nivel de producción de lovastatina. En este cultivo, se observaron decrementos significativos con el nivel de acumulación de ROS en la idiofase de hasta el 71\% $(\mathrm{p}<0.05)$. Un análisis de regresión lineal simple entre ambas variables, mostró un índice de correlación $(\alpha \leq 0.05)$, para establecer la existencia de una relación entre la 
producción de ROS y lovastatina. Los resultados obtenidos sugieren la existencia de una estrecha relación entre ambas variables $\left(\mathrm{R}^{2}=0.93, \mathrm{p}<0.05\right)$.

En FS, concentraciones de NAC hasta de $100 \mathrm{mM}$, redujeron tanto la producción de lovastatina como de ROS, hasta un 79\% y 53\% respectivamente $(\mathrm{p}<0.05)$, obteniéndose un índice de correlación muy estrecho entre ambas variables $\left(R^{2}=0.99 ; p<0.05\right)$.

Un análisis de Northern de los genes $\operatorname{lov} E$ y $\operatorname{lov} F$, reveló que el tratamiento con NAC influyó de negativamente sobre la expresión de ambos genes. En FS se observó un decremento promedio en la expresión del gen $l o v E$, del 35 y $50 \%$ con 50 y $100 \mathrm{mM}$ de NAC respectivamente. Mientras que con las mismas concentraciones de NAC, se observó un decremento en la expresión de $l o v F$ del 25 y $35 \%$ respectivamente.

En forma coincidente, el empleo de 10 y $50 \mathrm{mM}$ de NAC en FL, ocasionó decrementos promedio en la expresión de $l o v E$ del 35 y $50 \%$, y en el caso de $l o v F$ fueron del 15 y $35 \%$ respectivamente.

Estos datos demuestran que las ROS no sólo son necesarios para la producción normal de lovastatina, sino que contribuyen a la regulación transcripcional de los genes de la ruta biosintética de lovastatina, incluyendo al gen regulador $l o v E$.

Por otra parte, se observó la respuesta de la biosíntesis de lovastatina con el empleo de oxidantes como $\mathrm{H}_{2} \mathrm{O}_{2}$ y paraquat en cultivo sólido en Caja de Petri (CAJA DE PETRI), FS y FL; y fue en CAJA DE PETRI donde se lograron aumentos significativos de producción. El empleo de $\mathrm{H}_{2} \mathrm{O}_{2} 150 \mathrm{mM}$ aumentó la producción de lovastatina $233.3 \%(\mathrm{p}<0.05)$ respecto al control, mientras que con paraquat, el empleo de 1, 10 y $25 \mathrm{mM}$, aumentaron la biosíntesis del metabolito, 64, 149 y 106\% $(\mathrm{p}<0.05)$ respectivamente. Por otra parte, en FL el empleo de $\mathrm{H}_{2} \mathrm{O}_{2}$ no tuvo ningún efecto sobre el crecimiento y la biosíntesis Finalmente en FS, el empleo de $\mathrm{H}_{2} \mathrm{O}_{2}$ redujo tanto la biosíntesis de biomasa como de lovastatina con el empleo de 10 y 50 $\mathrm{mM}$ del oxidante. Lo anterior sugiere que los niveles de ROS deben ser finamente regulados, además, las ROS generadas en ciertos tiempos y por ciertos mecanismos (desconocidos) son las que podrían influir en la biosíntesis de este metabolito.

Para tratar de establecer el mecanismo por el cual las ROS regulan la biosíntesis de lovastatina, se analizaron los promotores de los genes $l o v E$ y lovF (1000 pb corriente arriba del codón de inicio de traducción), y se encontraron múltiples sitios de unión (probables) a Factores Transcripcionales que se relacionan con distintas funciones celulares, pero en su mayoría, con Factores Transcripcionales que responden a EOX tanto en hongos como en 
mamíferos. Así, se encontraron sitios de unión a AP-1 (en hongos Yap1), Skn7 (o SrrA), Msn2/Msn4, NF-к-B, NRF2, etc. Esto indica que la biosíntesis de lovastatina puede ser regulada a través de factores transcripcionales que responden a EOX.

El análisis de Northern realizado en micelio proveniente de la fermentación de lovastatina (FS y FL) sugirió que AtYap $1^{2}$ puede a su vez regular al gen sod1, ya que se observaron patrones de expresión similares. Se ha reportado que Sod1p es regulado a través de Yap1p en levadura, y un análisis in silico, realizado en esta tesis, para el gen sodl de A. terreus confirmó la existencia de sitios putativos de unión para AP-1 (ortólogo de Yap1p). A su vez, el promotor del gen $\operatorname{lov} E$ presentó dichos sitios de unión, sugiriendo que una posibilidad de mecanismo de regulación podría estar relacionado con Yaplp.

Considerando la presencia de sitios putativos para Yaplp en el promotor de los genes de lovastatina, se realizaron una serie de experimentos para tratar de dilucidar el mecanismo por el cual las ROS modulan la biosíntesis de lovastatina, por medio del silenciamiento del gen que codifica para este Factor Transcripcional, empleando el vector pGdpPki-RNAi. Las mutantes con Atyapl silenciado, mostraron una marcada sensibilidad al $\mathrm{H}_{2} \mathrm{O}_{2}$, además presentaron una producción precoz y elevada de esporas respecto a la parental. Resultados preliminares mostraron también biosíntesis precoz y elevada de lovastatina, relacionando a este gen con el metabolismo secundario. Se ha reportado que Yap1p puede modular de manera positiva y negativamente diferentes genes de respuesta a EOX, por lo que se propone que AtYap1 podría regular positivamente a $\operatorname{sod} 1$, pero negativamente a los genes de la vía, particularmente $\operatorname{lovE}$. Estos resultados no son concluyentes, pero abren una brecha para indagar si es por este mecanismo por el cual la biosíntesis de lovastatina puede ser regulada.

En otro análisis, y debido a la existencia de varios sitios probables de unión a Skn7, se analizó por Northern-blot el perfil de expresión del gen $\operatorname{srr} A$ (homólogo a $s k n 7$ ) durante una cinética de producción de lovastatina. En FS, este gen se expresó sólo durante la idiofase, mientras que en FL, se expresó durante toda la trofo- e intermitentemente durante la idiofase de lovastatina.

Este patrón de expresión, aunado al hallazgo de los múltiples sitios de unión de este Factor Transcripcional, encontrados en los promotores de la vía, sugiere que también srrA puede

\footnotetext{
${ }^{2}$ Proviene de Aspergillus terreus.
} 
jugar un papel importante en el control de la producción de lovastatina, y quizás explicar particularidades de la biosíntesis en FS. 


\section{ABSTRACT}

This work represents the first attempt to establish a relationship between lovastatin biosynthesis and oxidative stress (EOX), through generation of Reactive Oxygen Species (ROS). In addition, an effort was made to establish the possible mechanism by which ROS can regulate the biosynthesis of this secondary metabolite produced by the fungus Aspergillus terreus.

Lovastatin has great commercial and pharmaceutical importance due to its anticholesterolamic properties. Commonly, lovastatin is produced by Submerged Fermentation (SmF), but Solid-State Fermentation (SSF) has become in an alternative process for industrial production.

It is known that lovastatin biosynthesis is regulated by catabolic repression; however, studies in SSF have made apparent that there are other mechanisms of regulation, since higher lovastatin production is obtained by mycelium growing in SSF, which conducted to the name "Physiology of Solid Medium".

It is currently known that ROS plays an important role in cellular processes and also in fungal differentiation. We considered that the change from trophophase to idiophase is a "metabolic" differentiation. Studies by Miranda et al., (2008) showed that during the trophophase (fast growth phase) sod 1 gen (antioxidant enzyme) was strongly expressed, in what we called initially an Oxidative Stress Period (PEO), that occurs just before the start of lovastatin idiophase (production phase). These results conducted to hypothesize the existences of PEO where high quantities of ROS accumulate just before the onset of idiophase.

Under this assumption we decided to characterize the redox state in both phases (tropho- and idiophase), and in both culture systems: SSF and SmF, through the measurement of ROS and redox balance (measured by the ratio of GSH/GSSG) kinetics during lovastatin fermentations. However, results showed an important build up of ROS (at the start of lovastatin biosynthesis) that was maintained throughout idiophase. This suggested a relationship between ROS accumulation and biosynthesis of lovastatin on both production systems.

Furthermore, we found that the level of ROS was 10 times higher in $\mathrm{SmF}$ in relation to the levels of ROS in SSF. Another difference found, between SSF and SmF, was that in idiophase 
ROS levels were constant in the first system, unlike what was found in SmF where ROS levels showed important fluctuations during culture development.

These results suggest that the low and controlled ROS levels, as found in SSF are adequate to achieve good and clear idiophase, particularly good lovastatin production.

In both culture systems, the GSH/GSSG ratio indicated that mycelium in trophophase had a more reducing intracellular environment than in idiophase. Interestingly, the GSH/GSSG ratio was four times greater in SSF compared with $\mathrm{SmF}$, which is consistent with smaller quantities of ROS found in SSF.

Moreover, the GSH/GSSG ratio indicated that in trophophase there was a more reducing environment than in idiophase. Also, that the GSH/GSSG ratio was four times greater in SSF than $\mathrm{SmF}$ during the idiophase, which is coincident whit the fact that was found ROS low quantities than SSF.

These findings contradict the existence of a PEO during trophophase, because ROS levels were relatively low during this stage, but there is indeed a coincidence between a start of ROS accumulation and the lovastatin biosynthesis. These results suggest that the high expression of sod 1 gen helps the cell contain ROS, maintaining an adequate redox state (reducing) to carry out the cellular functions of development. Results also suggest that the high ROS concentrations in idiophase is a consequence of Ajtyap1 and sod1 down regulation, and that ROS are important for signaling lovastatin biosynthetic genes.

We used exogenous antioxidants and oxidants to establish a relationship between ROS and lovastatin production, and to observe their influence on the metabolite biosynthesis. The use of NAC antioxidant ( $\mathrm{N}$-acetylcysteine) significantly reduced lovastatin biosynthesis in both culture systems. In SmF, a NAC concentration of $\geq 10 \mathrm{mM}$ reduced near of $62 \%(\mathrm{p}<0.05)$ the lovastatin production level. In this culture we observed a significantly reduction on ROS accumulation levels in idiophase near of $71 \%(\mathrm{p}<0.05)$. We conducted a linear regression analysis $(\alpha \leq 0.05)$ to establish a relation between ROS and lovastatin production. The results obtained suggest the existence a good relation between ROS and lovastatin production $\left(\mathrm{R}^{2}=0.93, \mathrm{p}<0.05\right)$.

In SSF, NAC concentrations up to $100 \mathrm{mM}$, reduced both, lovastatin and ROS production, up to 79 and $53 \%$ respectively $(\mathrm{p}<0.05)$, to yield an correlation index very close between variables $\left(\mathrm{R}^{2}=0.99, \mathrm{p}<0.05\right)$. 
Northern analysis of genes $l o v E$ and lov $F$ revealed that treatment with NAC (and hence lower ROS levels) had a negative influence on both genes expression. With the use of 50 and 100 $\mathrm{mM}$ of NAC concentration, in SSF we observed a decrease in expression of gen $l o v E$ in rates of 35 and $50 \%$ respectively, while with the same NAC concentrations we observed a decrease in expression of gen $l o v F$ in rates of 25 and $35 \%$ respectively.

Concurrently, the use of 10 and $50 \mathrm{mM}$ NAC in $\mathrm{SmF}$, caused decreases in $l o v E$ expression in rates of 35 and $50 \%$, and in the case of $l o v F$ were 15 and $35 \%$ respectively.

These data show that ROS are not only necessary for the normal production of lovastatin, but contribute to transcriptional regulation of the biosynthetic genes of lovastatin, including $\operatorname{lov} E$ regulatory gene, although the mechanism is still unknown.

On the other hand, we observed the response of lovastatin biosynthesis using the oxidants $\mathrm{H}_{2} \mathrm{O}_{2}$ and paraquat in solid culture in petri dish (CP), SSF and SmF. In CP, results showed significant increases. The use of $\mathrm{H}_{2} \mathrm{O}_{2} 150 \mathrm{mM}$, showed an increase of $233.3 \%$ relative to control $(\mathrm{p}<0.05)$, whereas with paraquat $(1,10$ and $25 \mathrm{mM}$ concentrations), increases were achieved $\left(64,149\right.$ and $106 \%(\mathrm{p}<0.05)$ respectively). However, in $\mathrm{SmF}$ the use of $\mathrm{H}_{2} \mathrm{O}_{2}$ had no effect on the lovastatin production. Moreover, in SSF, the use of 10 and $50 \mathrm{mM} \mathrm{H}_{2} \mathrm{O}_{2}$ decreased biomass and lovastatin biosynthesis. This suggests that ROS levels must be tightly regulated.

In order to establish a possible mechanism by which ROS exert their action on lovastatin biosynthesis, we analyzed the promoters of $\operatorname{lov} F$ and $\operatorname{lov} E$ genes (1000 bp upstream of the translation start codon) and found multisite binding sites (putative) for transcriptional factors (TFs) that are related to various cellular functions, but mostly oxidative-stress-related TFs that match both yeast and mammals. Thus, binding sites for AP-1 (in fungi Yap1) Skn7 (or SrrA), Msn2/Msn4, NF-א-B, NRF2, etc were found. This suggested that the lovastatin biosynthesis can be regulated by transcription factors that respond to EOX

Northern analysis suggested that Atyap $^{l}$ can regulate sod 1 gene, as observed similar expression patterns. It has been reported that Sod1p is regulated through Yap1p in yeast, and in silico analysis performed in sod 1 promoter region of $A$. terreus confirmed the existence of putative binding sites for AP-1 (orthologous of Yap1p). In turn, the promoter region of lovE gene, presented these binding sites, suggesting that ROS could regulate secondary metabolism through Atyap1p. 
An effort was made to try and elucidate the mechanism by which ROS modulate the lovastatin biosynthesis, and Atyap1, was silenced, using pGdpPki-RNAi vector. The transformants showed a marked sensitivity to $\mathrm{H}_{2} \mathrm{O}_{2}$, also showed an early and high sporulation. Preliminary results also showed a precocious and elevated level of lovastatin. It has been reported that Yap1 can Yap1p positively and negatively modulate different EOX response genes. Therefore, it is proposed that AtYap1 positively regulates Sod1, but negatively lovastatin pathway genes. i.e. $l o v E$. These results are not conclusive, but a wedge to discuss whether this mechanism by which lovastatin biosynthesis can be regulated.

In another analysis we fount the existence of several binding sites for transcription factor SrrA (Skn7) in the promoter regions of lovE and lovF. Northern-blot analysis was performed and the expression profile of $\operatorname{sr} A$ gene (homologous to $\mathrm{Skn} 7$ ), during lovastatin fermentation, was obtained, (Mendoza et al., in review). In SSF in this gene was expressed during idiophase while in SmF, apparently expressed throughout tropho- and idiophase of lovastatin, but at points of time lapses apparently expression.

This expression pattern, together with the discovery of the multiple binding sites of this transcriptional factor, found in the promoters of the pathway suggests that SrrA also can play an important role in controlling the production of lovastatin, perhaps explaining the particularities biosynthesis in SSF. 


\section{INTRODUCCIÓN}

Los metabolitos secundarios (MS) microbianos son usualmente productos de alto valor comercial, con un enorme rango de actividades biológicas. En hongos filamentosos, los MS usualmente no son producidos durante la fase rápida del crecimiento, sino que son sintetizados durante una etapa subsecuente (idiofase) (Barrios-González et al. 2005).

La lovastatina, es un metabolito secundario producido por $A$. terreus, y por sus propiedades anticolesterolémicas, es un producto de alto valor farmacéutico y comercial. El hecho de que la principal causa de muerte a nivel mundial, sean las enfermedades relacionadas con eventos cardiovasculares, que a su vez están relacionadas con altos niveles de colesterol en plasma, explica el éxito comercial de la lovastatina, simvastatina y otras estatinas en el campo comercial (Barrios-González \& R. Miranda 2010).

El clúster biosintético de la lovastatina, consta de 18 probables ORFs, entre los cuales el gen lovE codifica la proteína reguladora del clúster. Este gen codifica para un factor transcripcional del tipo Dedos de Zinc++ binuclear. Las mutantes con este gen delecionado no produjeron lovastatina ni sus intermediarios, y por tanto se asumió que el gen $l o v E$ regula la producción de lovastatina a nivel transcripcional, i.e. un factor de transcripción específico de la ruta (Kennedy 1999). Además, el producto del gen creA actúa negativamente mediante represión por catabolito en Aspergillus. La presencia de probables sitios de unión a CreAp (SYGGRG) en el promotor de lovE sugiere que CreAp puede mediar la represión de la biosíntesis de lovastatina por glucosa (Hajjaj et al. 2001). Además, se ha encontrado que LaeAp (regulador global del metabolismo secundario) es requerido para la expresión del clúster biosintético de lovastatina en A. terreus (Bok \& Keller 2004).

Por otra parte, la biosíntesis de lovastatina en FS ha hecho evidente la existencia de otros factores o estímulos, relacionados particularmente con este sistema de cultivo, y que influyen sobre la expresión de los genes biosintéticos de lovastatina (Barrios-González 2012).

La FS es un método de cultivo alternativo que ha ganado la atención de los investigadores en los últimos 20 años. Existen varias ventajas en el empleo de varios procesos de FS sobre la FL convencional. Muchas de estas ventajas están relacionadas a la fisiología especial del hongo en FS, i,e., un comportamiento que se desvía del mostrado por el hongo en FL, algunas veces, a esto se le denomina "fisiología del medio sólido". Las razones para esta fisiología diferente en FS no está completamente entendida, pero los avances recientes en este campo, muestran un panorama interesante. 
Se ha reportado que la producción de lovastatina mediante FS, ha llegado a ser 30 veces mayor con respecto a la FL (Baños et al. 2009). Con el objeto de investigar sobre los eventos responsables para que se dieran estas diferencias en el nivel de producción del metabolito, se desarrollaron estudios a nivel molecular. Los resultados mostraron que la alta producción de lovastatina en FS está relacionada con una mayor intensidad en la transcripción del gen regulador lovE y los genes biosintéticos (Barrios-González et al. 2008).

Estos y otros estudios indicaron que existen ciertos estímulos ambientales que hacen notar al hongo que se encuentra en medio sólido. Estos estímulos pueden ser detectados y entonces transducidos, disparando así, un número de eventos a nivel molecular. Además, algunos estímulos ambientales del medio sólido (señales) se han identificado (Barrios-González 2012).

Un estímulo ambiental que puede ser detectado por el micelio en FS, es el contacto directo con el aire, y es posible que este efecto de estimulación sobre el metabolismo secundario, pueda ser a través del EOX o por la formación de ROS.

Las ROS son generadas como subproductos del metabolismo aeróbico. Un exceso de ROS conduce al EOX y como consecuencia, puede dañar directa o indirectamente moléculas como el ADN, proteínas y lípidos (Folch-Mallol et al. 2004), sin embargo, existe evidencia que esta acumulación de ROS también provee señales vitales para funciones de diversos procesos celulares (Rhee 2006; Veal et al. 2007).

Se conoce que las ROS producidas en ciertos puntos de tiempo durante el ciclo celular y a concentraciones fisiológicas adecuadas, pueden participar de manera significativa en la homeostasis del organismo y sus funciones celulares (Reverberi et al. 2008). Como segundos mensajeros, las ROS juegan un papel importante en el proceso de desarrollo de las plantas, así como en los mecanismos de defensa contra patógenos (Jones 1994). Efectos similares han sido mostrados en mamíferos, donde niveles apropiados de ROS estimulan las reacciones antioxidantes, la modulación del sistema inmune y la regulación de la proliferación celular (Bokoch \& Knaus 2003).

Estudios recientes en hongos, han evaluado la participación de las ROS en los procesos de diferenciación (Aguirre et al. 2005; Aguirre et al. 2006). Por ejemplo, las ROS generadas por la NADPH oxidasa, las cuales en gran parte son controladas por la superóxido dismutasa (SOD) y la catalasa (CAT), desempeñan una actividad importante en diferentes aspectos del desarrollo fúngico, tales como el crecimiento y la diferenciación (Lara-Ortíz et al. 2003). Es 
importante notar que el gen sodl codifica para la superóxido dismutasa (SOD1) citoplásmica, la cual es inducida por EOX en hongos (Pócsi et al. 2005). En Neurospora crassa, el inicio de la transición de conidia a germinación es afectado por el oxígeno singulete, generando un desbalance redox (Lledías et al. 1998). También en A. nidulans, niveles elevados de ROS se han detectado durante la diferenciación celular (Lledías et al. 1998; Aguirre et al. 2005).

Estudios recientes apoyan una interacción funcional entre el EOX y el metabolismo secundario (Roze et al. 2011). Se ha propuesto que como una respuesta compensatoria a una situación de EOX, es la formación de MS con función antioxidante (Lee et al., 2005), por ejemplo, Narasaiah et al., (2006) sugirieron que la biosíntesis de aflatoxinas (AT) producidas por A. parasiticus, puede aparecer en respuesta a la acumulación de ROS, para restablecer el estado redox del hongo.

Actualmente, el mecanismo molecular que conecta al MS, con el EOX y el desarrollo no está claro (Roze et al. 2011). Cabe aclarar, que el modelo de estudio que hasta ahora ha sido empleado para estudiar esta relación, es la biosíntesis de AT por diferentes especies de Aspergillus (Narasaiah et al. 2006; Jayashree \& Subramanyam 2000; Reverberi et al. 2008; Roze et al. 2011), no encontrándose hasta el momento, ningún estudio que relacione al EOX con otro tipo de MS.

Hasta la fecha, las ROS no han sido asociadas con la biosíntesis de lovastatina (un MS diferente a las AT), por lo que el presente trabajó se enfocó en encontrar una relación entre el EOX y la biosíntesis de éste metabolito. Además, se ha realizado un esfuerzo en encontrar las diferencias en la acumulación y control de ROS en FS y FL, lo cual podría ayudar a explicar la alta producción de la lovastatina y quizás otras características de la fisiología del medio sólido. 


\section{ANTECEDENTES.}

\subsection{Metabolismo Secundario.}

\subsubsection{Aspectos Generales.}

Los metabolitos secundarios (MS) microbianos, son compuestos producidos principalmente por hongos y actinomicetos, usualmente en la fase tardía del crecimiento (idiofase), son compuestos con una variedad en estructuras químicas complejas, producidos por cepas de ciertas especies microbianas, y por algunas plantas (Barrios-González et al. 2005).

Aunque los antibióticos son los MS mejor estudiados, existen otros con un enorme rango de actividades biológicas, y que por lo tanto, tienen importancia potencial para la industria (Barrios-González et al. 2003).

Estos compuestos, no juegan un rol fisiológico durante la fase exponencial del crecimiento. Además, se han descrito como opuestos a los productos del metabolismo primario (como aminoácidos, nucleótidos, lípidos y carbohidratos), que son esenciales para el crecimiento (Barrios-González et al. 2003).

Una característica de los MS, es que éstas moléculas no se producen durante la fase rápida del crecimiento (trofofase), sino que son sintetizados en una etapa de producción subsecuente (idiofase) (Barrios-González et al. 2003).

La producción de estos compuestos inicia cuando el crecimiento es limitado por el agotamiento de un nutriente clave: carbono, nitrógeno o fosfato. Por ejemplo, la biosíntesis de penicilina por Penicillium chrysogenum inicia cuando la glucosa se agota del medio de cultivo y el hongo inicia el consumo de lactosa, que es un azúcar de más lenta asimilación (Barrios-González \& Tomasini 1988) .

\subsubsection{Familias biosintéticas.}

Los MS microbianos, muestran una enorme diversidad de estructuras químicas. Sin embargo, sus rutas biosintéticas están unidas a una red más uniforme del metabolismo primario. Se ha mostrado que éstas moléculas, son formadas por rutas alternas al metabolismo primario y que parten de un número pequeño de puntos de ramificación, los cuales definen una amplia categorías de familias biosintéticas (Barrios-González et al. 2003; Keller et al. 2005): 
1. Metabolitos derivados del ácido shikímico (aminoácidos aromáticos): ejemplos son los alcaloides ergot y los antibióticos candicidina y cloramfenicol.

2. Metabolitos derivados de aminoácidos: esta familia incluye los antibióticos $\beta$-lactámicos, como penicilina, cefalosporinas y cefamicinas, así como antibióticos ciclicopéptidicos tales como la gramicidina o la ciclosporina como agente inmunosupresivo.

3. Metabolitos derivados del Acetil-CoA (y compuestos relacionados, incluyendo los intermedios del ciclo de Krebs): Esta familia puede subdividirse en policétidos y terpenos. Ejemplos de este grupo, incluye al antibiótico eritromicina, el compuesto insecticida/antiparasitario avermectina, y el agente antitumoral doxorubicina. Un ejemplo del segundo grupo es el agente antitumoral no toxigénico taxol.

4. Metabolitos derivados de azúcares: ejemplos de este grupo, son la estreptomicina y la kanamicina .

\subsection{MS derivados del Acetil-CoA: LAS ESTATINAS.}

De acuerdo con la Organización Mundial de la Salud, las enfermedades cardiovasculares son la principal causa de muerte. Se calcula que en 2008 murieron por esta causa 17,3 millones de personas, lo cual representa un $30 \%$ de todas las muertes registradas en el mundo ${ }^{3}$. La hipercolesterolemia es la acumulación de colesterol en el plasma sanguíneo, que provoca la aterosclerosis (obstrucción de las arterias), propiciando el desarrollo de enfermedades coronarias y ataques cardíacos (Lara et al. 2004)

Del colesterol total, sólo una tercera parte es derivada de los alimentos que consumimos, mientras que los otros dos tercios son sintetizados por el hígado y en menor cantidad por otros órganos (Alberts et al. 1980). Por esta razón, el control del colesterol mediante la inhibición de su biosíntesis, es una estrategia importante para reducir los niveles de colesterol en sangre (Rollini 2002).

3 Global status report on noncommunicable disaeses 2010. Geneva, World Health Organization, 2011. 
Las estatinas son un grupo de fármacos que inhiben selectivamente la HMG-CoA reductasa (3-hidroximetil-3-metilglutaril-coenzima A), que es la enzima reguladora y limitante de la velocidad en la biosíntesis del colesterol (Fig. 1) (Kapur \& Musunuru 2008; Rollini 2002).

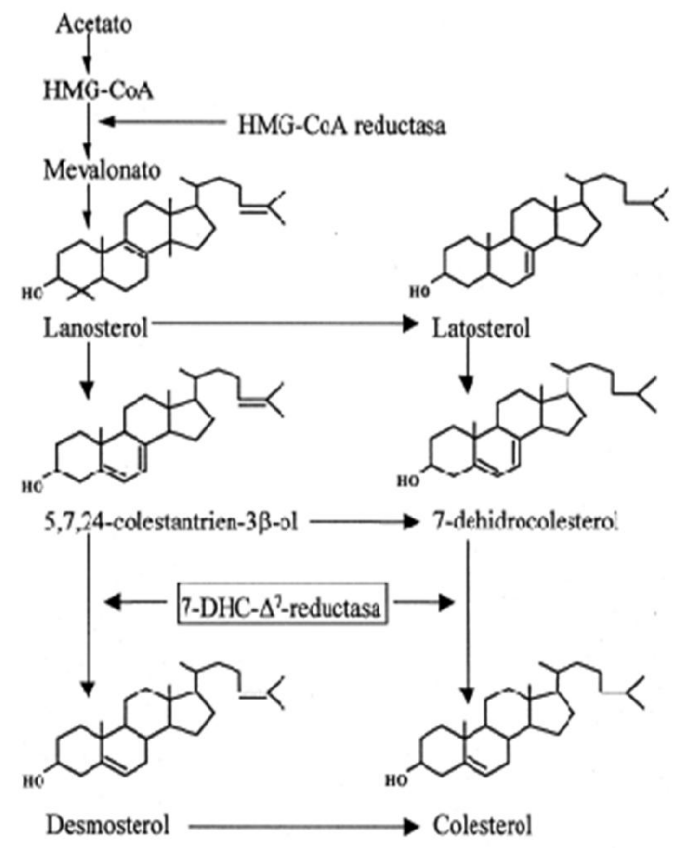

Fig. 1Ruta biosintética del colesterol. La HMG-CoA reductasa es la enzima limitante de la biosíntesis de esta molécula.

Dentro de este grupo podemos encontrar estatinas naturales (lovastatina y pravastatina), semisintéticas (simvastatina) y sintéticas (atorvastatina y fluvastatina) (Fig. 2) (Barrios-González \& R. Miranda 2010). Estos compuestos disminuyen los niveles de colesterol; particularmente las lipoproteínas de baja densidad o colesterol de baja densidad (conocido popularmente como el colesterol malo); con un ligero aumento de las lipoproteínas de alta densidad (colesterol bueno), por consiguiente, previenen la acumulación de la placa de colesterol dentro de las arterias (Alberts et al. 1980; Manzoni et al. 1999). 


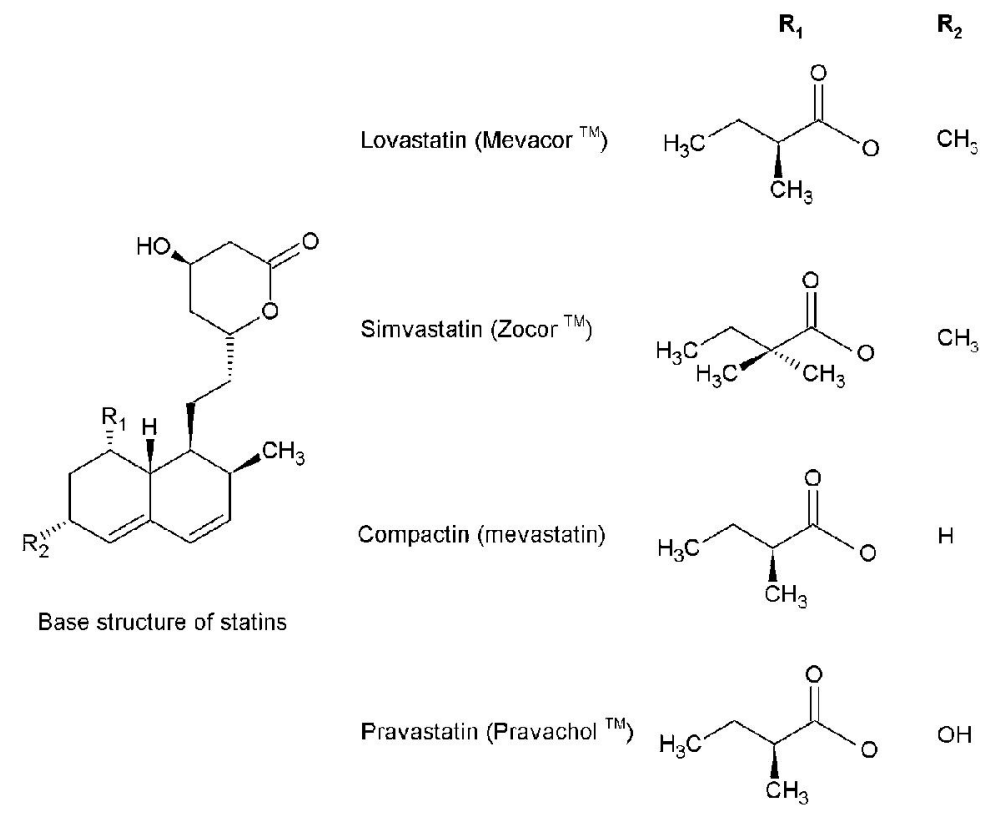

Fig. 2 Estructuras químicas de las estatinas naturales y sus derivados: simvastatina y pravastatina (Barrios-González \& R. Miranda 2010).

Además, las estatinas han surgido como medicamentos preventivos de vanguardia, por que reducen la tasa de mortalidad en pacientes con colesterol elevado (Maiques Galán et al. 2004). También se han observado efectos pleiotrópicos (o asociados) con el empleo de las estatinas (Wang et al. 2008). Es así que potencialmente, estás moléculas podrían emplearse como terapia en enfermedades crónicas como:

Cáncer: Se encontraron decrementos significativos en la incidencia de nuevos melanomas cuando se evaluó la eficacia de lovastatina en la prevención de enfermedades cardiovasculares (Dulak \& Józkowicz 2005), además se observó una reducción en el riesgo de diferentes tipos de cáncer como el colorectal, de mama, próstata, hígado y páncreas con el empleo de la terapia de estatinas (Bonovas et al. 2006; Glynn et al. 2008).

Síndrome Metabólico y Diabetes mellitus: Las estatinas pueden tener un efecto antihipertensivo, promoviendo la circulación coronaria colateral, mejorando así el metabolismo de la glucosa y la sensibilidad a insulina (Guijarro 2001). 
Osteoporosis: se observó en ensayos clínicos que las estatinas tienen efectos benéficos sobre la densidad mineral ósea, reduciendo así el riesgo de fractura (Pahan 2006)

Enfermedad de Alzheimer: se ha observado hasta un 70\% de disminución del riesgo en desarrollar esta enfermedad. Ensayos preclínicos mostraron que las estatinas pueden atenuar la amiloidosis cerebral reduciendo con ello el riesgo de padecer la enfermedad (Fassbender et al. 2001).

Enfermedad de Parkinson: las estatinas potencialmente regulan el metabolismo lipídico cuando éste se encuentra desregulado, lo cual puede ser crucial para prevenir daños en el sistema nervioso central (Adibhatla \& Hatcher 2008).

Esclerósis múltiple (EM): Diversos ensayos clínicos demostraron que las estatinas redujeron la morbilidad en pacientes con EM, al reducir el número y volumen de nuevas lesiones. Además se mostró que las estatinas previenen y pueden revertir la encefalomielitis autoinmune en modelos animales con EM (Pahan 2006).

Artritis reumatoide (AR): las estatinas demostraron en ensayos clínicos un efecto inmunomodulatorio y antiinflamatorio en pacientes con esta enfermedad, ya que modificó la función endotelial en pacientes con AR (McCarey et al. 2005).

Otros usos potenciales de las estatinas: se han reportado que las estatinas también disminuyen el riesgo de Depresión con en pacientes con enfermedades de arteria coronaria (Pahan 2006); así también se redujo el riesgo en presentar el Síndrome de Ovario Poliquístico, el cual frecuentemente coexiste con ostros desordenes cardiovasculares (Kodaman \& Duleba 2008). El mecanismo por el cual las estatinas pueden actuar en el tratamiento de estos padecimientos, se justifica en la Fig. 3. 


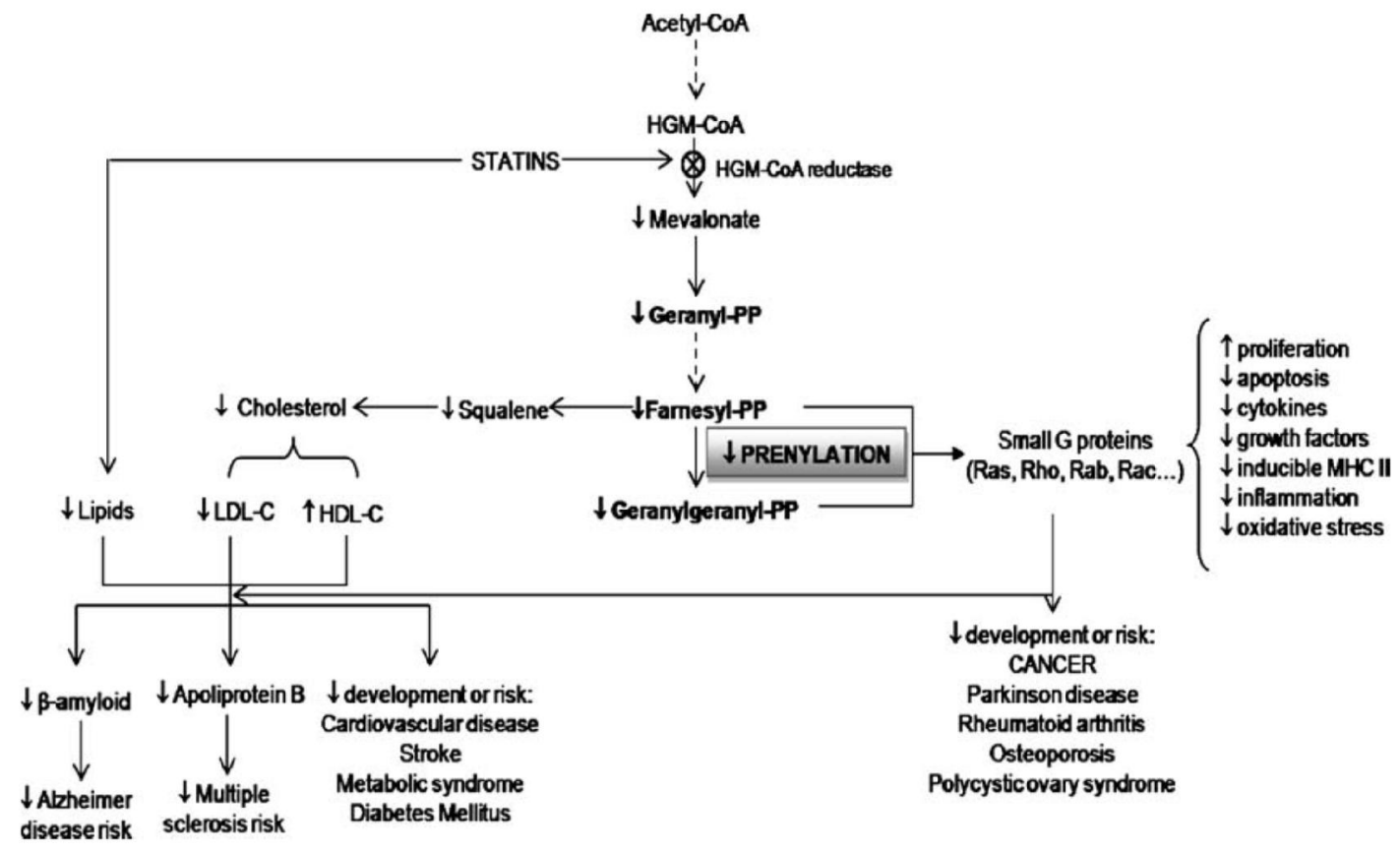

Fig. 3 Modelo que explica la gran variedad de efectos biológicos de las estatinas; y por tanto, los usos actuales y potenciales. La inhibición de la HGM-CoA reductasa, no solamente reduce los niveles de colesterol, sino también los intermediarios isoprenoides, afectando la prenilación de las proteínas G (i.e., Ras). Esto puede resultar en la modulación de la transducción de señales de los receptores hacia la expresión de los genes, que directa o indirectamente afectan el balance proliferación/apoptosis, quimiosinas inflamatorias, y mensajeros citogenéticos, todos mediados por proteínas G (BarriosGonzález \& R. Miranda 2010).

Por las razones antes mencionadas, se explica el gran éxito a nivel mundial de las estatinas en el campo médico y comercial. Tan sólo en el 2006, dos de las estatinas encabezaron la lista Forbes de los 20 fármacos más vendidos, reportando ventas de hasta 8.4 billones de dólares anuales; y con todos los usos potenciales, se pronostica un incremento en el uso de estos fármacos (Barrios-González \& R. Miranda 2010).

\subsection{La lovastatina.}

La lovastatina es generada a través de la ruta de síntesis de los policétidos (), su fórmula molecular es $\mathrm{C}_{24} \mathrm{H}_{36} \mathrm{O}_{5}$, con un peso molecular de $404.5 \mathrm{~g} / \mathrm{mol}$ y su estructura se presenta en la Fig. 4. Está fue la primera estatina desarrollada para uso clínico y aprobada por la US FDA (United States Food and Drug Administration), para el tratamiento de la hipercolesterolemia el 31 de agosto de 1987 (Tobert 2003). 


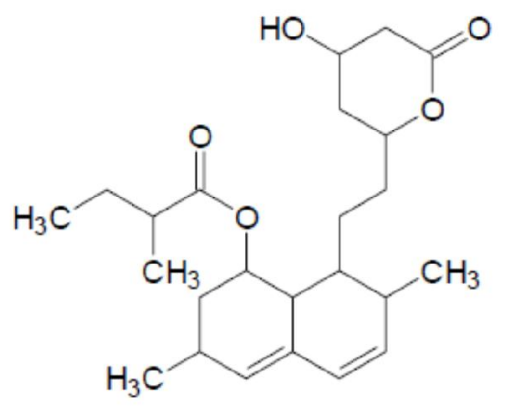

Fig. 4 Estructura química de la lovastatina (Rollini 2002)

La lovastatina es un inhibidor de la enzima hidroximetilglutaril coenzima A (HMG- CoA) reductasa (mevalonato: NADP1 oxidoreductasa [EC 1.1.1.34]) la cual cataliza la reducción de HMG-CoA a mevalonato () durante la síntesis del colesterol (Hajjaj et al. 2001).

La ruta biosintética de la lovastatina se ha investigado por resonancia magnética nuclear y espectroscopia de masas (Yoshizawa et al. 1994; Hendrickson et al. 1999). Estos estudios concluyeron que la lovastatina está compuesta de dos cadenas de policétidos unidas a través de un enlace éster, las cuales son ensambladas por la Policétido Sintasa, resultados que provienen de la clonación y la parcial caracterización del clúster de genes biosintéticos de lovastatina de A. terreus (Hajjaj et al. 2001).

El clúster de genes biosintéticos de la lovastatina consiste en 18 probables marcos de lectura abiertos (open reading frames u ORFs), 2 de los cuales codifican para proteínas reguladoras, lovE y lovH ( Fig. 5, (Rollini 2002). 


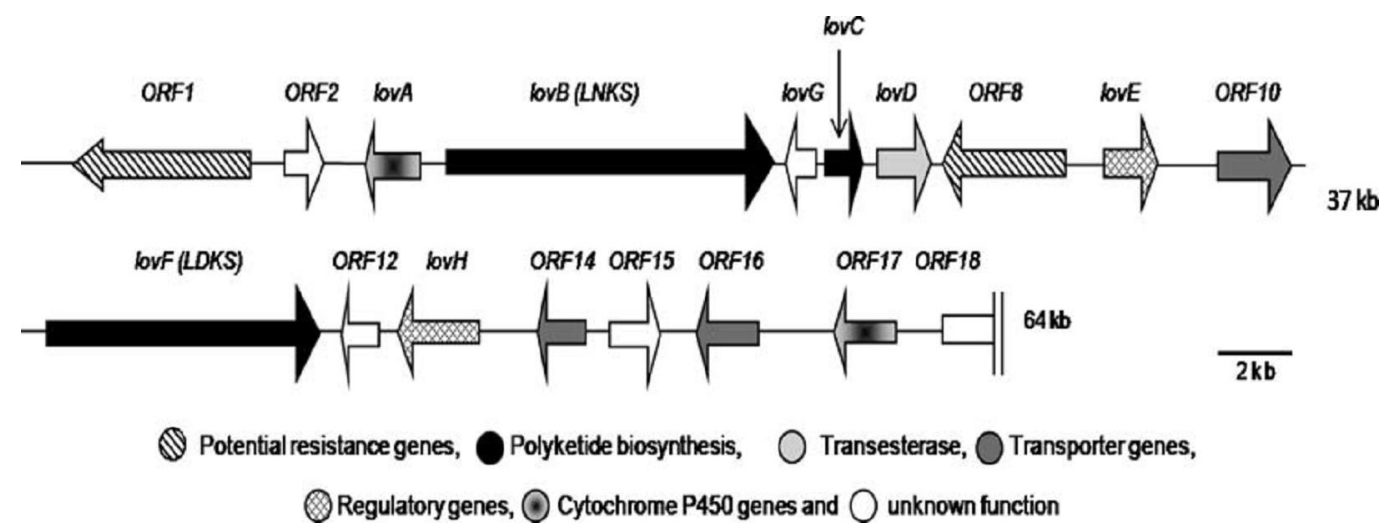

Fig. 5 Clúster biosintético de la lovastatina: $\operatorname{lov} B$ y $\operatorname{lov} F$ biosíntesis de policétidos; $l o v C$ enoil reductasa; $\operatorname{lov} D$ transesterasa; lovE y lovH genes reguladores; ORF2 y ORF17 genes del citocromo P-450; ORF1 y ORF10 genes potenciales de resistencia; ORF12 y ORF16 genes de transporte; lovG, ORF12, ORF15 y ORF18 función desconocida) (Barrios-González \& R. Miranda 2010).

\subsubsection{Biosíntesis.}

Investigaciones anteriores llevadas a cabo en una cepa de Monascus ruber sobre las estatinas monacolina $\mathrm{J}$ y L, y que fueron marcadas con ${ }^{14} \mathrm{C}$, sugiere que estos compuestos son precursores de la lovastatina y que por lo tanto pueden clasificarse como metabolitos intermediarios de la ruta de biosíntesis de lovastatina (Endo et al. 1985).

Estudios en Monascus ruber, Paecilomyces viridis y Aspergillus terreus sobre la ruta que involucra la síntesis de lovastatina, han demostrado que la ruta es iniciada a partir de unidades de acetato. La monacolina L, que es sintetizado a partir de 9 moléculas de acetato, es convertido luego a monacolina $\mathrm{J}$ mediante una hidroxilación, para posteriormente convertirse en lovastatina () (Rollini 2002; Barrios-González \& R. Miranda 2010).

Recientes investigaciones genéticas han estudiado el mecanismo enzimático involucrado en la biosíntesis de lovastatina. Los resultados mostraron que hay un Sistema Multifuncional de Policétidos Sintasa (PKSs) el cual comprende una Nonácetido Sintasa (LNKS) involucrada en la ciclación de la cadena principal de policétidos, para formar el sistema de anillos de hexahidronaftaleno, y una Dicétido Sintasa (LDKS) involucrada en la transferencia del metilbutiril al costado de la cadena de la monacolina J (Kennedy 1999).

Han sido dilucidados los genes que codifican estas enzimas y los factores regulatorios en la producción de lovastatina en $A$. terreus que son la clave en el entendimiento de la biosíntesis. 
En general, los recientes avances en la clonación de genes han permitido la identificación de más enzimas involucradas en la biosíntesis de la lovastatina y han confirmado la ruta de biosíntesis hipotética de investigaciones anteriores.
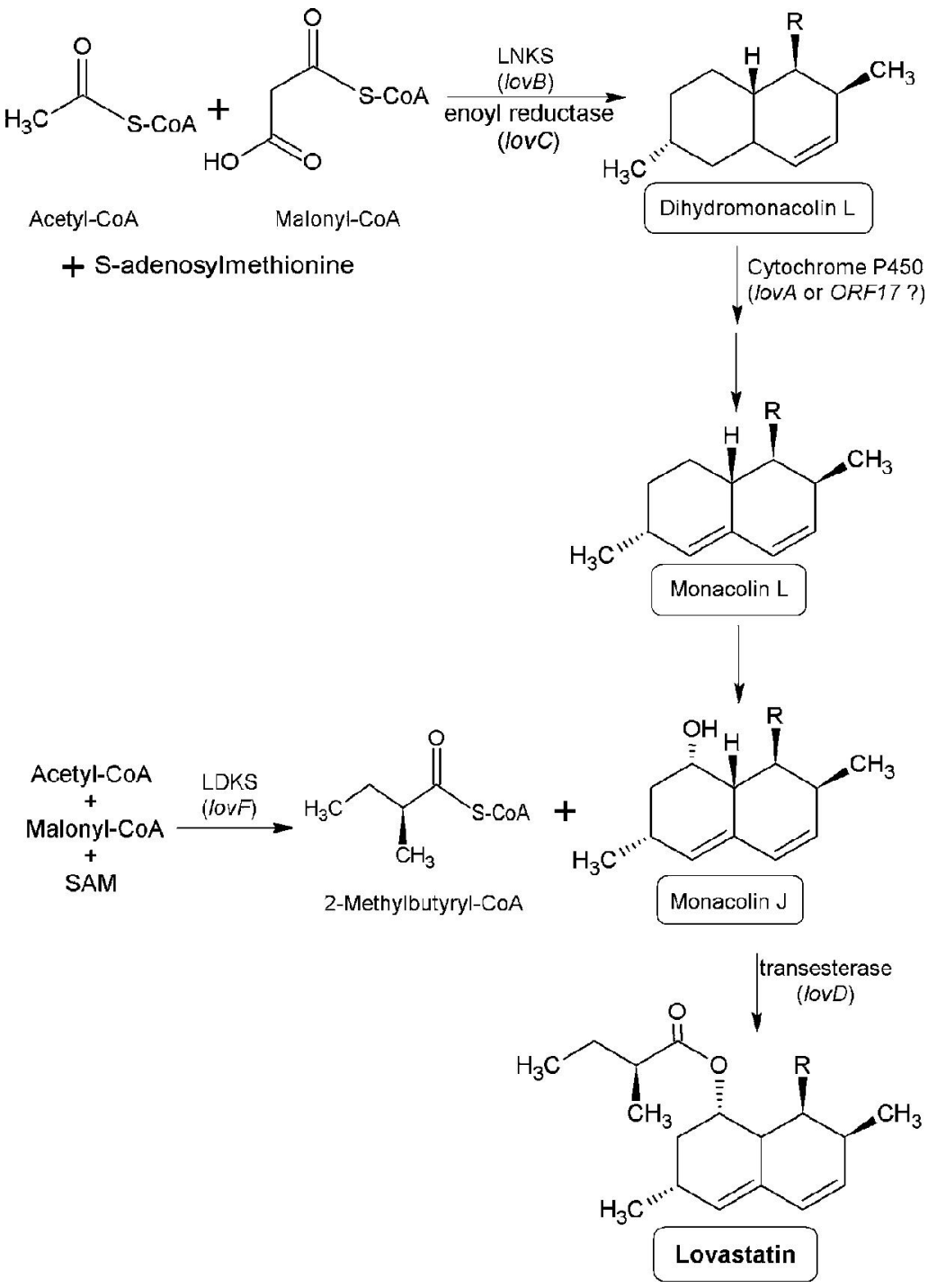

Fig. 6 Ruta biosintética de lovastatina, mostrando las enzimas involucradas y los genes que lo codifican (Barrios-González \& R. Miranda 2010). 


\subsubsection{Producción Industrial.}

Las investigaciones llevadas a cabo desde 1970 han indicado la posibilidad de obtener un amplio rango de estatinas, tanto como los productos finales e intermediarios del metabolismo microbiano secundario.

Se han desarrollado procesos a gran escala solamente para pocas de las estatinas descritas en la literatura. Para otras moléculas, la investigación todavía está en curso y por lo tanto son susceptibles de desarrollo. Estos estudios han resultado en un profundo entendimiento de los diferentes aspectos relativos a los mecanismos involucrados en la producción de las estatinas, lo que ha generado el conocimiento necesario para el desarrollo de proceso a gran escala.

La lovastatina (llamada mevinolina) fue la primera estatina en ser aprobada por la FDA de EU (1987) y puesta a disposición para el mercado farmacéutico como un medicamento anticolesterolémico. Esta estatina fue obtenida de una cepa aislada del suelo y clasificada como Aspergillus terreus en los Laboratorios CIBE en Madrid (España) y de Monascus ruber (llamada monacolina K) por (Endo 2008). Pocos años después la lovastatina también fue obtenida de 17 cepas de diferentes especies de 124 cepas probadas de Monascus, en particular, M. ruber, M. purpureus, M. pilosus, M. vitreus, y M. pubigerus. (Hajjaj et al. 2001; Rollini 2002).

La producción convencional de lovastatina se ha llevado a cabo mediante FL empleando mutantes mejoradas de $A$. terreus (Manzoni et al. 1998). Recientemente la productividad de la cepa de A. terreus ATCC 20542 (productor original de lovastatina), fue incrementado por el grupo Metkinen OY (Finland), hasta alcanzar 7- $8 \mathrm{~g} / \mathrm{L}$, utilizando procedimientos de mutagénesis y la experiencia adquirida en el desarrollo de programas de mejoramiento de procesos (Rollini 2002).

Por otro lado, se ha producido lovastatina empleando Aspergillus flavipes mediante FS usando diferentes sustratos sólidos, tales como salvado de trigo, harina de soya, salvado de grano, desechos frutales y sus combinaciones. Se encontró que empleando salvado de trigo se llegaba a producir hasta $13.49 \mathrm{mg} / \mathrm{g}$ (sólido seco) de lovastatina en camas estancadas y 16.65 $\mathrm{mg} / \mathrm{g}$ de lovastatina en camas agitadas aireadas, después de 6 días de fermentación (Valera et al. 2005).

La FS es un método de cultivo antiguo que se ha modernizado en los últimos 20 años, de manera que se considera una tecnología emergente con gran potencial para la producción de 
enzimas y metabolitos microbianos (Robinson et al. 2001). Existen varios estudios para la obtención de lovastatina mediante FS (Valera et al. 2005; Wei \& Xu 2007; Baños et al. 2009).

En años recientes, los investigadores han mostrado un creciente interés en este tipo de fermentación, como una alternativa potencial a la FL, dado que se pueden utilizar sustratos económicos (como residuos agrícolas), se requiere poco procesamiento y las etapas de transmisión continua, utiliza menos potencia y genera menos efluentes. Además, la FS tiene una alta productividad y ofrece mejor estabilidad de producto. Previamente, este cultivo era empleado principalmente para la producción de enzimas industriales, pero en la actualidad, esta tecnología es aplicada para la producción de MS (Barrios-González et al. 2005; Robinson et al. 2001; Barrios-González 2012).

Biocon (Biocon, Bangalore, India) es una de las compañías que ha obtenido la aprobación para la producción de lovastatina por el FDA de EU (Enero 2001). Fue la primer compañía hindú, en obtener esta aprobación para moléculas derivadas de fermentación para uso farmacéutico. El proceso de producción de lovastatina, está basada en una tecnología propia de fermentación, el Plafractor, un biorreactor a gran escala de matriz sólida (Suryanarayan \& Mazumdar 2003). Este nuevo biorreactor, tiene las ventajas de un sustrato sólido y la FL, y permite la reducción de problemas debidos a procesos posteriores durante la extracción del producto.

También se ha encontrado que al producir lovastatina por Aspergillus terreus en FS, empleando poliuretano como soporte inerte, hay una producción 30 veces mayor que en FL. Al emplear un soporte inerte, permitió conocer la producción específica, obteniendo un parámetro comparable con respecto a lo obtenido en FL, y se encontró que ésta era 13 veces mayor en FS con respecto a FL (Baños et al. 2009).

\subsection{Regulación de la Biosíntesis de MS.}

Ya que las rutas biosintéticas secundarias están vinculadas a las rutas metabólicas primarias y utilizan los mismos intermedios, los mecanismos regulatorios tales como: inducción, regulación por catabolito y/o regulación por retroalimentación, regulan su biosíntesis. Estos mecanismos regulatorios específicos de las rutas, operan en conjunto con un control general el cual está ligado a la velocidad de crecimiento (Barrios-González et al. 2005). 
En FL, estos mecanismos regulatorios son controlados por manipulaciones ambientales. En procesos de fermentación para producción de antibióticos regulados por carbono, son conducidos lentamente utilizando fuentes de carbono como la lactosa (Pandey et al. 2008).

Estudios a nivel molecular han mostrado que los genes de las rutas biosintéticas de los MS están agrupados (en clúster) en el genoma del hongo o de los actinomicetos. Además, hay estudios que indican que frecuentemente un gen específico regulatorio está incluido dentro de este conjunto de genes (Keller et al. 2005).

\subsubsection{Factores Transcripcionales que regulan la Biosíntesis de MS.}

La co- regulación de estos clusteres puede, en parte, se explicado por el control transcripcional coordinado de los genes biosintéticos por factores de transcripción de dominio "estrecho" o "amplio" en hongos (Keller et al. 2005).

Los reguladores específicos de dominio estrecho, usualmente se localizan en el clúster y regulan positivamente la expresión de genes. Estas proteínas son a menudo de tipo $\mathrm{Zn}(\mathrm{II})_{2} \mathrm{Cys}_{6}$ zinc binuclear, las cuales son una clase de proteínas que sólo están en hongos y tienen dominio de unión al ADN en clúster. Las proteínas arquetípicas en este grupo es AflR (regulador de la biosíntesis de aflatoxinas), las proteínas $\mathrm{Zn}(\mathrm{II}) \cdot \mathrm{Cys}$ son requeridas para la activación de genes de biosíntesis de aflatoxinas y esterigmatocistina. Típico para este grupo de proteínas de unión al $\mathrm{ADN}$, AflR reconoce y se une a secuencias palindrómicas encontradas en los promotores de los genes biosintéticos (Woloshuk et al. 1994).

Se ha conocido por mucho tiempo que la biosíntesis de MS se produce en respuesta a estímulos ambientales, incluyendo la fuente de carbono, nitrógeno, temperatura, luz y $\mathrm{pH}$. Los factores de domino amplio, son Factores Transcripcionales importantes en integrar las respuestas a estos parámetros. Varios estudios indican que las respuestas a las señales ambientales son transmitidas a través de Factores Transcripcionales de tipo de Dedos Cys·His·Zinc que median la señalización de carbono (CreA), nitrógeno y pH (PacC). La regulación por factores de transcripción de dominio amplio o estrecho, asegura que las rutas de los MS pueden responder a la demanda de un metabolismo celular general y la presencia de inductores de ruta específicos (Keller et al. 2005). 


\subsubsection{Manipulación de la Regulación de la Biosíntesis de Lovastatina para mejorar su Producción Biotecnológica.}

El entendimiento de los mecanismos de regulación de la biosíntesis de lovastatina, podría resultar en mejoras en los niveles de producción de este metabolito secundario, ya sea mejorando las condiciones del cultivo para el hongo, o realizando mejoramiento genético de la cepa. A continuación se mencionan algunos avances en esta área:

\subsubsection{Regulación por Represión Catabólica.}

Debido al conocimiento de los genes y enzimas involucrados en la ruta de biosíntesis, poco es conocido a cerca de la regulación y fisiología de la biosíntesis de lovastatina. Se ha observado que a través de las fuentes de carbono y nitrógeno son por las que se ejerce una regulación compleja sobre la expresión de genes y actividades de enzimas de la síntesis de policétidos, posiblemente a nivel de represión por catabolito o debido a señales debido a la limitación en la velocidad de crecimiento o la limitación de sustrato (Hajjaj et al. 2001).

El inicio de la biosíntesis de lovastatina después del consumo de glucosa, puede atribuirse tanto al desahogo de la represión por catabolito o por la limitación de la fuente de carbono. La represión catabólica por carbono, es mediada por el producto del gen creA que actúa negativamente. La unión de la proteína CreAp e un sitio específico del promotor de genes involucrados en la utilización de fuentes alternativas de carbono, previene su expresión en presencia de glucosa u otras fuentes represivas de carbono (Hajjaj et al. 2001)

El clúster biosintético de la lovastatina, consta de 18 ORF's, entre los cuales, se han señalado a dos como proteínas regulatorias, LovE y ORF13 (o LovH). El análisis del clúster genético de la biosíntesis de lovastatina, reveló que posee la secuencia consenso SYGGRG, el motivo de unión de la proteína CreAp in vivo, esta presente de forma duplicada en la región proximal al 5' del ORF13 (SYGGRG(N) ${ }_{15} \mathrm{SYGGRG)}$ y en el promotor de ORF8 y lovE $\left(\mathrm{SYGGRG}(\mathrm{N})_{7} \mathrm{CYCCRW}\right)$. La presencia de probables sitios de unión funcionales para CreAp en dos genes regulatorios, sugieren que la represión de la biosíntesis de lovastatina por glucosa, podría ser regulada por CreAp.

Se han reportado buenas producciones de lovastatina con una cepa silvestre de Aspergillus terreus (TUB F-514), empleando un medio de producción que contenía lactosa como fuente de carbono, harina de colza como fuente de nitrógeno orgánico y nitrato de potasio como fuente de nitrógeno inorgánica, así como una solución de elementos traza, logrando obtener 
producciones de lovastatina cercanas a los $400 \mu \mathrm{g} / \mathrm{ml}$ (Szakács et al. 1998). Este medio fue modificado y empleado logrando con éxito mayores producciones tanto en FL (convencional) y FS (empleando un medio concentrado 2.5x) con la misma cepa empleada por Szákacs et al. (1998), lográndose producciones de $570 \mu \mathrm{g} / \mathrm{ml}$ (493 $\mu \mathrm{g} / \mathrm{mg}$ biomasa) en FL y de $815 \mu \mathrm{g} / \mathrm{mg}$ biomasa en FS, es decir, 13 veces mayor respecto a la producción específica en este último sistema (Baños et al. 2009).

\subsubsection{Regulación por Producto Final.}

También se ha identificado que regulación por producto final existe en la biosíntesis de lovastatina en $A$. terreus, i.e., la lovastatina inhibe su propia biosíntesis. La liberación de esta inhibición por producto final puede mejorar la producción de lovastatina considerablemente (Jia et al. 2010).

\subsubsection{Regulador Global del Metabolismo Secundario: LaeA}

LaeA, es un regulador del metabolismo secundario fúngico. La deleción de laeA, bloquea la expresión del clúster de genes, como el de la esterigmatocistina (carcinógeno), penicilina (antiobiótico) y lovastatina. Contrario a esto, la sobreexpresión de laeA, dispara el incremento de la transcripción de genes de la penicilina y lovastatina y su subsecuente formación de producto en Aspergillus sp. (Fig. 13). La expresión de laeA es regulada negativamente por AflR, un factor de transcripción $\mathrm{Zn}_{2} \mathrm{Cys}_{2}$ de la esterigmatocistina, en una retroalimentación cíclica, así como por dos elementos de la transducción de señales, la proteína quinasa $\mathrm{A}$ y RasA. Aunque estas dos últimas proteínas, también regulan negativamente, las cepas ØlaeA muestran poca diferencia en la producción de esporas, comparadas con la cepa silvestre, indicando que el rol primario de LaeA es el de regular los clúster de genes metabólicos (Bok \& Keller 2004).

En Aspergillus terreus (TUB F-514) se observó que la sobreexpresión de laeA, incrementó su nivel de producción de manera significativa (Pérez-Aguirre, manuscrito en preparación).

\subsubsection{Fisiología Especial del Medio Sólido.}

La producción de lovastatina mediante FS, ha hecho evidente la existencia de otros factores o estímulos que pueden regular la biosíntesis de lovastatina, además de los ya mencionados. 
La FS es un método de cultivo alternativo a la FL, el cual ha ganado la atención de los varios investigadores a nivel mundial en los últimos 20 años, debido a que existen muchas ventajas sobre el cultivo tradicional (FL), como lo son los altos rendimientos de productos de valor comercial; además, ciertas enzimas y MS solamente pueden ser producidos mediante FS, a esto se le ha denominado "físiología especial del medio sólido" (Barrios-González et al. 2008).

Como se mencionó anteriormente, se han reportado producciones mayores de lovastatina 30 veces mayores con respecto a la FL (Baños et al. 2009), lo cual lo hace interesante desde el punto de vista de producción, por lo que el sistema ya fue patentado. Esto llama la atención por las implicaciones biotecnológicas que puede alcanzar, por lo que querer entender los mecanismos regulatorios que permiten la alta producción en FS, nos permitirá a futuro diseñar estrategias racionales de mejoramiento genético de cepas que puedan emplearse a nivel industrial.

Con objeto de entender los mecanismos o eventos responsables de estas diferencias en el nivel de producción, se realizaron estudios a nivel molecular. Los resultados mostraron que la alta producción de lovastatina en FS está relacionada a una mayor intensidad en la transcripción del gen regulador lovE y los genes biosintéticos (Barrios-González et al. 2008).

Estos estudios indicaron que existen ciertos estímulos ambientales que hacen notar al hongo que se encuentra en medio sólido. Estos estímulos deben ser detectados y entonces transducidos, disparando un número de eventos a nivel molecular. Además, se han identificado algunos estímulos ambientales en cultivo sólido (señales) (Barrios-González 2012).

Un estímulo que potencialmente puede ser detectado por el micelio en FS, incluye el contacto directo con el aire, y es posible que este contacto pueda estimular la biosíntesis a través del EOX o por la formación de ROS.

\section{5. ¿Qué son las ROS?}

El dioxígeno $\left(\mathrm{O}_{2}\right)$ es uno de los gases más importantes de la Tierra. Constituye el $21 \%$ de la atmósfera, $89 \%$ del peso del agua de mar y al menos $47 \%$ de la corteza terrestre. Además, casi todos los seres vivos utilizan el dioxígeno para respirar y obtener energía. La vida aeróbica es aquella que se da en un ambiente rico en oxígeno $\left(\mathrm{O}_{2}\right)$ y que desarrolla un metabolismo consistente en la transferencia final de electrones al $\mathrm{O}_{2}$ reduciéndolo a agua $\left(\mathrm{H}_{2} \mathrm{O}\right)$ para la 
obtención de energía. Este proceso constituye el último paso de la fosforilación oxidativa, que se da a nivel mitocondrial y que acopla un flujo electrónico, cuyo aceptor final es el $\mathrm{O}_{2}$, a la generación de ATP (Folch-Mallol et al. 2004).

A partir del $\mathrm{O}_{2}$ se forman durante la respiración, moléculas más reactivas conocidas como especies reactivas de oxígeno o ROS (Fig. 7). Las ROS regulan varios procesos celulares pero también resultan nocivas para los organismos (Aguirre et al. 2005).

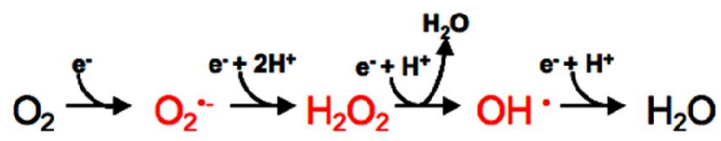

Fig. 7 Las especies reactivas del oxígeno (ROS), superóxido $\left(\mathrm{O}_{2} \bullet-\right)$, peróxido de hidrógeno $\left(\mathrm{H}_{2} \mathrm{O}_{2}\right)$, y radical hidroxilo (HO•), se generan a partir de la reducción parcial del oxígeno molecular $\left(\mathrm{O}_{2}\right)$.

Las ROS son derivados del oxígeno más reactivo que el $\mathrm{O}_{2}$ en su estado basal. $\mathrm{El}_{2} \mathrm{H}_{2}$ es un oxidante débil; sin embargo, difunde y cruza las membranas fácilmente $\mathrm{y}$, al reaccionar con algunos metales de transición como el fierro o el cobre reducidos $\left(\mathrm{Fe}_{2}^{+} \mathrm{o} \mathrm{Cu}^{+}\right.$ respectivamente) forma al radical hidroxilo $(\mathrm{HO} \bullet)$ uno de los radicales conocidos con mayor reactividad. En el ion peróxido los dos átomos se encuentran unidos por un solo enlace débil, de tal forma que al aceptar un par de electrones extra, este enlace se elimina totalmente. La protonación de este producto genera agua (Folch-Mallol et al. 2004).

El dioxígeno singulete $\left(1 \mathrm{O}_{2}\right)$ a diferencia de las ROS mencionadas, no es producto de la reducción parcial del dioxígeno basal. El $1 \mathrm{O}_{2}$ se genera mediante la captación de energía por uno de los electrones desapareados del $\mathrm{O}_{2}$ en su estado basal, al cambiar de giro forma el $1 \Sigma \mathrm{gO}_{2}$. Esta forma del oxígeno singulete es muy inestable y decae en la forma $1 \Delta \mathrm{O}_{2}$ cuando se aparean los dos electrones de los orbitales $\pi^{*}$ de antiunión. La forma $1 \Delta \mathrm{O}_{2}$ puede volver al estado de dioxígeno basal con la emisión de un fotón o bien puede aceptar un electrón o un par de electrones con giros opuestos, razón por la cual el $1 \mathrm{O}_{2}$ resulta tan reactivo (Fig. 8). 


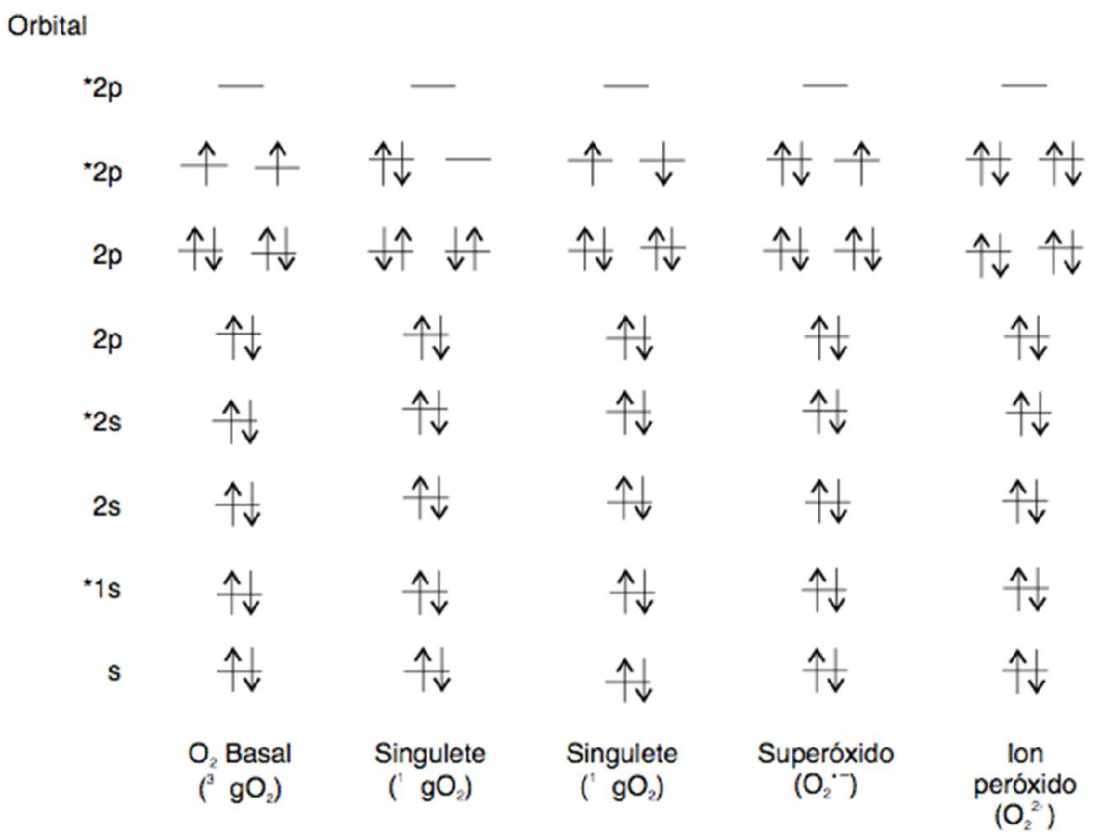

Fig. 8 Estructura electrónica de las ROS generadas a partir de la molécula de dioxígeno (Folch-Mallol et al. 2004).

\subsubsection{Generación de ROS.}

En aerobiosis, la principal fuente de ROS es la cadena de transporte electrónico mitocondrial, que acopla la reducción del $\mathrm{O}_{2}$ a la generación de ATP. Esencialmente, los electrones de flavinas reducidas $\mathrm{FADH}_{2}$ (flavina adenina dinucleótido) y NADH (nicotinamida adenina dinucleótido) provenientes de la glucólisis o del ciclo de Krebs fluyen hasta el $\mathrm{O}_{2}$ a través de una serie de complejos proteicos ubicados en la membrana interna mitocondrial: Complejo I: NADH deshidrogenasa, complejo II: succinato deshidrogenasa, complejo III: citocromo $c$ reductasa y complejo IV: citocromo oxidasa. Los electrones fluyen a través de los complejos por transferencia a grupos flavinas, centros hierro-sulfuro (Fe-S), grupos hemo e iones cobre que poseen las proteínas de estos complejos.

La ubiquinona y el citocromo $c$ son las moléculas encargadas de transportar los electrones desde un complejo al siguiente. Cualquiera de estas moléculas es susceptible de donar un electrón al $\mathrm{O}_{2}$ en lugar de al siguiente componente de la cadena, generándose así el ión $\mathrm{O}_{2}{ }^{\circ-}$. La reducción puede seguir hasta la formación de $\mathrm{H}_{2} \mathrm{O}_{2}$ por superposición de orbitales moleculares entre el dador electrónico y el anión $\mathrm{O}_{2}{ }^{-}$. Este proceso genera una mezcla de $\mathrm{O}_{2}{ }^{--}$y $\mathrm{H}_{2} \mathrm{O}_{2}$ en proporción diferente entre los distintos componentes de la cadena de transporte electrónico. 
Existen xenobióticos que interaccionan con los componentes de la cadena de transporte electrónica y que provocan un aumento en la producción de $\mathrm{O}_{2}{ }^{-{ }^{-}}$a través de dos mecanismos: bloqueando el transporte electrónico en algún punto de la cadena, con un aumento consiguiente en el estado reducido de los transportadores anteriores, o funcionando como aceptores de electrones de algún transportador y donadores de estos electrones al $\mathrm{O}_{2}$, siendo éste el caso de drogas como el paraquat o la menadiona, que utilizan los electrones de NADH o NADPH para reducir al $\mathrm{O}_{2}$ generando $\mathrm{O}_{2}{ }^{--}$en un mecanismo conocido como redox-cycling.

Existen más fuentes de electrones, a nivel mitocondrial, que pueden reducir parcialmente al oxígeno, como la glicerol-fosfato deshidrogenasa (Drahota et al. 2002) o la monoamin oxidasa (Hauptmann et al. 1996; Cadenas \& Davies 2000), que cataliza la desaminación oxidativa de aminas biogénicas, generando $\mathrm{H}_{2} \mathrm{O}_{2}$.

La exposición a radiaciones $\mathrm{X}, \gamma$ o UV también promueve la formación de ROS. La producción de ROS puede ser enzimática, como es el caso de los enzimas detoxificadores SOD, que generan $\mathrm{H}_{2} \mathrm{O}_{2}+\mathrm{O}_{2}$ a partir de 2 moléculas de $\mathrm{O}_{2}{ }^{--}$. Es también el caso de las NADPH oxidasas, localizadas en la membrana celular de macrófagos, células polimorfonucleares y células endoteliales (Babior 2000; Babior 2002; Vignais 2002) así como de las oxigenasas dependientes del citocromo P450 (Coon et al. 1992). Durante el metabolismo de las purinas, las enzimas xantina deshidrogenasa y xantina oxidasa son otra fuente de $\mathrm{O}_{2}{ }^{--}$y $\mathrm{H}_{2} \mathrm{O}_{2}$ (Turrens 2003).

Existen fuentes de $\mathrm{H}_{2} \mathrm{O}_{2}$ independientes de la producción de $\mathrm{O}_{2}{ }^{--}$; es el caso de la $\beta$-oxidación de ácidos grasos, catalizada por la acil-CoA oxidasa, que se da a nivel peroxisomal en células eucariotas (Chance et al. 1979) (Fig.9). 


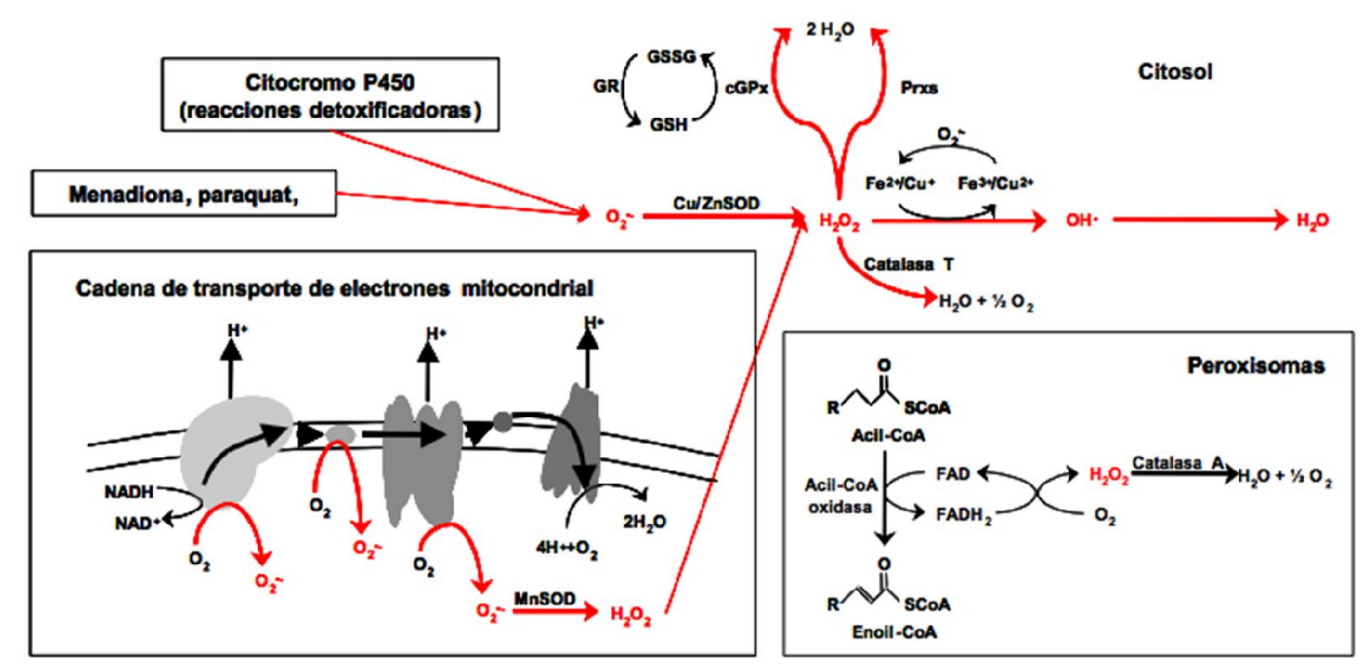

Fig. 9 Producción y detoxificación de ROS en las células eucariotas

El radical $\mathrm{OH} \bullet$ se genera cuando un átomo de hierro ferroso transfiere un electrón al $\mathrm{H}_{2} \mathrm{O}_{2}$ según la reacción de Fenton:

$$
\mathrm{H}_{2} \mathrm{O}_{2}+\mathrm{Fe}^{2+} \rightarrow \mathrm{OH}-+\mathrm{FeO}_{2}++\mathrm{H}^{+} \rightarrow \mathrm{Fe}^{3+}+\mathrm{OH}-+\mathrm{OH} \bullet
$$

El $\mathrm{Fe}^{3+}$ es reducido a $\mathrm{Fe}^{2+}$ por el anión $\mathrm{O}_{2}{ }^{--}$así como por cisteínas o glutatión. De esta forma, lugares en los que se generan radicales $\mathrm{H}_{2} \mathrm{O}_{2} \mathrm{y}_{2}{ }^{{ }^{-}}$, como es el caso de la cadena de transporte electrónico mitocondrial, proporcionan las condiciones para la formación de radical $\mathrm{OH} \bullet$ según la reacción de Fenton. El cobre (en su forma $\mathrm{Cu}+$ ) también puede catalizar esta reducción. El hierro ferroso libre, es decir, no incorporado en enzimas ni en proteínas que almacenan hierro, proviene de la liberación desde centros Fe-S dañados por oxidación, de la pérdida espontánea de metales que sufre, por ejemplo, la aconitasa de Escherichia coli (Varghese et al. 2003) así como de pérdidas en procesos de tráfico de hierro. 


\subsubsection{Generación de ROS en hongos.}

Junto con las fuentes de ROS mencionadas anteriormente, son más de tres enzimas que producen ROS en las células fúngicas y están involucradas en la regulación del desarrollo en eucariontes, la NADPH oxidasa (NOX), la glioxal oxidasa y la NO sintasa (Belozerskaya \& Gessler 2007; Aguirre et al. 2005).

La NADPH oxidasa (NOX) fue el primer ejemplo de enzima dedicada a la producción de ROS y fue descrita en animales y plantas. El reciente descubrimiento de enzimas NOX en microorganismos eucarióticos, expande el rango de posibilidades de las funciones de esta enzima sobre la regulación (Aguirre et al. 2005).

\subsubsection{Las ROS como moléculas señalizadoras.}

Se han establecido los efectos dañinos de las ROS sobre el ADN, proteínas, lípidos y otros componentes celulares y su participación en los procesos patológicos, sin embargo, una gran cantidad de evidencia muestra que las ROS juegan un papel específico en las funciones celulares (Cano-Dominguez et al. 2008).

Estudios anteriores han demostrado que las ROS participan activamente en diversos procesos biológicos, que incluyen el normal crecimiento celular, inducción y mantenimiento de un estado transformado, la muerte celular programada y la senescencia celular (Finkel 2003; Aguirre et al. 2006).

Se sabe que las ROS producidas en ciertos puntos de tiempo del ciclo de vida celular y a bajas concentraciones fisiológicas, desempeñan funciones cruciales en la homeostasis del organismo y las funciones celulares (Reverberi et al. 2008).

Como segundos mensajeros, las ROS están involucrados en procesos de desarrollo en plantas y en mecanismos de defensa contra patógenos y estrés abiótico (Apel \& Hirt 2004; Jones 1994). Efectos similares se han observado en mamíferos, donde niveles apropiados de ROS estimulan las reacciones antioxidantes, la modulación del sistema inmune y la regulación de la proliferación celular (Bokoch \& Knaus 2003).

Así mismo, estudios recientes han revelado que las rutas de señalización son reguladas por el estado intracelular redox (Kamata \& Hirata 1999). 


\subsubsection{Las ROS en el desarrollo fúngico.}

Se ha propuesto que la diferenciación celular es una respuesta al EOX. De acuerdo a esto, el crecimiento y los estados diferenciados, son condiciones estables en las cuales los niveles de ROS son mantenidos por un balance en la generación de ROS (i.e. por mitocondria y NOX) y la eliminación (por enzimas antioxidantes) (Cano-Dominguez et al. 2008). Un cambio entre estos dos estados ocurre cuando un incremento transiente en los niveles de ROS, además de su capacidad celular de neutralizarlas (Aguirre et al. 2005) (Fig. 10).

El carácter transitorio de esta respuesta es debido en parte a que, el hecho de que niveles elevados de ROS resultan en una alta expresión de enzimas que las descomponen. Además, varios reportes en diferentes microorganismos eucarióticos han mostrado una correlación entre los procesos de desarrollo y la regulación de enzimas antioxidantes específicas, tales como las superóxido dismutasas (SODs), catalasas, peroxidasas y peroxirredoxinas (Aguirre et al. 2005).

\section{Radical anión superóxido $\left(\mathrm{O}_{2}{ }^{\circ}\right)$.}

Durante la respiración, parte del oxígeno usado por la mitocondria (2 al 5\%) es reducido incompletamente, formando el anión radical superóxido $\mathrm{O}_{2}{ }^{-{ }^{-}}$(cuya producción calculada para S. cerevisiae es de 6-7 $\mathrm{nmol} / \mathrm{min}$ ). Además de la cadena respiratoria, el $\mathrm{O}_{2}{ }^{-{ }^{-}}$es un producto intermediario generado en reacciones que involucran a la xantina oxidasa, monooxigenasas microsomales, lipooxigenasas y como resultado de la autooxidación de tioles, flavinas, quinonas y catecolaminas, así como la reducción de xenobióticos. El estrés por superoxido en Aspergillus nidulans conduce a cambios en la expresión de genes e inicia la diferenciación de la cleistotecia (órgano de reproducción sexual). La fusión de mixamoebae y la diferenciación subsecuente en el mixomiceto Dictyostellium discoideum son acompañados por un incremento en el contenido intra y extracelular de $\mathrm{O}_{2}{ }^{--}$. La deficiencia del radical superóxido perjudica el proceso sexual y la germinación de las ascosporas en el ascomiceto Podospora anserine y Neurospora crassa (Belozerskaya \& Gessler 2007). 


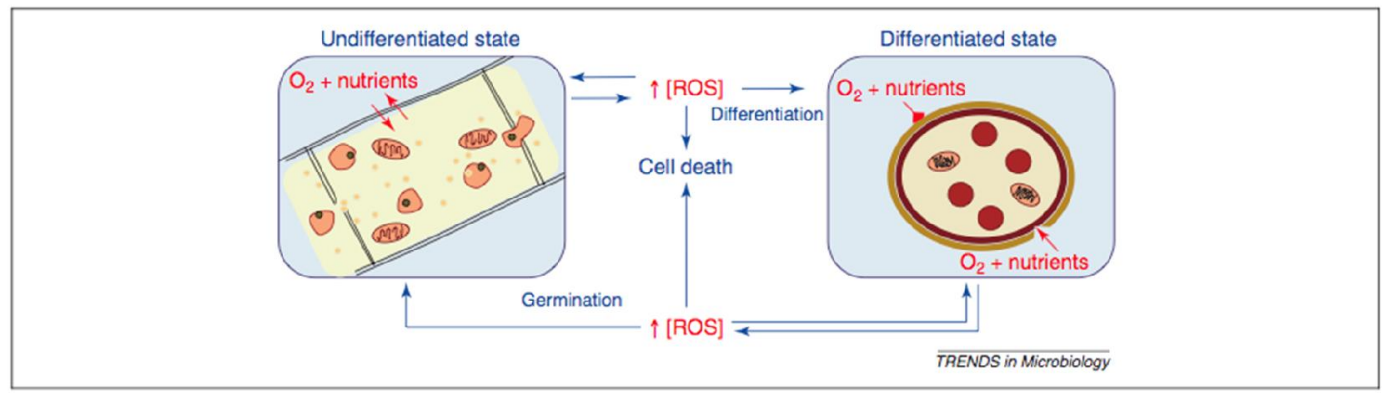

Fig. 10 Modelo de regulación de la diferenciación celular por ROS (Aguirre et al. 2005).

\section{$\mathrm{H}_{2} \mathbf{O}_{2}$.}

El $\mathrm{H}_{2} \mathrm{O}_{2}$ es generado durante la transformación del $\mathrm{O}_{2}{ }^{--}$tanto espontáneamente como con el involucramiento de la SOD (superoxido dismutasa). El estudio de la formación de $\mathrm{H}_{2} \mathrm{O}_{2}$ en el hongo Scleotium rolfsii antes del comienzo de la diferenciación (antes del desarrollo del esclerotium), demostró que la tasa de formación en el micelio fue de $4 \pm 0.5 \mathrm{nmol} / \mathrm{min} / \mathrm{g}$ biomasa seca e incrementó 2.5 veces después de iluminación o de la adición de iones de hierro. En hongos, la molécula de $\mathrm{H}_{2} \mathrm{O}_{2}$ como molécula señal está involucrada en varios procesos, tales como el cambio en tasa de crecimiento, diferenciación y proliferación. Como se demostró, el $\mathrm{H}_{2} \mathrm{O}_{2}$ influencia la actividad de los genes de $A$. nidulans, incluyendo los genes de defensa antioxidante; induce la diferenciación de la esclerotia en $S$. rolfsii y la transición del crecimiento filamentoso y la patogenicidad en Ustilago maydis; y activa la queratogénesis en N. crassa (Belozerskaya \& Gessler 2007).

\section{HO•.}

$\mathrm{El} \mathrm{H}_{2} \mathrm{O}_{2}$ es capaz de reaccionar con metales de valencia variable, por ejemplo, con $\mathrm{Fe}^{2+} \mathrm{y} \mathrm{Cu}^{+}$ (reacciones de Fenton) o con $\mathrm{O}_{2}{ }^{--}$(reacciones de Haber-Weiss), para formar un radical extremadamente reactivo como es el radical hidroxilo $(\mathrm{HO} \bullet)$. El tiempo de vida del $\mathrm{HO} \bullet$ es muy corta (menor de $1 \mathrm{~ns}$ ); sin embargo actúa muy rápido (a una tasa constante de $10^{9}-10^{10} 1$ $\left.\mathrm{mol}^{-1} \mathrm{~s}^{-1}\right)$. El HO es capaz de reaccionar virtualmente con todas las moléculas biológicas, oxidando DNA, proteínas y lípidos (Belozerskaya \& Gessler 2007).

\section{${ }^{1} \mathbf{O}_{2}$}

La luz visible aumenta la generación intracelular $\operatorname{del}{ }^{1} \mathrm{O}_{2}$. El ${ }^{1} \mathrm{O}_{2}$ reacciona con biomoléculas, por ejemplo, con ácidos grasos y bases de $\mathrm{ADN}$, formando $\mathrm{H}_{2} \mathrm{O}_{2}$ e hidroperóxidos. $\mathrm{El}{ }^{1} \mathrm{O}_{2}$ 
estimulan la formación de esporas, el desarrollo de la conidia, y la síntesis de carotenoides en N. crassa.

\section{Iones, Radiaciones y otros factores.}

La ionización (rayos $\alpha-, \beta-, \delta-y$ rayos x) y radiaciones ultravioleta (extremo 200-290 nm, medio 290-320 nm y cerca 320-420 nm) aumentan la generación de ROS en células y esencialmente influyen en la actividad fisiológica de los hongos (Belozerskaya \& Gessler 2007).

Además, los cambios de $\mathrm{pH}$ en el medio, temperatura, osmosidad, presión parcial de oxígeno, así como concentraciones de sustratos, secado, daño mecánico y otros factores externos influencian el crecimiento y desarrollo microbiano e induce la generación de radicales de oxígeno en las células fúngicas (Belozerskaya \& Gessler 2007).

\subsubsection{Enzimas Antioxidantes como Indicadores de ROS en el Desarrollo Celular.}

Las Superóxido Dismutasas (SOD), son enzimas abundantes presentes en muchos de los organismos aeróbicos y anaeróbicos. Su actividad conocida es la dismutación del radical superóxido $\left(\mathrm{O}_{2}{ }^{-}\right)$para dar dioxígeno y peróxido de hidrógeno:

$$
2 \mathrm{O}_{2}^{\cdot-}+2 \mathrm{H}^{+} \rightarrow \mathrm{O}_{2}+\mathrm{H}_{2} \mathrm{O}_{2}
$$

Varios investigadores han estudiado la respuesta al EOX midiendo la actividad de la enzima SOD y/o la expresión de su gen correspondiente (Kreiner et al. 2000).

En varios hongos Aspergillus y Neurospora crassa, el gen que codifica para una $\mathrm{Cu}$, Zn-SOD, es conocido como sod1 (Bermingham-McDonogh et al. 1988). La levadura posee dos SOD, la MnSod codificada por el gen sod2 que se localiza en la mitocondria y la $\mathrm{Cu} / \mathrm{Zn}$-Sod codificada por el gen sod1 de localización citoplásmica. $\mathrm{La} \mathrm{Cu} / \mathrm{Zn}$ Sod parece ser la enzima que remueve $\mathrm{O}_{2}{ }^{\cdot-}$ del citoplasma y posiblemente también del peroxisoma, mientras que la MnSod parece proteger la mitocondria del $\mathrm{O}_{2}{ }^{\cdot-}$ generado durante la respiración y en la exposición al etanol (Jamieson 1998). Cabe mencionar que la falta de esta proteína también provoca un fenotipo osmosensible (Garay-Arroyo et al. 2003).

Se ha observado que el gen de la SOD de manganeso, es inducido durante el desarrollo de la espora en Colletotrichum graminícola y en el desarrollo de esferulación en el hongo Physarum polucephalum. Durante la fase estacionaria, muchos microorganismos desarrollan 
resistencia a estrés que se compara con esporas. La SOD es esencial para la sobrevivencia en la fase estacionaria de Saccharomyces cerevisiae y en Candida albicans, una SOD manganeso citoplásmica es expresada a la entrada de la fase estacionaria. Además, una de cuatro $\mathrm{Cu}, \mathrm{Zn}-\mathrm{SOD}$ es inducida durante la transición a hifa y también es requerida para virulencia en la levadura C. albicans (Aguirre et al. 2005).

La Catalasa también conocida como $\mathrm{H}_{2} \mathrm{O}_{2}$ oxidoreductasa (Ec. 1.11.1.6), transforma el $\mathrm{H}_{2} \mathrm{O}_{2}$ en $\mathrm{O}_{2}$ y $\mathrm{H}_{2} \mathrm{O}$. S. cerevisiae posee dos de estas enzimas codificadas por los genes CTAl y CTT1. El gen CTA1 codifica para la catalasa que se localiza en los peroxisomas, la cual es la encargada de remover el $\mathrm{H}_{2} \mathrm{O}_{2}$ que se produce durante la $\beta$-oxidación de los ácidos grasos. Como se ha mencionado, el gen CTT1 se regula por EOX, osmótico y ante la falta de nutrientes. Las cepas deficientes en ambas catalasas son hipersensibles al $\mathrm{H}_{2} \mathrm{O}_{2}$ en la fase estacionaria y las mutantes en uno $u$ otro gen son incapaces de montar una respuesta adaptativa al $\mathrm{H}_{2} \mathrm{O}_{2}$ en fase de crecimiento exponencial (Folch-Mallol et al. 2004).

En el caso de hongos filamentosos, se ha encontrado que contienen distintos genes que codifican la misma clase de enzimas que son reguladas diferencialmente de acuerdo a las condiciones. Es el caso de dos genes de catalasas, catA y catB, de Aspergillus oryzae (Hisada et al. 2005), y tres en el caso de Aspergillus nidulans (Kawasaki et al. 1997).

En el caso de Aspergillus nidulans, el gen catA codifica para una catalasa específica de esporas, la cual se va perdiendo durante la germinación y el crecimiento, la actividad de catB apenas es detectable en esporas asexuales (conidios), desaparece después de la germinación e inicia a acumularse a las $10 \mathrm{~h}$ después de la inoculación de esporas, desde principio a fin del crecimiento y conidiación. El mRNA del $c a t B$ se encuentra ausente en la conidia, y su acumulación se correlaciona con la actividad catalasa, sugiriendo que la expresión de cat $B$ es regulado a nivel de transcripción. El gen catB es inducido por $\mathrm{H}_{2} \mathrm{O}_{2}$, choque térmico, paraquat, o el catabolismo del ácido úrico pero no por el EOS. Este patrón de regulación y su rol protectivo en contra del $\mathrm{H}_{2} \mathrm{O}_{2}$ ofrecido por catA y catB, en diferentes estados del ciclo de A. nidulans, sugieren que los genes catalasas desarrollan una función redundante de satisfacer la demanda de las catalasas en los diferentes estados de la regulación metabólica y genética representada por el crecimiento de la hifa contra las esporas (Kawasaki et al. 1997).

Las enzimas de la ruta de las pentosas glucosa-6-fosfato deshidrogenasa ( $Z W F 1)$, la trancetolasa $(T K L 1)$ y la ribulosa-5-fosfato epimerasa (RPE1) son enzimas cruciales para la 
producción de poder reductor celular en la forma de NADPH. La glutatión reductasa y la tiorredoxina reductasa (ver abajo) requieren del NADPH como reductor para reducir el glutatión oxidado (GSSG) y la tiorredoxina. Dado que el GSH y la tiorredoxina son antioxidantes importantes, no es sorprendente que las mutaciones que afectan a los genes de las enzimas de la ruta de las pentosas vuelvan a las células hipersensibles a oxidantes tales como el $\mathrm{H}_{2} \mathrm{O}_{2}$ (Folch-Mallol et al. 2004).

La glutatión reductasa es la enzima responsable de la reducción de glutatión oxidado (GSSG) y, por lo tanto del mantenimiento de la proporción GSH/GSSG intracelular. Las mutantes con defectos en el gen de la glutatión reductasa (GLR1) acumulan un exceso de glutatión oxidado y son hipersensibles a oxidantes. La glutatión peroxidasa cataliza la reducción de hidroperóxidos, al usar GSH como reductor. $S$ cerevisiae presenta tres de estas enzimas Gpx1p, Gpx2p, y Gpx3p. Mientras que la mutante nula de Gpx3p es hipersensible al peróxido, las mutantes de las otras isoformas no muestran un fenotipo evidente (Folch-Mallol et al. 2004).

La tiorredoxina peroxidasa ( $\boldsymbol{T} \mathbf{s} \boldsymbol{a}$ ) es una enzima abundante en la levadura, su nivel aumenta al doble en respuesta a una concentración de $\mathrm{O}_{2}$ del $95 \%$ o en presencia de agentes que contengan tioles como el mercaptoetanol. La tiorredixina peroxidasa reduce el $\mathrm{H}_{2} \mathrm{O}_{2}$ y a hidroperóxidos de alquilo en conjunto con la tiorredoxina reductasa y el NADPH (FolchMallol et al. 2004).

Las peroxirredoxinas (Prxs) son una superfamilia de proteínas antioxidantes que dependen de un grupo tiol para su función. A diferencia de las otras enzimas antioxidantes mencionadas, las peroxirredoxinas no requieren de cofactores redox tales como metales o grupos prostéticos. También conocidas como tiorredoxina peroxidasas (Tpx) o alquilo hidroperóxido reductasas, estas enzimas protegen contra el $\mathrm{H}_{2} \mathrm{O}_{2}$, hidroperóxidos orgánicos o peroxinitritos. Saccharomyces cerevisiae tiene al menos cinco peroxirredoxinas que se localizan en distintos compartimientos celulares donde realizan diferentes funciones. Además de su papel como antioxidantes algunas Prxs están implicadas en la regulación de mecanismos de señalización mediados por $\mathrm{H}_{2} \mathrm{O}_{2}$ (Folch-Mallol et al. 2004). 


\subsubsection{Percepción de las ROS y las respuestas antioxidantes en hongos.}

Para entender los efectos de las ROS en la diferenciación celular, es importante definir cómo las células detectan las ROS y como los niveles de éstas son ajustadas. Aunque es posible que las ROS endógenas y exógenas no causan los mismos efectos celulares, estudios sobre las respuestas a las ROS exógenas en microorganismos eucarióticos han proveído un entendimiento relevante en el entendimiento de la señalización por ROS (Aguirre et al. 2005). Una característica crítica en la respuesta al EOX es la necesidad de una rápida señalización de un nuevo ambiente estresante, el cual a su vez conduce a una reprogramación de genes y la expresión de lo productos génicos requeridos para amortiguar la elevación letal de ROS. Debido a que una elevación de ROS puede pasar rápidamente, las rutas de respuesta de los hongos deben ser igualmente rápidas, la célula debe ser capaz de detectar el balance redox alterado, modular la actividad de reguladores transcripcionales apropiados, y entonces inducir la expresión de genes blanco relevantes (Moye-Rowley 2003).

Los mecanismos que regulan la respuesta fúngica en el cambio oxidante, pueden ser clasificados en dos tipos:

\section{a) Control por Localización Nuclear y}

\section{b) Regulación de la Actividad Vía Fosforilación.}

Ciertas rutas, tales como la modulación de la proteína quinasa Styl en Schizosaccharomyces pombe, son influencias por estos dos tipos de mecanismos regulatorios. Otros factores de respuesta oxidante, tales como Yap1p o Hsflp de S. cerevisiae, parecen ser regulados a nivel de localización nuclear o fosforilación (Moye-Rowley 2003).

\section{a) Control por localización nuclear.}

La compartamentalización del ADN genómico dentro de la membrana nuclear provee un importante mecanismo para la regulación de las proteínas regulatorias sintetizadas transcripcionalmente. La barrera de la membrana nuclear permite el acceso de factores de transcripción hacia sus genes blanco para controlar la regulación a través de la localización de estas proteínas modulatorias clave. Estos genes reguladores, como todas las proteínas con un sitio de acción nuclear, deben cruzar la membrana nuclear a través del poro nuclear (MoyeRowley 2003). 
Las proteínas que son factores de transcripción tipo bZip (cremalleras de leucina) operan bajo este mecanismo. Entre los factores más extensamente estudiados en $S$. cerevisiae están tres proteínas llamadas Yap1p, Yap2p y Gcn4p las cuales participan en la respuesta protectora de la levadura contra las condiciones de EOX (Folch-Mallol et al. 2004).

Brevemente, la Fig. 11 muestra que el regulador clave del movimiento direccional nuclear es una pequeña GTPasa llamada Ran en células mamíferas, y codificada por el gen GSP1 en $S$. cerevisiae. Gsplp es mantenida en un estado primario unido a GTP dentro del núcleo a través de la acción de un factor de intercambio de nucleótidos de guanina llamada Prp20p, mientras que la actividad de Gsp1p GTPasa es estimulada principalmente por la proteína de activación Rna1p GTPasa presente en el citoplasma. Las proteínas contienen secuencias de señal cortas conocidas como señales de localización nuclear que interactúa con carioferinas (importinas) que en turno pueden ser importadas a través del poro dentro del interior nuclear. Una vez llegadas adentro del núcleo, la Gsp1p-GTP estimula la disociación del complejo cargado de la carioferina. A la inversa, la exportación nuclear ocurre cuando una proteína contiene una señal de exportación nuclear (NES, por nuclear export signal) unida al homólogo de la carioferina llamada Exportina (tal como Crm1p en $S$. cerevisiae y $S$. pombre) junto con Gsp1p-GTP. El complejo entonces se mueve al citoplasma, donde Rnalp estimula la actividad de la GTPasa de Gsp1p, conduciendo a la disociación del complejo (Moye-Rowley 2003).

Las células fúngicas han dirigido la localización nuclear de varios componentes de su maquinaria de respuesta a la modulación del EOX. Esto permite la preexistencia de conjuntos de proteínas para ser rápidamente reclutadas dentro de sus roles de respuesta al estrés (MoyeRowley 2003).

Uno de los primeros ejemplos de un factor de transcripción en el cual la localización nuclear es regulada por el EOX es la proteína de región básica de cremallera de leucina (bZip), llamada Yap1p de S. cerevisiae.

Yap1p fue primero identificado por su similaridad bioquímica con AP-1 de mamíferos (Aguirre et al. 2006; Reverberi et al. 2008). La secuencia de ADN de Yap1p indicó que el producto génico muestra similaridad en la secuencia limitada a la región del dominio bZip. En S. cerevisiae parece ser que Yap1p es un regulador positivo de la expresión de genes, pero poco se conoce acerca de su papel in vivo de esta proteína, aunque el trabajo de varios laboratorios evidencian que Yap1p juega un rol en la homeostasis redox (Moye-Rowley 2003). 
A.

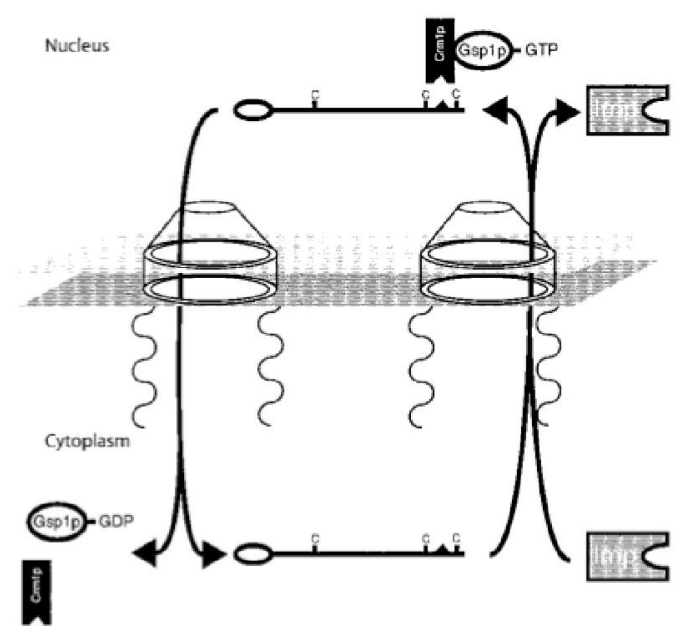

B.

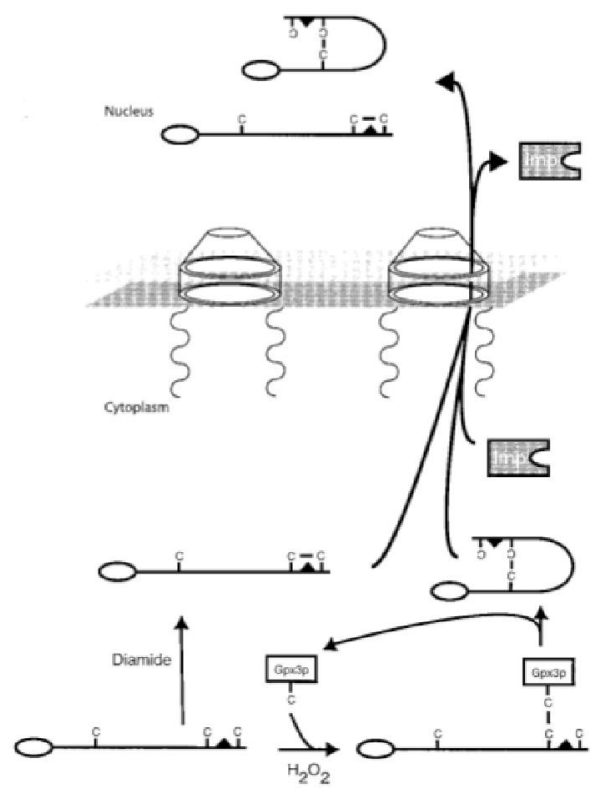

Fig. 11 Regulación por oxidantes de Yap1p. A) Condiciones de no estrés y B) Condiciones de EOX por diamida o por $\mathrm{H}_{2} \mathrm{O}_{2}$ (Moye-Rowley 2003). 
El papel de Yap1p en la regulación de enzimas que protegen contra oxidantes se hizo evidente cuando se descubrió que mutantes en yapl resultaban hipersensibles a diferentes agentes oxidantes. Las mutantes deficientes en Yaplp presentan una disminución en la transcripción de los genes que codifican varias enzimas con actividad antioxidante como la superóxido dismutasa, la glucosa-6-fosfato deshidrogenasa y la glutatión reductasa (Folch-Mallol et al. 2004).

En estas mutantes la respuesta adaptativa al $\mathrm{H}_{2} \mathrm{O}_{2}$ se encuentra seriamente afectada, lo cual muestra que Yap1p afecta la transcripción de los genes que median esta respuesta. Esto se ve apoyado por el hecho de que la presencia del gen $Y A P 1$ en un alto número de copias resulta en un incremento modesto en los niveles celulares de glutatión y en las actividades de las enzimas antioxidantes mencionadas. Entre los genes activados por Yaplp se encuentran aquellos que codifican para proteínas que participan en la síntesis del glutatión y de la vía de las pentosas, la cistationina $\gamma$-liasa $(C y s 3)$ que genera cisteína, un precursor del glutatión a partir de la cistationina, la $\gamma$-glutamilocisteína sintasa (GSH1), que es la enzima limitante en la biosíntesis de GSH y la glutatión reductasa dependiente de NADPH (GLR1), que recicla el GSH oxidado. Yap1p también activa a la glucosa-6-fosfato deshidrogenasa ( $Z W F 1)$, que regula el flujo de carbón a través de la ruta de las pentosas y la transaldolasa (TAL1). Datos experimentales demuestran que Yap1p y Skn7p cooperan para activar un grupo de genes entre los que se incluye la catalasa citosólica (CTT1), la citocromo c peroxidasa (CCP1), la peroxirredoxina (TSA1), la alquilo hidroperóxido reductasa (AHP1), la tiorredoxina 2 (TRX2), la tiorredoxina reductasa (TRR1), la cobre/zinc (SOD1) y la manganeso (SOD2) superóxido dismutasas (Folch-Mallol et al. 2004).

Los posibles sitios de unión de Yap1p se han localizado en la secuencia del promotor de algunos genes como SOD1, TWF, TRX2, GLR1 y GSH1 (Folch-Mallol et al. 2004).

La regulación de los genes de la respuesta antioxidante mediada por Yap1p depende de la acumulación nuclear del factor. En presencia de $\mathrm{H}_{2} \mathrm{O}_{2}$, dos residuos de cisteína forman un enlace disulfuro intramolecular provocando un cambio conformacional que enmascara el sitio de reconocimiento del factor por un sistema de exportación nuclear (mediado por Crm1p/Xpolp), esta oxidación promueve la acumulación nuclear. Una tiorredoxina nuclear, también controlada por Yap1p, reduce al factor y permite su devolución al citoplasma (Fig. 11) (Folch-Mallol et al. 2004).

Uno de los primeros factores que mostraron ser reclutados en el núcleo en respuesta al estrés fue la proteína de unión elemento respuesta a estrés Msn2p (y su homólogo Msn4p). Msn2p 
se encontró que es requerida para la activación de la expresión del gen de la catalasa citosólica CTT1 en respuesta al EOX. Mientras que claramente se ha demostrado que Msn2p se requiere tanto para la expresión de CTT1 y ser localizada hacia el núcleo en respuesta a otros estreses. Modelos actuales para la regulación de Msn2p/Msn4p argumentan que esos factores parecen responder a un amplio conjunto de estreses para inhibir el crecimiento y de esta forma permitir que las células se ajusten a la imposición del estrés. Estudios detallados sobre la localización nuclear de Msn2p han mostrado que reducciones en los niveles de AMP cíclico pueden provocar la acumulación nuclear, aunque un segundo regulatorio introducido parece inhibir el exporte de esta proteína bajo la imposición de estrés. De este modo, Msn2p (y Msn4p) no está directamente regulado por cambios en el estado redox sino que es regulado por más efectos globales causados por estrés. Es interesante que, al menos en el caso de $C$. albicans, este circuito de estrés general Msn2p/Msn4p se ha reportado que no existe. (MoyeRowley 2003)

El control de la localización nuclear es una importante área experimental bajo una intensa investigación.

\section{b) Regulación vía Fosforilación.}

Uno de los sistemas más ampliamente estudiados, involucra un serie de proteínas quinasas que actúan secuencialmente, referidas como la cascada de la proteína quinasa mitógeno activada (MAPK, del inglés Mitogen- $\underline{A}$ ctivated Protein Kinase). Este módulo de señalización, consiste de un MAPK quinasa quinasa (MAPKKK) corriente arriba que es activada para fosforilar su objetivo, una MAPK quinasa (MAPKK). La fosforilación de MAPKKK hacia MAPKK entonces permite que ésta quinasa fosforile la último objetivo quinasa en la ruta, que es la MAPK, conduciendo a la activación de esta molécula de señalización clave. MAPK fosforilada y activa, puede entonces regular corriente abajo moléculas efectoras, conduciendo a los efectos regulatorios apropiados (Moye-Rowley 2003).

Las rutas de MAPK han sido implicadas en la tolerancia al EOX en células animales y ciertas especies fúngicas.

Una familia conservada de MAPK's que incluye en $S$. cerevisiae a Hog1, en $S$. pombe a Spc1 (también llamada Sty1) y en mamíferos p38 y JNK, son cruciales para la transducción de muchas señales de estrés, principalmente de EOX (Aguirre et al. 2005). 
Estudios sobre las MAPK Spc1-Styl han conducido a la caracterización de una ruta completa involucrada en la respuesta a $\mathrm{H}_{2} \mathrm{O}_{2}$. Esta ruta involucra un sistema de fosforilación de tipo bacteriano, compuesta por un híbrido de quinasas de histidina Mak2, Mak3, proteínas de fosfotransferencia Mpr1 y regulador de respuesta Mcs4, el cual activa la cascada de estrés MAPK, compuesta de la MAPKKK Wis4 (llamada también Win1), MAPKK Wis1 y MAPK Spc1-Styl (Aguirre et al. 2005).

El híbrido de histidina quinasa Mak1 y el regulador de respuesta Prr1, parecen estar involucrados en la transducción de señales por $\mathrm{H}_{2} \mathrm{O}_{2}$, también ambos son requeridos para inducir el gen de catalsa $c t t 1+$ en respuesta al $\mathrm{H}_{2} \mathrm{O}_{2}$, en un modo independiente de $\mathrm{Spc1}$. Además del Prrl, los factores de transcripción bZIP Atfl y Papl median la expresión inducida por peróxido de $c t t 1+\mathrm{y}$ otros genes. Una vez que Atf1 es activado por Spc1-Styl, es regulada la expresión de un conjunto de genes en respuesta al $\mathrm{H}_{2} \mathrm{O}_{2}$ y otras condiciones de estrés. Pap1 no es un sustrato de Spc1-Sty1 pero puede activar ctt1+ en respuesta a $\mathrm{H}_{2} \mathrm{O}_{2}$ independientemente de esta MAPK (Aguirre et al. 2005).

Resultados recientes indican que bajas concentraciones de $\mathrm{H}_{2} \mathrm{O}_{2}$ inducen la formación de enlaces disulfuro intramolecular y la activación de Pap1. En $S$. cerevisiae el homólogo de Pap1 es Yap1, el cual desempeña una función fundamental en la activación de la expresión de genes en respuesta al EOX. Se ha demostrado que Yap1 puede discriminar entre diferentes tipos de EOX y que la tiol peroxidasa Gpx3 (Orp1) trabaja como un sensor-transductor de $\mathrm{H}_{2} \mathrm{O}_{2}$ que media la oxidación-activación de Yap1, a través de la formación transitoria de un enlace disulfuro intramolecular entre Gpx3 y Yap1. La Tioredoxina inactiva esta ruta por la reducción del sensor y regulador (Aguirre et al. 2005).

Se ha sugerido por los datos reportados un mecanismo análogo por el cual Tpx1, el único 2Cys-peroxiredoxina presente en $S$. pombe, regula la activación inducida por el $\mathrm{H}_{2} \mathrm{O}_{2}$ de $\mathrm{Styl}$ (Spc1) a través de la formación del enlace disulfuro entre Tpx1 y Styl (Veal et al. 2007). En células de mamíferos, la tioredoxina actúa como un inhibidor sensible al redox de MAPKKK ASK1, la cual activa las rutas de JNK y p38 y regula la muerte inducida por estrés. La activación inducida por $\mathrm{H}_{2} \mathrm{O}_{2}$ de Trx-ASK1, Gpx3-Yap1 y Tpx-Spc1 puede mostrar mecanismos con la regulación redox de otras proteínas señalizadoras (Aguirre et al. 2005).

En $S$. pombe Atf1, Prr1 y Pap1 participan en rutas que detectan el $\mathrm{H}_{2} \mathrm{O}_{2}$, involucran la expresión de numerosos genes necesarios para contender con este y otros tipos de estrés; respuestas comunes y similares se han reportado para S. cerevisiae y C. albicans. Es probable que varios de estos mecanismos que detectan $\mathrm{H}_{2} \mathrm{O}_{2}$ también estén conservados en hongos 
filamentosos y otros eucariontes inferiores. En A. nidulans, SakA MAPK, homólogo a Spc1Styl, es activado por $\mathrm{H}_{2} \mathrm{O}_{2}$ y EOS y regula la expresión del gen de catalasa $c a t B$ en respuesta a $\mathrm{H}_{2} \mathrm{O}_{2}$. Además, los homólogos de todos los componentes de las rutas que detectan $\mathrm{H}_{2} \mathrm{O}_{2}$ descritas en $S$. pombe se encuentran en A. nidulans y N. crasa (Fig. 12).

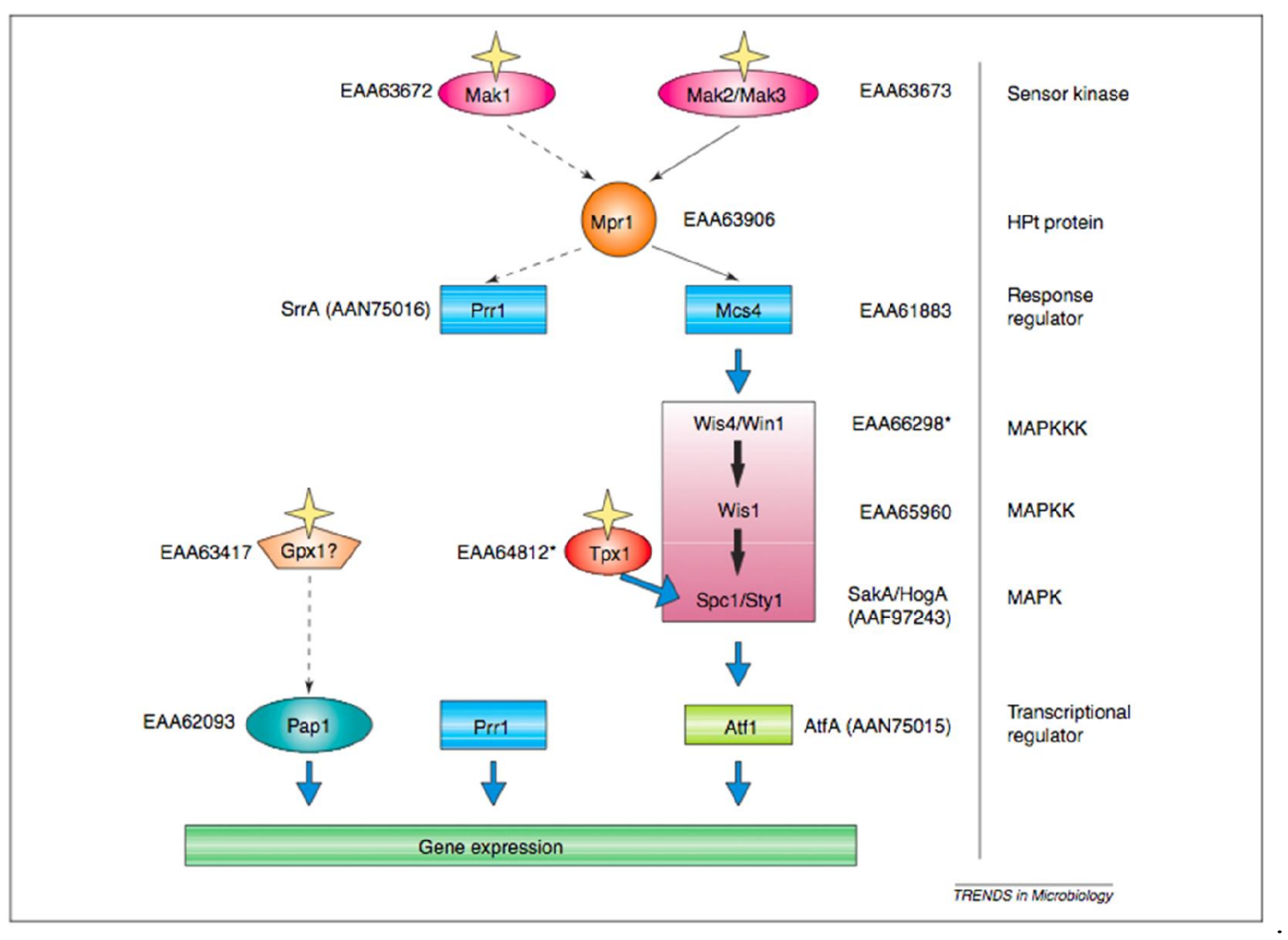

Fig. 12 Ruta responsable de la respuesta $\mathrm{H}_{2} \mathrm{O}_{2}$ en Schizosaccharomyces pombe (Aguirre et al. 2005)

\subsection{Relación del Metabolismo Secundario, Desarrollo Fúngico y EOX.}

\subsubsection{Metabolismo Secundario y Desarrollo Fúngico.}

Se ha observado por décadas, una asociación entre la formación de un producto natural y el desarrollo morfológico. Por ejemplo, una clase inusual de mutantes de Aspergillus parasiticus llamadas 'sec', son deficientes tanto para la esporulación, como para la producción de aflatoxinas. Aunque están presentes los genes que codifican las enzimas para sintetizar aflatoxinas, la expresión de $a f l R$, que es un regulador específico de la ruta, se reduce de 5 a 10 veces en cepas toxigénicas comparada con la cepa parental. Un ejemplo similar, involucra una mutación en el gen fluP de $A$. parasiticus, que resulta en un fenotipo morfológico de hifa 
esponjosa, una reducción en el número de esporas asexuales producidas y una reducción en el nivel de producción de aflatoxinas (Keller et al. 2005).

Se ha revisado recientemente la correlación del metabolismo secundario con el desarrollo fúngico, y los autores hacen una nota especial en la regulación conjunta de estos procesos, a través de la proteína $\mathrm{G}$ heterométrica y la ruta de transducción de señales de la proteína quinasa A. Particularmente, han sido bien caracterizadas FadA, una proteína $\mathrm{G}$ en A. nidulans, y PkaA, una proteína quinasa que se encuentra corriente abajo en la ruta regulatoria de FadA (Calvo et al. 2002). Ambas proteínas, regulan negativamente la síntesis de aflatoxinas y esterigmatocistina (Fig. 13) (Keller et al. 2005).

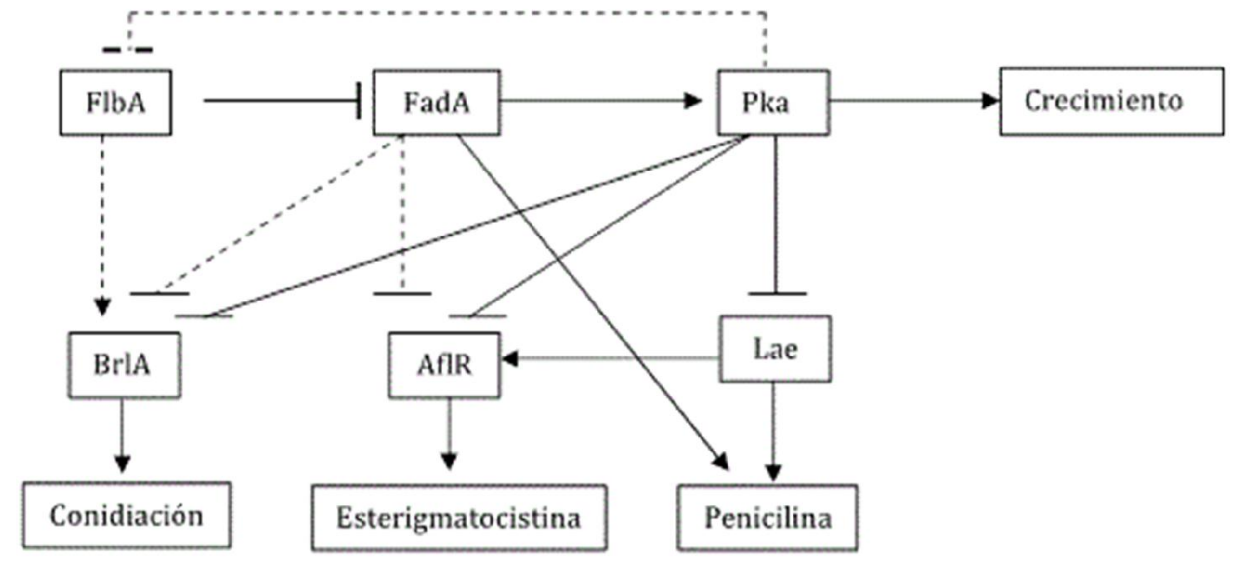

Fig. 13 Controles integrados en la transducción de señales en la producción de esporas (conidiación) y el metabolismo secundario en Aspergillus nidulans. Las líneas continuas, muestran las rutas conocidas, y las líneas punteadas indican una ruta hipotética. FadA, subunidad $\alpha$ de una proteína $\mathrm{G}$, heterotrimérica; FlbA, una proteína regulatoria que tiene un motivo RGS (regulador de la señalización de proteína G); PkaA, subunidad catalítica de una proteína quinasa A; BrlA, factor de transcripción, producto del primer gen de la vía reguladora central de la conidiogénesis; AflR (regulador de aflatoxinas), un factor de la transcripción específica de la biosíntesis de esterigmatocistina/aflatoxina (Keller et al. 2005).

PkaA regula la producción de esterigmatocistina transcripcional y post- transcripcionalmente, a través del producto del gen de $a f l R$, y se postula que una cascada regulatoria similar, controla la regulación en A. parasiticus. AflR es inactivado por PkaA, mediante fosforilación, y la transcripción de aflR es reprimida por la actividad de PkaA; la represión de la transcripción de aflR es mediada por PkaA a través de una metil transferasa, llamada LaeA (Bok \& Keller 2004). 


\subsubsection{Metabolismo Secundario y EOX.}

Toda la evidencia mostrada anteriormente, relaciona estrechamente el desarrollo fúngico con el metabolismo secundario. Pero también se ha relacionado el desarrollo fúngico con la producción de ROS como moléculas reguladoras o señalizadores, importantes para dicho proceso, por ello no es difícil pensar que el metabolismo secundario puede estar relacionado con la generación de ROS.

Anteriormente, en Aspergillus parasiticus se observó que cepas toxigénicas (productoras de aflatoxinas) requerían mayores concentraciones de oxígeno en la trofofase, con respecto a las no toxigénicas (cepas mutadas que no producían aflatoxinas), de igual modo se observó que las actividades enzimáticas antioxidantes fueron mayores en el paso de trofo- a idiofase. Estos resultados sugirieron en su momento, que la producción de aflatoxinas por la cepa toxigénica, puede ser una consecuencia de un incremento en el nivel de EOX (Jayashree \& Subramanyam 2000). Mas adelante, se propuso que la formación de aflatoxinas puede ocurrir como una respuesta compensatoria a la acumulación de ROS (Narasaiah et al. 2006).

La presencia de probables sitios de unión a AP-1 en el promotor de aflR, sugirió que el EOX puede regular la biosíntesis de aflatoxinas. Mutantes $\triangle$ ApyapA (ortólogo de AP-1) en Aspergillus parasiticus, mostraron un incremento en el EOX, conidiogénesis y biosíntesis de aflatoxinas prematura (Reverberi et al. 2008). Estos resultados comienzan a mostrar un panorama de que el metabolismo secundario está relacionado con el EOX, sin embargo, pocos son los reportes que comienzan aportar sobre cual o cuales son los mecanismos por los que puede llevar a cabo estas interacciones (Roze et al. 2011).

Hasta la fecha, las ROS no han sido asociadas en particular con la biosíntesis de lovastatina y mucho menos, se ha establecido si las ROS regulan de manera particular la biosíntesis de este. 


\section{JUSTIFICACIÓN}

Los MS microbianos, son compuestos con una variedad en estructuras químicas complejas, producidos principalmente por hongos y actinomicetos (Barrios-González et al. 2003). Aunque los antibióticos son los MS más conocidos, existen otros con distintas actividades biológicas; ejemplo de ello es la lovastatina, molécula que posee propiedades anticolesterolémicas (Endo 2008).

Las enfermedades cardiovasculares, son la principal causa de muerte a nivel mundial siendo la hipercolesterolemia, uno de los factor detonantes (Alberts et al. 1980). La lovastatina es un MS producido por A. terreus, y es de gran importancia comercial y médica, por que además de sus propiedades anticolesterolémicas, ensayos clínicos han demostrado que ésta y otras estatinas tienen efectos pleiotrópicos (asociados) y potencialmente pueden emplearse en el tratamiento de otras enfermedades crónicas como el cáncer (Bonovas et al. 2006). Hoy en día, la lovastatina es blanco de estudio en protocolos de investigación clínica para el tratamiento de otras enfermedades (Dulak \& Józkowicz 2005), incluso, el año pasado se reportó el uso de éste fármaco en el tratamiento de pacientes con VIH (Montoya et al. 2012) . Además, de la lovastatina se obtiene el derivado "simvastatina", fármaco que ha llegado a ser el más vendido a nivel mundial, generando ventas de hasta 12 billones de dólares anuales (Kidd 2006).

Por su importancia médica, la producción biotecnológica de lovastatina ha sido y es blanco de estudio. Particularmente, con este trabajo se pretende aportar un poco del conocimiento sobre los muchos eventos que a nivel molecular pueden influir en la biosíntesis de éste metabolito secundario, lo cual podrá servir como base para diseñar estrategias racionales de mejoramiento genético de la cepa productora, o incluso desarrollar mejores sistemas de producción.

Hasta la fecha, se han hecho esfuerzos para lograr mejorar las condiciones fisiológicas del hongo para que éste produzca mayores concentraciones de lovastatina, mediante la optimización del medio y/o sistema de producción (Szakács et al. 1998; Suryanarayan \& Mazumdar 2003; Casas López et al. 2004; Baños et al. 2009), o realizando estrategias de mejoramiento genético de las cepas productoras, empleando herramientas tradicionales de mutagénesis (Rollini 2002).

Los más recientes avances en esta área, han indicado que es mediante la producción en FS donde se han logrado las más altas producciones de este metabolito. En nuestro grupo se 
desarrolló un sistema novedoso en FS (empleando como espuma de poliuretano como soporte inerte), donde se logró una producción de lovastatina 30 veces mayor que en FL (Baños et al. 2009). Con el objeto de encontrar los eventos responsables de la diferencia en la producción de lovastatina entre FS y FL, se realizó un análisis de expresión de dos genes de la vía: lovE y lovF. Los resultados mostraron que la alta producción de lovastatina en FS, se correlaciona con altos niveles de expresión de ambos genes y por un periodo más largo. La acumulación de transcritos de $l o v E$ en FS fue 4.6 veces mayor que en FL. Similarmente, la acumulación de transcritos de $\operatorname{lov} F$, fue 2 veces mayor que los detectados en FL. Estos resultados mostraron por primera vez, que la alta producción de lovastatina en FS es debido, al menos parcialmente, a elevados niveles de expresión del factor transcripcional lovE(BarriosGonzález et al. 2008).

La observación de que en FS el micelio está en contacto directo con el aire, en contraste con el micelio de FL, nos hizo proponer la hipótesis de que éste estímulo puede influir en la alta producción de lovastatina, a través de la generación de EOX o la producción de ROS. En este sentido, en nuestro grupo se desarrollaron métodos de selección racional y se aislaron mutantes resistentes a EOX. Los resultados mostraron que $42 \%$ de estas mutantes, fueron sobreproductoras en FS, pero malas productoras en FL y con ello, se concluyó que la resistencia al EOX es una ventaja para que $A$. terreus produzca mayores concentraciones de lovastatina en FS (Baños et al., 2010).

El EOX es un desbalance entre la producción de ROS y la capacidad antioxidante de la célula (Folch-Mallol et al. 2004), y se sabe que las ROS generadas en ciertos puntos del desarrollo y a concentraciones fisiológicas, juegan un papel importante en la homeostasis del organismo, regulando diversos procesos celulares como la estimulación de las reacciones antioxidantes, la respuesta inmune, regulación de la proliferación celular, la diferenciación, etc., esto en mamíferos, plantas y hongos (Jones 1994; Rhee 2006; Veal et al. 2007; Bokoch \& Knaus 2003; Aguirre et al. 2005).

En hongos, estudios recientes han evaluado el rol que juegan las ROS en los procesos de diferenciación; por ejemplo, se ha encontrado un desbalance redox provocado por una elevación en el nivel de ROS en el inicio de la transición de conidio a hifa aérea en $N$. crassa (Aguirre et al. 2005; Aguirre et al. 2006), y si con respecto al metabolismo secundario se considera que el paso de trofo- a idiofase es una diferenciación metabólica, se estableció la hipótesis de que un estado oxidante (provocado por una elevación en la concentración de ROS) estaría relacionado con el inicio de la idiofase en $A$. terreus, por lo que se decidió 
estudiar comparativamente el estado oxidante que existe justo antes de iniciarse la idiofase de lovastatina en FS y FL. Se analizó la expresión del gen sodl como un indicador del estado oxidante y se encontró que su expresión fue fuerte durante la trofofase y decayó bruscamente justo al iniciar la idiofase (observado por la expresión del gen $l o v E$ ) en los dos sistemas de cultivo. Además se observaron diferentes características en la expresión de este gen para cada uno de los sistemas de producción tanto en intensidad como en duración. La expresión de sod1 fue hasta 2 veces más fuerte en FL que en FS, por un periodo de $6 \mathrm{~h}$ y de $8 \mathrm{~h}$ respectivamente (Miranda et al. 2008), sugiriendo que en FS la respuesta a EOX es más eficiente que en FL y quizás sea esta característica la que influye sobre el nivel de producción de lovastatina.

Son pocos los trabajos que han asociado a las ROS con el metabolismo secundario, y todos ellos son referentes a la producción de aflatoxinas (un metabolito secundario diferente a la lovastatina) producido por diferentes especies Aspergillus (Jayashree \& Subramanyam 2000; Narasaiah et al. 2006; Reverberi et al. 2008; Roze et al. 2011).

Hasta la fecha, las ROS no han sido asociadas con la biosíntesis de lovastatina, por lo que el presente trabajó se enfocó en encontrar una relación entre el EOX y la biosíntesis de este metabolito. Además, se realizó un esfuerzo en encontrar las diferencias en la acumulación y control de ROS en FS y FL, lo cual podría ayudar a explicar la alta producción del metabolito y quizás otras características de la fisiología del medio sólido.

Una mejor comprensión de la fisiología del medio sólido, en particular durante la idiofase, podrá ser aplicada en el mejoramiento genético de cepas sobre productoras de lovastatina especiales para FS e incluso cepas mejoradas para FL. Además, estos conocimientos podrían aplicarse al diseño de procesos más eficientes de FS o incluso procesos de FL novedosos. que aprovechen estímulos de medio sólido para producción más eficiente de lovastatina (o incluso para la producción de otros metabolitos secundarios). 


\section{HIPÓTESIS}

Un estado oxidante es necesario para iniciar y mantener la biosíntesis de lovastatina, ya que las ROS contribuyen a su regulación. Las características de este estado oxidante (intensidad y duración), determinan el nivel de producción en FS y FL.

\section{OBJETIVOS}

\subsection{OBJETIVO GENERAL}

Estudiar la participación de las ROS en la biosíntesis de lovastatina y su influencia sobre el nivel de producción en FS y FL.

\subsection{OBJETIVOS ESPECÍFICOS}

1) Confirmar la existencia de un $\mathrm{PEO}$ en la trofofase, que precede el inicio de biosíntesis de lovastatina.

2) Confirmar que las ROS son necesarias para la biosíntesis de lovastatina, mediante el empleo de oxidantes/antioxidantes exógenos.

3) Demostrar que las ROS inciden sobre la expresión del gen regulador lovE y biosintético lovF.

4) Caracterizar in silico el promotor del gen $\operatorname{lovE}$ (factor transcripcional del clúster biosintético de lovastatina). 


\section{MATERIALES Y MÉTODOS}

\subsection{Cepas, medio de cultivo y condiciones de cultivo.}

\subsubsection{Microorganismos utilizados.}

\subsubsection{Aspergillus terreus.}

La cepa TUB F-514 utilizada para la producción de lovastatina fue aislada previamente del suelo en el desierto de Irak, por el Dr. György Szakács y pertenece a la colección de la Technical University of Budapest, Hungría. Esta cepa fue la mejor productora de lovastatina en FL. Esta cepa es considerada de alta producción (Szakács et al. 1998).

\subsubsection{Neurospora crassa.}

La cepa FGSC 4200 (Fungal Genetics Stock Center), fue utilizada para la realización del bioensayo, debido a la sensibilidad que presenta a la forma activa de la lovastatina, la $\beta$ hidroxiácida (Kumar et al. 2000).

\subsubsection{Propagación de esporas para FL y FS.}

Esporas de Aspergillus terreus se generaron inoculando 50 ul de un stock de esporas (guardadas en glicerol al $25 \%$ a $-80^{\circ} \mathrm{C}$ ), sobre $50 \mathrm{ml}$ de Agar de medio Power en matraces Erlenmeyer de $250 \mathrm{ml}$, se incubó a $30^{\circ} \mathrm{C}$ durante 4-5 días, las esporas se colectaron con Tween 80 al $0.2 \%$ y fueron contadas con ayuda de la cámara de Newbawer. La cantidad se ajustó para inocular con $2 \times 10^{6}$ esporas $/ \mathrm{ml}$ a la FL, y con $1 \times 10^{8}$ esporas $/ \mathrm{ml}$ a la FS. 


\subsubsection{Medios de Cultivo.}

6.1.3.1. Medio de propagación de esporas y conservación de cepas.

El medio para Propagación de esporas y mantenimiento de cepa se describe en la Tabla 1.

Tabla 1 Composición del medio Power (mantenimiento y propagación de esporas)

\begin{tabular}{|c|c|}
\hline Elemento & $g / L$ \\
\hline Sacarosa & 15 \\
\hline Lactosa & 2.5 \\
\hline Bacto Peptona & 2.5 \\
\hline Sólidos de Maceración de Maíz & 0.5 \\
\hline $\mathrm{NaCl}$ & 2 \\
\hline $\mathrm{NaNO}_{3}$ & 1 \\
\hline $\mathrm{K}_{2} \mathrm{HPO}_{4}$ & 0.28 \\
\hline $\mathrm{MgSO}_{4} \cdot 7 \mathrm{H}_{2} \mathrm{O}$ & 0.275 \\
\hline $\mathrm{FeSO}_{4} \cdot 7 \mathrm{H}_{2} \mathrm{O}$ & 0.005 \\
\hline $\mathrm{FeCl}_{3} \cdot 6 \mathrm{H}_{2} \mathrm{O}$ & 0.0015 \\
\hline $\mathrm{CuSO}_{4} \cdot 5 \mathrm{H}_{2} \mathrm{O}$ & 0.0005 \\
\hline Agar & 15 \\
\hline
\end{tabular}

\subsubsection{Producción de Lovastatina.}

Tabla 2 Composición del Medio de Producción de Lovastatina para FL y FS.

\begin{tabular}{|l|l|l|}
\hline Elemento & FL & FS \\
& $\mathrm{g} / \mathrm{L}$ & $\mathrm{g} / \mathrm{L}$ \\
\hline Glucosa & 6 & 15 \\
\hline Lactosa & 34 & 85 \\
\hline Harina de soya & 3 & 7.5 \\
\hline KNO $_{3}$ & 2 & 5 \\
\hline KH$_{2} \mathbf{P O}_{4}$ & 3 & 7.5 \\
\hline $\mathrm{NaCl}$ & 0.5 & 1.25 \\
\hline $\mathrm{MgSO}_{4}$ & 0.5 & 1.25 \\
\hline
\end{tabular}

Se ajustó el pH a 6.5 con $\mathrm{NaOH} 0.1 \mathrm{~N}$. 


\subsubsection{Condiciones de cultivo.}

\subsubsection{FL.}

$50 \mathrm{ml}$ de medio de producción (Tabla 2), se dosificaron en matraces Erlenmeyer de $250 \mathrm{ml} \mathrm{y}$ se inocularon con $2 \times 10^{6}$ esporas $/ \mathrm{ml}$. Los cultivos se incubaron a $30^{\circ} \mathrm{C}$ a $200 \mathrm{rpm}$.

\subsubsection{2. $\quad$ FS.}

Se empleó el medio de FL concentrado 2.5 veces (Tabla 2), el cual se inoculó de $1 \times 10^{8}$ esporas/ml, el cual se usó para impregnar el soporte sólido (PUF de alta densidad, pretratado como describe (Tomasini et al. 1997), a una humedad final de 85\%. Se emplearon $6 \mathrm{~g}$ de medio sólido por cada matraz Erlemeyer de $250 \mathrm{ml}$, el cual iba cubierto con una tapa de papel aluminio y parafilm (Pechiney Plastic Packaging, Menasha, WI, USA).

\subsubsection{CAJA DE PETRI.}

En experimentos iniciales se realizaron cultivos en Caja de Petri para determinar con facilidad el rango de concentraciones de los antioxidantes y oxidantes exógenos. Se empleó el medio de producción de FL, suplementado con agar al $2 \%$. Se inocularon $1 \times 10^{3}$ esporas en el centro de la caja, se incubó a $30^{\circ} \mathrm{C}$ durante 10 días.

\subsubsection{Empleo de Antioxidantes y Oxidantes exógenos.}

Se emplearon antioxidantes como $\mathrm{N}$-acetilcisteína (NAC, stock de $0.2 \mathrm{~g} / \mathrm{ml}$ en $\mathrm{H}_{2} \mathrm{O}$, y ajustado a pH 6.5 con $\mathrm{NaOH} 1 \mathrm{M}$ ) y tetrametiltiourea (TMTU, stock de $0.5 \mathrm{M}$ en etanol al 95\%), y los pro-oxidantes Paraquat (Methyl viologen dichloride hydrate, stock $0.5 \mathrm{M}$ en $\mathrm{H}_{2} \mathrm{O}$ ) y $\mathrm{H}_{2} \mathrm{O}_{2}(9.8 \mathrm{M})^{4}$. Todos los reactivos fueron suministrados por Sigma-Aldrich.

\footnotetext{
${ }^{4}$ Para medir la concentración del stock de $\mathrm{H}_{2} \mathrm{O}_{2}$ y emplearlo a la concentración deseada, se empleó su coeficiente de extinción molar $\left(E=43.6 \mathrm{M}^{-1} \cdot \mathrm{cm}^{-1}\right)$, y empleado la fórmula $\mathrm{A}=\mathrm{E} \cdot \mathrm{M} \cdot \mathrm{L}$, donde $\mathrm{A}=\mathrm{Absorbancia}$ a $240 \mathrm{~nm}, \mathrm{M}=$ molaridad y $\mathrm{L}=$ Longitud del haz $(=1)$.
} 
En Caja de Petri, los antioxidantes/oxidantes, fueron suplementados a la concentración requerida antes de que se solidificara el medio. En FL, se suplementaron diferentes concentraciones en el tiempo inicial del cultivo, y en otros ensayos, a diferentes tiempos de la trofo- e idiofase. En FS, los anti/oxidantes fueron suplementados en el medio de producción a la concentración indicada, justo antes de impregnar el soporte sólido.

\subsection{Técnicas analíticas}

\subsubsection{Biomasa.}

En FL, la biomasa se determinó por peso seco, filtrando todo el contenido de un matraz a través de un papel filtro de peso conocido, y secando a $80^{\circ} \mathrm{C}$ durante 3 días hasta peso constante. En el caso de FS, se determinó indirectamente usando el contenido de ácidos nucleicos como lo reportado anteriormente (Pei-lian 2006), pero con las siguientes modificaciones. Un gramo de cultivo sólido, fue tratado con $5 \mathrm{ml}$ de ácido tricloroacético (TCA, Sigma-Aldrich) al $5 \%$, y se incubó a $120^{\circ} \mathrm{C}$ durante $25 \mathrm{~min}$, inmediatamente se enfrío en hielo durante $10 \mathrm{~min}$. De ahí, $1 \mathrm{ml}$ de sobrenadante se centrifugó a $10,000 \mathrm{x} \mathrm{g} \mathrm{a} 4^{\circ} \mathrm{C}$ durante 15 min. El sobrenadante se diluyó (de 5 a 20 veces) con TCA al 5\% y se leyó a una absorbancia de $260 \mathrm{~nm}$ (Biophotometer, Eppendorf). El contenido de biomasa de FS, se correlacionó con el contenido de ácidos nucleicos contenidos en una cantidad conocida de biomasa de FL del mismo tiempo del muestreo. La concentración de ácidos nucleicos del sobrenadante, se calculó asumiendo que una solución que contiene $1 \mathrm{mg} / \mathrm{ml}$ de ácidos nucleicos, tuvo un absorbancia de 23 a $260 \mathrm{~nm}$ (Ooijkaas et al. 1998).

\subsubsection{Extracción y cuantificación de Lovastatina.}

Para FS, se colocó $1 \mathrm{~g}$ de cultivo sólido en un tubo de ensayo con $10 \mathrm{ml}$ de una mezcla de acetonitrilo:agua $(1: 1 \mathrm{v} / \mathrm{v})$, seguido de una agitación a $200 \mathrm{rpm}$ durante $30 \mathrm{~min}$, e incubado en un baño sónico (Bradson) durante $30 \mathrm{~min}$. Para FL, la lovastatina se extrajo tanto de micelio como del caldo, de acuerdo a lo establecido por Baños et al. (2009). La cuantificación de lovastatina (intracelular y extracelular), se realizó por HPLC, empleando una columna 
Novapack C-18 (150x3.9mm, $4 \mu \mathrm{m})$ de Waters Co., usando una fase móvil de acetonitriloácido fosfórico $0.1 \%(60: 40 \mathrm{v} / \mathrm{v})$, con un flujo de $1.5 \mathrm{ml} / \mathrm{min}$, donde la forma $\beta$-hidroxiácida, se determinó a $238 \mathrm{~nm}$ con un detector de arreglo de diodos. Todos los solventes orgánicos fueron proveídos por J.T.Baker.

En el caso de Caja de Petri, la extracción de lovastatina se realizó mediante el siguiente procedimiento. Un taco de agar por caja de Petri, fue retirado con ayuda de un sacabocados de $10 \mathrm{~mm}$ de diámetro, se colocó dentro de un tubo de ensaye que contenía $5 \mathrm{ml}$ de Acetato de Etilo (J.T.Baker), se maceró y se dejó reposando durante $2 \mathrm{~h}$, después de este tiempo, se tomaron $20 \mu \mathrm{l}$ del sobrenadante, y se impregnó un papel filtro de $10 \mathrm{~mm}$ de diámetro hasta secarse. El papel filtro impregnado, junto con controles de concentración conocida (curva estándar), se colocaron sobre una caja para bioensayo $(20 \times 20 \mathrm{~cm})$ con medio PDA, previamente inoculado con $2 \times 10^{6}$ esporas de $N$. crassa. La caja se selló con papel parafilm y se incubó a $30^{\circ} \mathrm{C}$ durante $16 \mathrm{~h}$. Se tomó la lectura, midiendo los halos de inhibición, que se correlacionaron con los datos obtenidos en la curva estándar.

\subsubsection{Conversión de la lovastatina de su forma Lactona a su forma $\beta$ - hidroxiácida.}

$20 \mathrm{mg}$ de lovastatina (Fermic S.A. de C.V.), se disolvieron en $50 \mathrm{ml}$ de $\mathrm{NaOH} 0.1$ (preparado con una solución de Acetonitrilo al 25\%). Esta mezcla se ajustó a pH 7.7 con $\mathrm{HCl} 0.1 \mathrm{~N}$ (preparado en Acetonitrilo), se incubó a $45^{\circ} \mathrm{C}$ durante $1 \mathrm{~h}$, se ajustó el volumen a $100 \mathrm{ml}$ y se guardó en alícuotas de $1 \mathrm{ml} \mathrm{a}-20^{\circ} \mathrm{C}$. Este proceso asegura un $98 \%$ de conversión de la forma lactona a la forma $\beta$-hidroxiácida (Yang \& Hwang 2006), sin embargo, hubo que confirmarlo mediante HPLC, para obtener una curva patrón con las concentraciones reales de la forma $\beta$ hidroxiácida.

\subsubsection{Extracción y cuantificación de azucares.}

Para FS, se colocó 1 g de soporte húmedo en un tubo con $10 \mathrm{ml}$ de agua destilada, se agitó durante $30 \mathrm{~min}$ a $200 \mathrm{rpm}$, del sobrenadante se tomó $1 \mathrm{ml}$ para análisis. Para FL, se tomó directamente $1 \mathrm{ml}$ del caldo para análisis. La cuantificación se realizó por HPLC, empleando

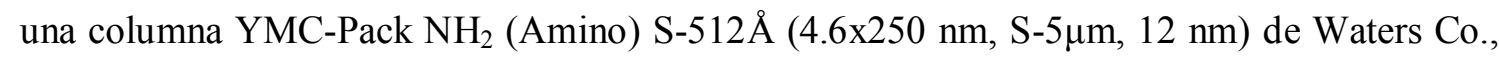
usando una fase móvil de acetonitrilo:agua $(75: 25 \mathrm{v} / \mathrm{v})$ a un flujo de $2.0 \mathrm{ml} / \mathrm{min}$. Se estimaron glucosa y lactosa a $138 \mathrm{~nm}$ con un detector de arreglo de diodos. 


\subsubsection{Cuantificación de ROS.}

La oxidación de la sonda $\mathrm{H}_{2}$ DCF-DA (Sigma-Aldrich) por las ROS, se midió a través de una cinética. A $10 \mathrm{ml}$ de PBS con una concentración de $20 \mathrm{mM} \mathrm{H} \mathrm{H}_{2}$ DCF-DA, se le adicionaron 100 mg de micelio de FL o en su caso, 1 g de cultivo sólido de FS. La reacción se incubó en condiciones de oscuridad y en hielo durante $30 \mathrm{~min}$. Transcurrido el tiempo, cada muestra se filtró, se congeló y se molió con $\mathrm{N}_{2}$ líquido (con ayuda de mortero y pistilo). Aproximadamente $500 \mathrm{mg}$ del polvo (micelio molido y congelado), se adicionaron a un microtubo de $1.5 \mathrm{ml}$ negro (o ámbar), y a éste se le adicionó $1 \mathrm{ml}$ de PBS frío. El tubo fue vortexeado durante $20 \mathrm{seg}$ y centrifugado a 12,000 x g a $4^{\circ} \mathrm{C}$ por $15 \mathrm{~min} .200 \mu \mathrm{ldel}$ sobrenadante se colocaron sobre un placa de 96 pozos para fluorescencia, la cual se leyó en el lector multimodal DTX 880 Multimode Detector (Beckman-Coulter, Inc, Brea, CA, USA), empleando $485 \mathrm{~nm}$ de excitación y $530 \mathrm{~nm}$ de emisión. Se realizó el mismo procedimiento, pero sin emplear la sonda $\mathrm{H}_{2}$ DCF-DA (control negativo), al final a la fluorescencia emitida en las muestras tratadas con la sonda, se les restó la fluorescencia del control negativo. La normalización de la Fluorescencia (dado en Unidades Relativas de Fluorescencia, o URF) se obtuvo al dividir éste resultado entre el contenido de proteína (determinado por Bradford) o por biomasa, en FL por peso seco y en FS por ácidos nucleicos. Todo se realizó por triplicado.

\subsubsection{Determinación de GSH/GSSG (balance redox).}

Una muestra de 200 ul de polvo de micelio molido congelado de FL o 500 ul de polvo de cultivo sólido de FS, se agregaron a 800 y $400 \mu$ de Buffer PBS frío, respectivamente. Subsecuentemente, se le adicionó a cada muestra $200 \mu \mathrm{l}$ de ácido metafosfórico al 5\% (J.T. Baker), seguido de un ligera agitación con vórtex. Las muestras fueron centrifugadas a 8000 x g por $10 \mathrm{~min}$ a $4^{\circ} \mathrm{C}$, y $500 \mu \mathrm{l}$ del sobrenadante se mezclaron con $500 \mu \mathrm{l}$ de cloroformo, mezclando por inversión. La mezcla se centrifugó 5 min a 8,000 x g a $4^{\circ} \mathrm{C}$, y $100 \mu \mathrm{l}$ del sobrenadante se tomaron para analizar en HPLC. La cuantificación de GSH y GSSG se realizó empleando una columna Synergi $4 \mathrm{~mm}$ Hydro-RP (150 mm x $4.6 \mathrm{~mm}$ ) de Phenomenex Inc, empleando una fase móvil de acetonitrilo: $20 \mathrm{mM} \mathrm{KH}_{2} \mathrm{PO}_{4} \mathrm{pH} 2.7$ (1:99). GSH y GSSG se analizaron a $210 \mathrm{~nm}$ con un detector de Arreglo de Diodos (Waters 996) (Water Corporation, Milford, MA, USA). Los estándares GSH $\left(\mathrm{C}_{10} \mathrm{H}_{17} \mathrm{~N}_{3} \mathrm{O}_{6} \mathrm{~S}\right)$ y GSSG $\left(\mathrm{C}_{20} \mathrm{H}_{32} \mathrm{~N}_{6} \mathrm{O}_{12} \mathrm{~S}_{2}\right)$ se obtuvieron de Sigma-Aldrich. 


\subsection{Técnicas Moleculares.}

\subsubsection{Northern-blot.}

\subsubsection{1. $\quad$ Extracción de RNA.}

Cada muestra previamente congelada se trituró con $\mathrm{N}_{2}$ líquido. Se llenaron los tubos a un volumen, para muestras de FL, no más de $250 \mu \mathrm{l}$, y para el caso de muestras de FS, no más de $500 \mu 1$. Se llenaron hasta 4 tubos por muestra, los cuales se echaron a flotar en $\mathrm{N}_{2}$ líquido. El polvo restante se guardó en microtubos de $1.5 \mathrm{ml}$ y se guardaron a $-70^{\circ} \mathrm{C}$ hasta su procesamiento.

A cada uno de estos tubos, se le adicionó $1 \mathrm{ml}$ de TRIZOL (Invitrogen), se mezcló por agitación con vórtex hasta su descongelación e incorporación total del reactivo. Para muestras de FS, se centrifugó a 12,000 x g por 5 min a temperatura ambiente (TA) y para muestras de FL, solamente se incubaron durante 5 min a TA. Los tubos se centrifugaron a $4^{\circ} \mathrm{C}$ a $12,000 \mathrm{x}$ g por $15 \mathrm{~min}$. La fase acuosa se colectó y se colocó en un nuevo tubo. La precipitación se realizó con $500 \mu \mathrm{l}$ de isopropanol y se almacenaron a $-20^{\circ} \mathrm{C}$ O.N. Se centrifugó a $4{ }^{\circ} \mathrm{C}$ a $12,000 \mathrm{x}$ g por $30 \mathrm{~min}$. El precipitado se lavó con $1 \mathrm{ml}$ de etanol al 75\%, se mezcló por agitación en vórtex y se centrifugó a $4^{\circ} \mathrm{C}$ a 7,500 x g por 5 min. Finalmente el ARN se resuspendió en $11 \mu \mathrm{l}$ de $\mathrm{H}_{2} \mathrm{O}$ tratada con $\mathrm{DEPC}^{5}$ (dietilpirocarbonato) por cada tubo. Para resuspender, se dejó en hielo durante $10 \mathrm{~min}$, y después se incubaron a $65^{\circ} \mathrm{C}$ por $10 \mathrm{~min}$ con agitación.

\subsubsection{Cuantificación del RNA.}

Se emplearon dos formas: 1) Se preparó un gel con formaldehído (como se describe en los siguientes apartados) y se corrió $1 \mu \mathrm{l}$ de cada muestra o tubo con RNA. Se visualizó con luz UV y esta imagen sirvió como base para obtener concentraciones homogéneas con cantidades equiparables de ARN. 2) Cada una de las muestras, se leyó con el espectrofotómetro, este método sirvió también para ver parámetros de pureza y limpieza. Se empleó el Nanodrop

\footnotetext{
${ }^{5}$ DEPC: se empleó a una concentración de $1 \mu \mathrm{l} / \mathrm{ml}$.
} 
2000c (Thermo Scientific) a 260, 230 y $280 \mathrm{~nm}$ de absorbancia. Se hicieron cálculos para correr $10 \mu \mathrm{g}$ de ARN por cada muestra de FS o FL.

\subsubsection{3. $\quad$ Electroforesis en geles con Formaldehído.}

Por cada $100 \mathrm{ml}$ de solución de agarosa se necesitaron de $1.2 \mathrm{~g}$ de agarosa $+87 \mathrm{ml}$ de agua (destilada estéril), la mezcla se fundió al microondas. Entre $50-55^{\circ} \mathrm{C}$, se le agregaron $10 \mathrm{ml}$ de MAE $10 X^{6}$. En la campana de extracción, se le agregaron $3 \mathrm{ml}$ de formaldehído al frasco. Tras gelificación, se colocaron dentro del tanque de electroforesis tampón MAE 1X. Las muestras se colocaron dentro del pocillo del gel y se aplicó 100 volts durante 2 h. Las bandas se visualizaron con la luz ultravioleta, se tomó la foto y se procedió a la transferencia a membrana.

\subsubsection{Transferencia del RNA a Membrana Hybond-N+.}

La transferencia se realizó por capilaridad como se describe a continuación: La cámara de transferencia se limpió con SDS $1 \%$ y se enjuagó con $\mathrm{H}_{2} \mathrm{O}$-depc. Se colocó buffer SSC10X en la cámara hasta los 2 bordes (pero sin rebasarlos). Se colocó 1 tira larga de papel filtro $3 \mathrm{MM}^{8}$ (Whatman) y se verificó que los extremos colgaran y fueran mojados por el buffer, enseguida se colocaron la 2 da. y la 3er. tira. Con cuidado, se colocó el gel boca abajo (de manera que la transferencia se haga de la parte mas plana), después se colocó la membrana de nylon Hybond-N+ (Amersham, GE Healthcare), y después se colocaron los 3 cuadros de filtro 3MM (al tamaño del gel), seguido de una torre de papel absorbente y/o papel periódico (altura aproximada de $15 \mathrm{~cm}$ ). Se colocó un vidrio cuadrado (centrado) y un libro de aproximadamente $250 \mathrm{~g}$. Se dejó toda la noche. Después de 12-16 h, la transferencia fue desmontada, quitando todo el peso hasta llegar a la membrana, la cual fue rotulada con lápiz.

\footnotetext{
${ }^{6}$ MAE10X: 0.2 M MOPS, $50 \mathrm{mM}$ acetato sódico y $10 \mathrm{mM}$ EDTA, ajustado a pH 7.0 con $\mathrm{NaOH}$.

${ }^{7} \mathrm{SSC} 10 \mathrm{X}: \mathrm{NaCl} 1.5 \mathrm{M}+$ Citrato de sodio $0.15 \mathrm{M}$, ajustado a $\mathrm{pH} 7$ con $\mathrm{HCl} 0.1 \mathrm{~N}$.

${ }^{8}$ Papel para cromatografía 3MM: velocidad de flujo $130 \mathrm{~mm} / 30 \mathrm{~min}$.
} 


\subsubsection{Fijación del RNA a la membrana.}

La membrana fue colocada sobre un placa o un soporte limpio con SDS al 1\% y cloroformo. El RNA fue fijado mediante UV (UVC Crosslinker, Amersham Bioscience) empleando $70,000 \mu \mathrm{J} / \mathrm{cm}^{2}$ de energía. La membrana se colocó dentro de SSC1X y con ayuda de una lámpara de UV, se marcaron los ribosomales y carriles con lápiz.

\subsubsection{Marcaje de Sondas.}

Las sondas correspondientes a los genes $\operatorname{sod} 1, \operatorname{lov} E, \operatorname{lov} F$, brlA, fadA, srr A y yapl (diseño de oligos se muestran en la Tabla 3), fueron obtenidas por PCR. 50 ng de sonda se marcaron con $5 \mu \mathrm{L}$ de $[\alpha-32 \mathrm{P}]-\mathrm{dCTP}(10 \mu \mathrm{Ci} / \mu \mathrm{l})$, utilizando el kit Ready-To-GoTM DNA Labelling Beads (-dCTP) (Amersham, GE Healthcare).

La exposición se llevó a cabo usando películas X-Ray (Kodak Sci. Imaging Film X-OMATblueXB-1). Las señales obtenidas fueron escaneadas (escáner Epson TX100) y analizadas por densitometría, usando el programa ImageJ (versión 1.4u). Los valores fueron normalizados con el RNA ribosomal teñido con bromuro de etidio (al $0.1 \%$ ). Una misma membrana con RNA proveniente de FS junto con otra con RNA de FL, se hibridaron al mismo tiempo con una sola sonda (mismo tiempo y condiciones de hibridación).

\subsubsection{Hibridación.}

Las membranas se prehibridaron junto con los controles correspondientes con $10 \mathrm{ml}$ de buffer $\mathrm{PSE}^{9}$, en el horno de hibridación a $65^{\circ} \mathrm{C}$ durante 10 o $20 \mathrm{~min}$. El PSE de pre-hibridación se desechó y se le agregó $10 \mathrm{ml}$ de PSE nuevo al tubo de hibridación mas $225 \mu \mathrm{l}$ de la sonda marcada $(50 \mu \mathrm{L}$ sonda $+175 \mu \mathrm{l}$ de $\mathrm{NaOH} 0.1 \mathrm{M})$, para posteriormente meterlos en el horno de hibridación a $65^{\circ} \mathrm{C}$ O.N.

\footnotetext{
${ }^{9}$ PSE:3ml de Fosfato sódico1M, pH 7.2, 7mL de SDS 10\%, y $20 \mu 1$ de EDTA 0.5M.
} 
Tabla 3 Secuencias de oligos diseñados y empleados en este trabajo.

\begin{tabular}{|c|c|c|c|}
\hline OLIGO & SECUENCIA & $\mathbf{p b}$ & REFERENCIA \\
\hline \multirow[t]{2}{*}{ sod1 } & TCCGTGGWGACTCCAARRTCWCCGG & \multirow[t]{2}{*}{281} & \multirow[t]{2}{*}{ Miranda et al. 2008} \\
\hline & CKKCTTGGAGCCSWYGGMGTTACCC & & \\
\hline \multirow{2}{*}{ brlA } & AACCGTCCCACTCCTATCCGGAAGG & \multirow{2}{*}{495} & \multirow{2}{*}{ Miranda et al. 2008} \\
\hline & GCATGGTCGCGTAATGATGCATGGC & & \\
\hline \multirow{2}{*}{ fadA } & TGCCATTGAGCGCATCGCTCAACC & \multirow{2}{*}{535} & \multirow{2}{*}{ Miranda et al. 2008} \\
\hline & CATTGACTGCGGCCATGACGAACC & & \\
\hline \multirow{2}{*}{$\operatorname{lovE}$} & GGGCCATGGCTGCGATCAAGGTATATTCA & \multirow{2}{*}{1512} & \multirow{2}{*}{ Barrios-González et al. 2008} \\
\hline & GCTGGATCCGTTCATGGAGGAATATTGTT & & \\
\hline \multirow{2}{*}{ lovF } & GCGTCGGTACATAAGGGGGG & \multirow{2}{*}{749} & \multirow{2}{*}{ Barrios-González et al. 2008} \\
\hline & GTGGTTCCAAGGGTAGGGCGG & & \\
\hline \multirow{2}{*}{$\operatorname{yap} 1 R N A i$} & TTCCGCTATCAATGCCATGGCCGGAGC & \multirow[t]{2}{*}{553} & \multirow[t]{2}{*}{ Este trabajo } \\
\hline & GATTCCTGCCCATCCATGGTGTTATAGG & & \\
\hline \multirow{2}{*}{$\operatorname{srr} A$} & ATGACCTCAGGTGCGCAAGC & \multirow{2}{*}{1998} & \multirow{2}{*}{ Mendoza-Rico et al., (en revisión) } \\
\hline & ACAGCATATGCAGCAACTGCC & & \\
\hline
\end{tabular}

\subsubsection{Lavados.}

Se etiquetaron tubos falcon de $15 \mathrm{ml}$ con el nombre de la sonda. Cada tubo de hibridación se saco del horno y se vació el líquido dentro del tubo falcón correspondiente, y posteriormente se guardó a $-20^{\circ} \mathrm{C}$. Por otra parte, al tubo de hibridación se le adicionaron $100 \mathrm{ml}$ de solución de lavado ${ }^{10}$, el cual fue llevado nuevamente al horno de hibridación a $65^{\circ} \mathrm{C}$ durante 20 min, esta acción se realizó dos veces.

\footnotetext{
${ }^{10}$ Solución de Lavado: Por cada $1050 \mathrm{ml}$ : Fosfato de sodio $1 \mathrm{M} \mathrm{pH} 7.2(105 \mathrm{ml})$, SDA al 10\% $(70 \mathrm{ml})$ y $875 \mathrm{ml}$ $\mathrm{H}_{2} \mathrm{Od}$.
} 


\subsubsection{Autorradiografía.}

Las membranas se colocaron entre dos películas de acetato y fueron envueltos en egapack y puestos dentro de un cassette de exposición (Hypercassette de Amersham GE Healtcare), el cual contenía pantallas intensificadoras de la misma marca. La exposición se llevó a cabo sobre películas Kodak Scientific Imaging Film, X-Omat Blue XB-1, de 18 x $24 \mathrm{~cm}$, a $-70^{\circ} \mathrm{C}$. El tiempo de exposición fue directamente proporcional a la señal proporcionada por el contador Geiger-Muller.

\subsubsection{Densitometría.}

Se utilizo el programa ImageJ (versión $1.43 \mathrm{u}$ ) para normalizar las señales emitidas en la película, las cuales eran proporcionales a la cantidad de transcritos del gen de estudio. Se empleo como base de calculo el RNA ribosomal en cada carril.

\subsubsection{Silenciamiento del gen Atyap1.}

\subsubsection{Vector de Silenciamiento.}

El plásmido pGpdPki-RNAi (Fig. 14) fue obtenido del plásmido pJL43-RNAi (Ullán et al. 2008) y modificado por Marcial et al., (2011). El vector pGdpPki-RNAi contiene el promotor del gen gliceraldehído-3-P-deshidrogenasa A $(g d h)$ de Aspergillus nidulans, el terminador del gen que codifica la citocromo oxidasa 1 (cycl) de Saccharomyces cerevisiae y el gen de resistencia a fleomicina (ble). Además, este vector posee los promotores de los genes gpd (gliceraldehído-3-fosfato deshidrogenasa) y pki (piruvato quinasa), en sentido opuesto y enfrentados, separados por un sitio de restricción NcoI, donde se insertó un fragmento de ADN (553 pb del gen Atyap $1^{11}$ ). El vector fue digerido con la enzima NcoI (Promega).

\footnotetext{
${ }^{11}$ Atyap1: Homólogo a Yap1 descrita en levaduras, pero el prefijo At, proviene de Aspergillus terreus.
} 


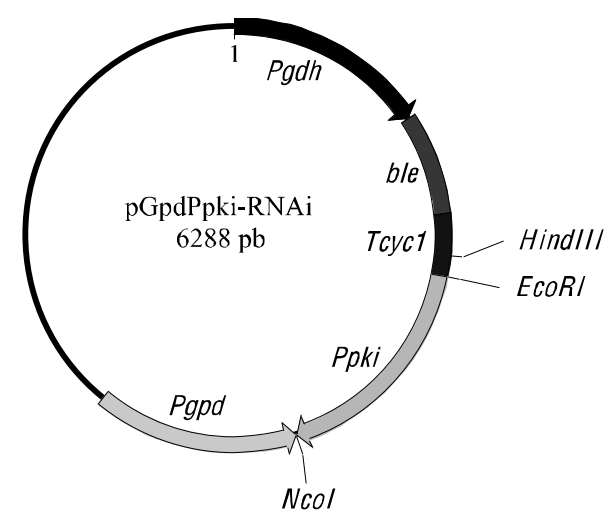

Fig. 14 Vector pGdpPki-RNAi empleado para silenciar Atyap1 de A. terreus (Marcial et al. 2011).

\subsubsection{Condiciones para la obtención del fragmento del gen Atyap1 para}

\section{Silenciamiento.}

Para silenciar el gen Atyap1, se diseñaron los oligos yap1RNAi (descritos en la Tabla 3). Las concentraciones empleadas para obtener el fragmento fueron las siguientes:

\section{Componente}

$\mathrm{H}_{2} \mathrm{O}$ (grado Biología Molecuar, MoBio Laboratorios)

Buffer 10x

dNTPs $10 \mathrm{mM}$

yapRNAi-Fwd $10 \mathrm{mM}$

yapRNAi-Rev $10 \mathrm{mM}$

MgSO4 100mM

Templado ADN (lug)

Vent (BioLabs)

Total

\section{Cantidad (ul)}

70.5

10.0

4.0

5.0

5.0

4.0

1.0

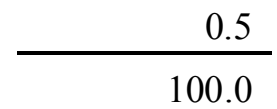

El programa en el Termociclador (Eppendorf Mastercycler Personal) se estableció con las siguientes condiciones:

Desnaturalización inicial de $98^{\circ} \mathrm{C}$ durante $30 \mathrm{seg}$; seguido de 35 ciclos que consistieron en lo siguiente: una desnaturalización a $98^{\circ} \mathrm{C}$ durante $30 \mathrm{seg}, 68.5^{\circ} \mathrm{C}$ de anillamiento o hibridación durante 50 segundos y $72^{\circ} \mathrm{C}$ de elongación durante $1 \mathrm{~min}$; después de los ciclos, una 
elongación final a $72^{\circ} \mathrm{C}$ durante 5 min para finalmente guardar la reacción a $4^{\circ} \mathrm{C}$. Este programa se guardó bajo el nombre de Yap1RNAi en el termociclador.

Dado que la reacción de PCR generó un producto con extremos romos, éste (purificado) se clonó dentro del vector pJet (Fermentas) siguiendo las instrucciones del proveedor. El producto de la ligación, se transformó en células electrocompetentes de E. coli DH5 ${ }^{12}$. Las transformantes obtenidas se analizaron por la técnica de Lisis Alcalina (LA) o PCR de colonia De la transformante seleccionada, se realizó un cultivo a mediana escala. El inserto de Atyap1 (553 pb) se obtuvo por digestión del ADN plasmídico con la enzima NcoI, el cual se purificó a partir de un gel de agarosa al 1\%, siguiendo el procedimiento de Purificación de productos de PCR y vectores.

\subsubsection{Lisis Alcalina: Técnica para obtener ADN plasmídico.}

Se colocaron cultivos O.N. de las células a analizar. Se centrifugaron $1.5 \mathrm{ml}$ de cultivo durante 2 min a 12,000 x g. Se desechó el sobrenadante y el pellet se resuspendió con ayuda de un palillo y agitación con vórtex en $200 \mu$ de SOLUCIÓN I ${ }^{13}$ hasta la homogeneidad. Se le adicionaron $200 \mu \mathrm{l}$ de SOLUCIÓN II $^{14}$ (preparada al momento) mezclando por inversión de 3 a 5 min o hasta que el lisado estuviera claro. Se agregaron $200 \mu$ de SOLUCIÓN III ${ }^{15}$, se mezcló por inversión y se dejó en hielo durante $5 \mathrm{~min}$. Se adicionaron $300 \mu \mathrm{l}$ de cloroformo (para precipitar proteínas), se mezcló bien por inversión y se centrifugó durante 10 min a $12,000 \times$ g para bajar los restos celulares y cromosomas. El sobrenadante se transfirió a otro tubo, adicionándole 2 volúmenes de etanol absoluto, mezclando por inversión y dejando a temperatura ambiente durante $5 \mathrm{~min}$, enseguida se centrifugó durante 10 min para bajar el ADN. El sobrenadante fue removido y desechado, el tubo se secó, se le agregó 1 volumen de

\footnotetext{
12 Cepa utilizada en experimentos de transformación por electroporación debido a la alta eficacia que puede conseguirse con ella, 5 x 108 transformantes/ $\mu$ g de ADN. Entre sus características destaca la de poseer el fragmento $\alpha$ de la $\beta$-galactosidasa, lo que permite seleccionar por color las células transformadas que contengan plásmidos capaces de originar $\alpha$-complementación, tales como pGEM-T® Easy (Promega, Madison, WI, E.U.A). Genotipo: deoR, endA1, gyrA96, recA1, hsdR17 (rk-, mk+), relA1, supE44, thi-1, $\Delta($ lacZYA$\operatorname{argFV169),~f80\delta lacZ~} \Delta \mathrm{M} 15 \mathrm{~F}-\lambda$ -

${ }^{13}$ SOLUCIÓN I:10 mM EDTA pH 8.0, 50 mM Glucosa y25 mM Tris-HCl pH 8.

${ }^{14}$ SOLUCIÓN II: Por cada 500 ul de solución: 400 ul de $\mathrm{H}_{2} \mathrm{O}, 50$ ul de SDS 10\%, 50 ul de NaOH 2N

${ }^{15}$ SOLUCIÓN III: $60.0 \mathrm{ml}$ de acetato de potasio $5 \mathrm{M}, 11.5 \mathrm{ml}$ de ácido acético glacial y $28.5 \mathrm{ml} \mathrm{de} \mathrm{agua}$ destilada. Se mantuvo en frío.
} 
etanol al 70\%. Se centrifugó durante 3 min a 12,000 x g y se desechó el sobrenadante. La pastilla de ADN se secó (a temperatura ambiente) y se resuspendió en 20-30 $\mu 1$ de agua ${ }^{\circ} \mathrm{BM}$ (MoBio Labs) y $1 \mu \mathrm{l}$ de RNAsa $(1 \mu \mathrm{g} / \mu \mathrm{l})$.

\subsubsection{PCR de colonia para identificación de clonas.}

Se emplearon las mismas condiciones descritas para la reacción de PCR normal y las mismas concentraciones de componentes, a excepción del templado de ADN, donde en su lugar se colocaron células potencialmente transformadas con el vector-inserto. Con ayuda de una punta para micropipeta, se tomó una transformante, la cual se resembró sobre una placa nueva de agar LB con Ampicilina $(100 \mu \mathrm{g} / \mathrm{ml})$, y lo restante se introdujo dentro del tubo con la mezcla de reacción de PCR, donde se dejó por 5 min, después la punta se desechó y se procedió a realizar la reacción como de costumbre. Las colonias que produjeron el producto de PCR de 553 pb se seleccionaron como transformantes viables para proseguir con el procedimiento.

\subsubsection{Purificación de productos de PCR y vectores.}

A partir de una electroforesis en gel de agarosa (de 0.8 o 1\%), se cortó con ayuda de un cutter el fragmento del gel con la banda de ADN (PCR, vectores digeridos con enzimas de reestricción, etc), La purificación del ADN, se realizó empleando el kit Wizard® ${ }^{\circledR}$ SV gel and PCR clean-up system (Promega) siguiendo las instrucciones del fabricante.

\subsubsection{Digestiones con enzimas de restricción.}

Las digestiones, se realizaron con $2 \mu \mathrm{l}$ de ADN obtenido por Lisis Alcalina, y se preparó la siguiente mezcla de reacción: 


$\begin{array}{lc}\mathrm{H}_{2} \mathrm{O}^{\circ} \mathrm{BM} & 14 \\ \text { Buffer10x } & 2 \\ \text { ADN } & 2 \\ \text { RNAsa } & 1 \\ \text { Enzima } & \frac{1}{20} \mathrm{ul}\end{array}$

La digestión se realizó por alguno de los siguientes métodos: 1) Incubación a $37^{\circ} \mathrm{C}$ durante 3 horas; 2) Incubación a $37^{\circ} \mathrm{C}$ O.N. (para enzimas sin actividad "star") o 3)En horno de microondas: 3 pulsos de 10 segundos a máxima potencia, con intervalos de descanso de 2 min. Se corrieron $10 \mu \mathrm{l}$ en una gel de agarosa al $1 \%$ para ver el producto, usualmente se corrió una muestra sin digerir como control negativo.

\subsubsection{Ligación Vector-Inserto.}

Debido a que el sitio de ligación en el vector fue $N c o$ I fue el mismo para los dos extremos, se realizó una desfosforilación del vector empleando Fosfatasa Alcalina (SAP, Thermo Scientific) siguiendo las instrucciones del proveedor.

Después de la desfosforilación, se procedió a realizar una mezcla para llevar a cabo la ligación del vector:inserto, tomando en cuenta el siguiente criterio:

$\frac{\mathrm{ng} \text { of vector } \times \mathrm{kb} \text { size of insert }}{\mathrm{kb} \text { size of vector }} \times$ insert:vector molar ratio $=\mathrm{ng}$ of insert

Se empleó una relación inserto:vector de 3:1. Se hicieron los ajustes para llevar a cabo la reacción en un volumen final de $10 \mu \mathrm{l}$

$\begin{array}{lc}\mathrm{H}_{2} \mathrm{O}^{\circ} \mathrm{BM} & (8-\mathrm{x}-\mathrm{y}) \\ \text { Buffer 10x } & 1 \\ \text { Vector } & \mathrm{x} \\ \text { Inserto } & \mathrm{y} \\ \text { T4 DNA Ligase (Promega) } & -\frac{1}{-} \\ \text { Volumen final } & 10 \mathrm{ul}\end{array}$




\subsubsection{Transformación.}

Las condiciones de Transformación tanto de E. coli DH5a y A. terreus, fueron las mismas empleadas y descritas por Pérez-Aguirre et al., (2009), empleando Ampicilina y Fleomicina como marcador de selección respectivamente.

\subsubsection{Análisis in silico del promotor.}

Se utilizaron los siguientes programas, siguiendo las instrucciones dadas por los mismos programas.

MEME: http://meme.sdsc.edu/meme4/submit.html

N_SITE de Softberry: www.softberry.ur

JASPAR: http://jaspar.genereg.net/ 


\section{RESULTADOS.}

\subsection{Cinéticas de producción en FS y FL de lovastatina.}

Se implementaron sistemas de FS y FL para propósitos de comparación. Como puede observarse en la Fig. 15, la producción de lovastatina (idiofase) inició aproximadamente al mismo tiempo (cerca de las $24 \mathrm{~h}$ ) tanto en FS y FL. También, se puede observar que la esporulación solo se presentó en FS (después de las 72 h). Es importante notar que el comportamiento del pH siguió un patrón similar en ambos sistemas de cultivo. La elevada producción de lovastatina en FS es parte de la denominada "fisiología del medio sólido".

A) FS
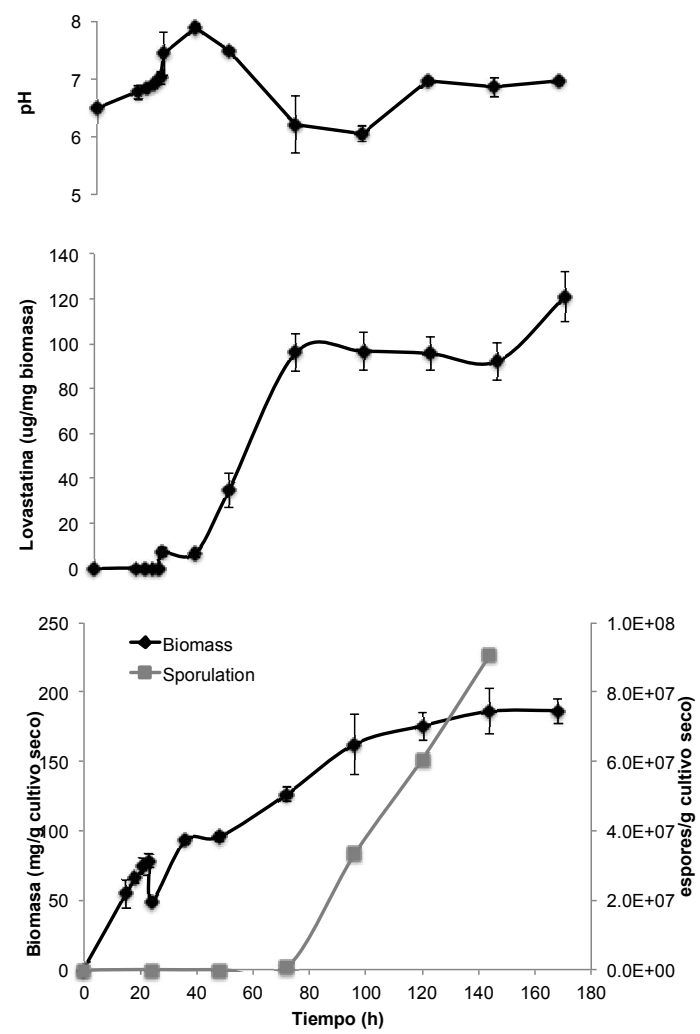

B) FL
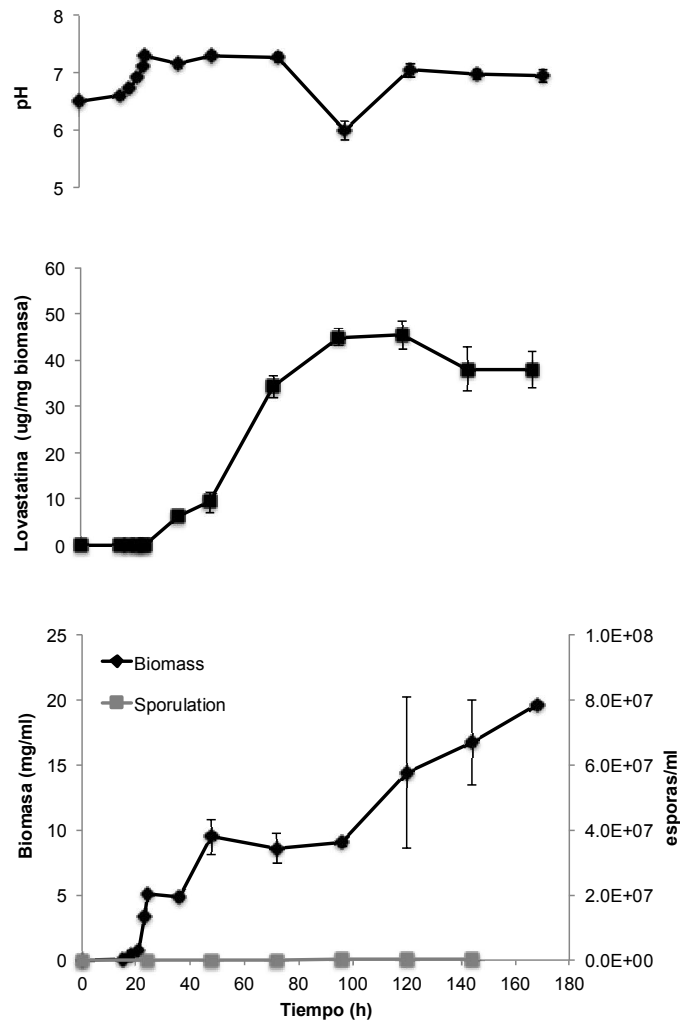

Fig. 15 Cinética de producción de lovastatina en A)FS y B)FL. También se presenta la cinética de producción de biomasa en ambos sistemas de cultivo. Nótese que el comportamiento del pH fue similar en ambos sistemas de producción. 


\subsection{Perfil de acumulación de ROS durante la trofofase e idiofase de producción en FS}

y FL.

Para confirmar la existencia del estado oxidante hipotético que precede el inicio de producción de lovastatina (idiofase), se cuantificó el contenido de ROS en el micelio proveniente de diferentes tiempos de la trofofase y de la idiofase de la FL y la FS.

A diferencia de lo esperado, los resultados mostraron concentraciones relativamente bajas durante la trofofase, mientras un abrupto incremento de ROS se observó exactamente a las 24 $\mathrm{h}$ en ambos sistemas de cultivo, continuando este alto nivel durante la idiofase (de las 24 a las 72 h). En relación a los sistemas de cultivo, los resultados mostraron que la concentración de ROS en FL fue 10 veces más alta que FS. Sin embargo, es importante notar que las concentraciones de ROS se mantuvieron en un nivel más estable (durante la idiofase) en FS

Fig. 16A.
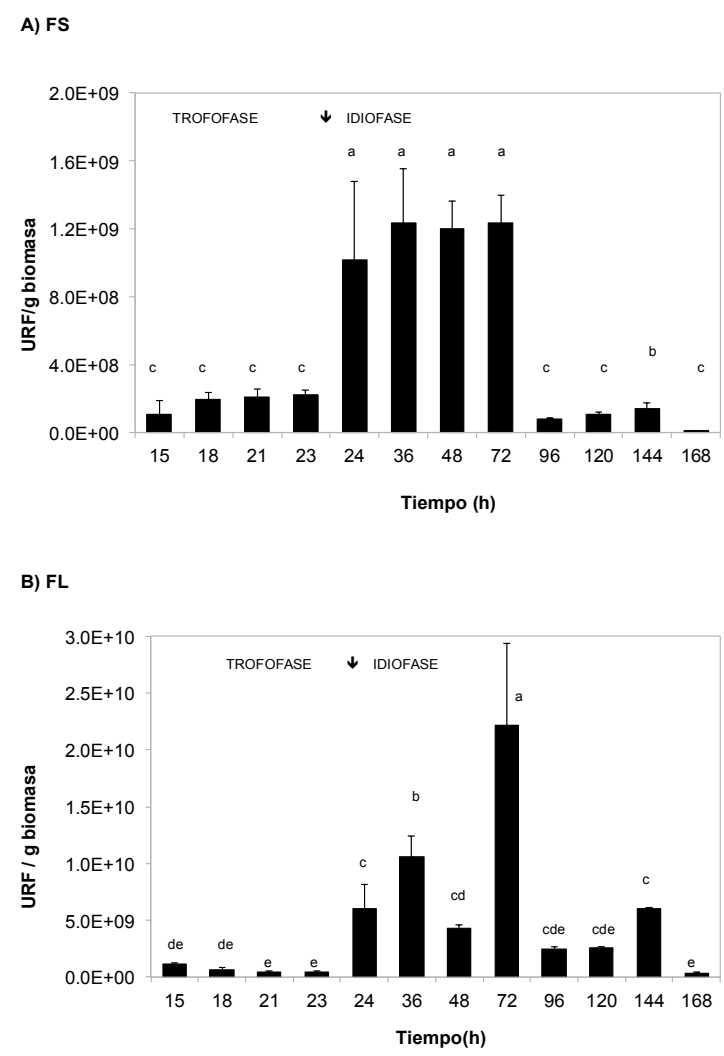

Fig. 16 Perfil de acumulación de ROS durante la trofofase e idiofase de A)FS y B)FL. Nótese la diferencia de escalas en la concentración de ROS entre los paneles A y B, debido a bajos niveles en FS. El contenido de ROS con diferentes letras indica diferencias significativas del resto, esto de acuerdo a la prueba de comparación LSD ( $\mathrm{p}<0.05)$. URF=Unidades Relativas de Fluorescencia 


\subsection{Estado redox de trofo- e idiofase de FS y FL.}

Para confirmar los resultados anteriores, se midió el estado redox a través del cociente GSH/GSSG durante la trofo- e idiofase de la fermentación de lovastatina en ambos sistemas de cultivo.

Como puede observarse en la Fig. 17, este balance fue relativamente alto (en ambos sistemas de cultivo) durante la trofofase, es decir, se encontró un ambiente reductor durante las primeras $48 \mathrm{~h}$ del cultivo. El estado, mostró una tendencia a hacerse oxidante durante toda la idiofase del cultivo (medido hasta las 168 h). En general, los resultados detectaron un decremento en el balance redox (cerca de 4 veces) en la idiofase.

En relación al sistema de cultivo, este parámetro también mostró diferencias notables. En FS el cociente GSH/GSSG fue 4 veces más alto (en ambas fases) que en FL.

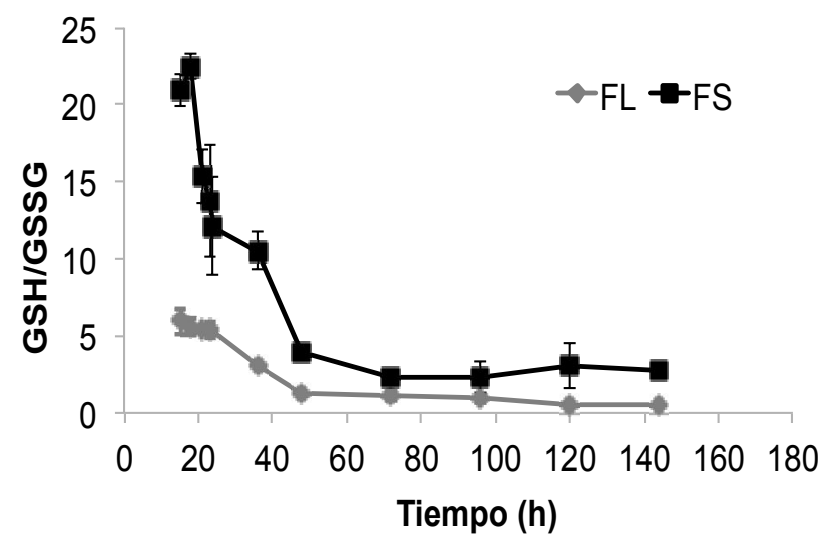

Fig. 17 Balance redox (GSH/GSSG) durante la trofo- e idiofase de la fermentación de lovastatina en FS y FL. Nótese la diferencia de escalas en el cociente GSH/GSSG entre FS y FL 


\subsection{Efecto de antioxidantes exógenos sobre la producción de lovastatina.}

Con la finalidad de demostrar una relación entre el EOX y la biosíntesis de lovastatina, se realizaron ensayos con antioxidantes exógenos y se observó su efecto en los distintos sistemas de cultivo.

\subsubsection{Efecto de antioxidantes en caja de Petri.}

Los antioxidantes que contienen grupos tiol (-SH), son neutralizadores efectivos de radicales $\mathrm{OH}^{+}$, ayudando a mantener concentraciones intracelulares adecuadas de ROS. NAcetilcisteína (NAC, Fig. 18) es un antioxidante que es permeable en la membrana y contiene un grupo tiol, el cual es susceptible de reaccionar con oxidantes. El NAC, tiene función antioxidante doble, primero por su grupo tiol y segundo, como precursor de glutatión (GSH), quizás siendo esta la molécula más abundante en la célula y por lo tanto, la que posee un papel importante en el mantenimiento del estado redox (Folch-Mallol et al. 2004).

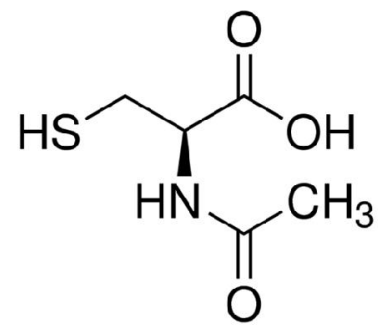

Fig. 18 Molécula de N-Acetil-L-cisteina

Con el objeto de determinar las concentraciones de antioxidante a emplear en FS y FL, se determinó el rango de concentraciones del NAC que tiene efecto en la biosíntesis de lovastatina. Para ello se realizaron cultivos en caja de Petri usando Medio de Producción 1X (ver sección Medios de Cultivo) con el antioxidante a diversas concentraciones. Se determinó su efecto sobre la morfología, crecimiento y producción de lovastatina por la técnica de extracción con acetato de etilo (ver sección Métodos Analíticos).

Los resultados mostraron que la producción de lovastatina se vio disminuida un $41 \%(\mathrm{p}<0.05)$ al emplear NAC 15 mM (Fig. 20) y se observó una disminución máxima del 72\% (p<0.05) empleando $100 \mathrm{mM}$ del antioxidante (Fig. 20). 


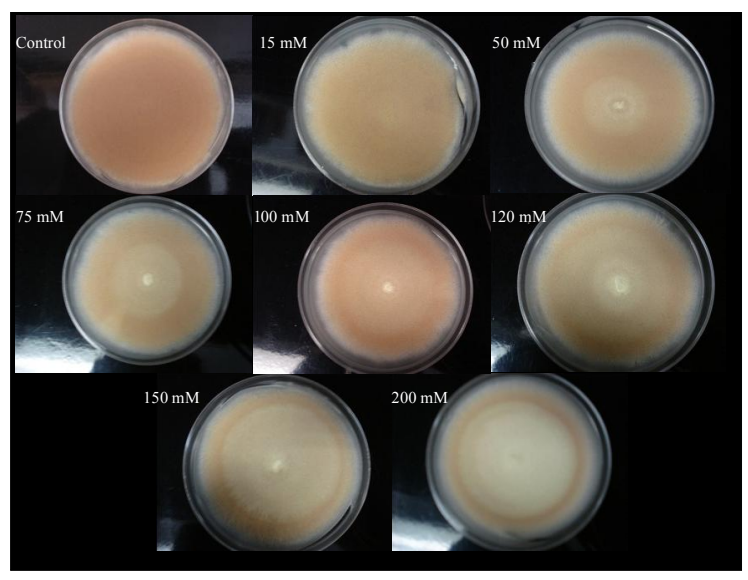

Fig. 19 Efecto de diferentes concentraciones del NAC sobre la morfología de Aspergillus terreus al día 10.

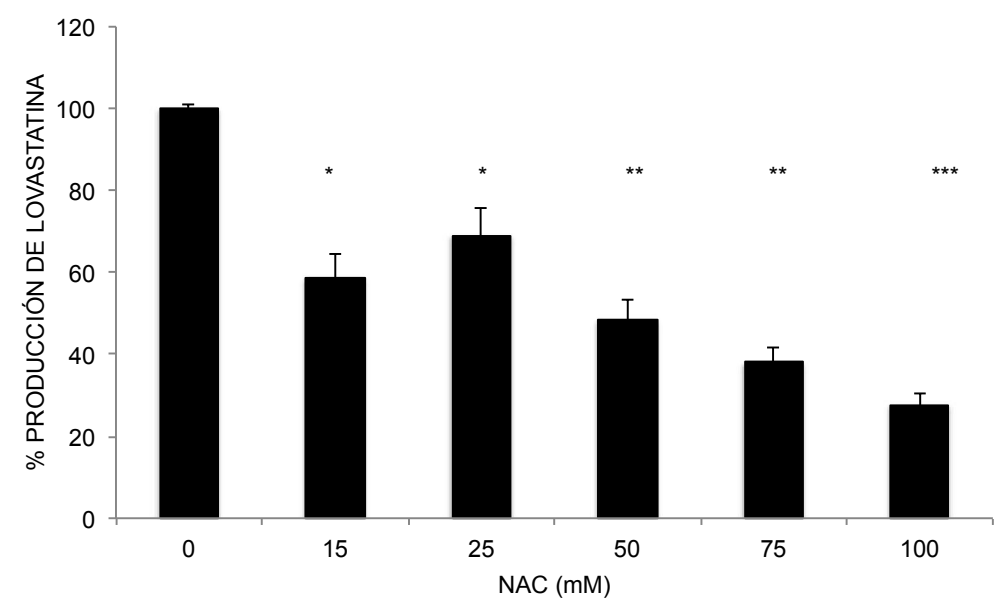

Fig. 20 Efecto sobre la biosíntesis de lovastatina al emplear diferentes concentraciones de NAC en cultivo sólido en caja de Petri al día 10. Los datos originalmente se obtuvieron en unidades de ug $/ \mathrm{ml}$, pero se representaron en \% para efectos de comparación. Se observaron diferencias significativas con respecto al control, de acuerdo a la prueba de Dunnet $(\mathrm{p}<0.05)$.

Se confirmó que el efecto de la disminución de la biosíntesis no se debió a diferencias en el crecimiento del hongo (Fig. 19). También se encontró que la esporulación se vio afectada en cuanto apariencia con el empleo de concentraciones altas del NAC (Fig. 19). 


\subsubsection{Efecto del antioxidante TMTU en cultivo en caja de Petri.}

Con el objeto de evitar artificios y verificar los resultados obtenidos anteriormente por el antioxidante NAC, se empleó un segundo antioxidante exógeno Tetrametiltiourea (TMTU, Fig. 21).<smiles>CN(C)C(=S)N(C)C</smiles>

Fig. 21 Molécula de Tetrametiltiourea

Los resultados mostraron un efecto negativo sobre la producción de lovastatina $(\mathrm{p}<0.05)$ con respecto al control, ya que se observó una disminución del 41 hasta el 50\%. Es importante notar que no hubo diferencias significativas en el nivel de producción, al emplear concentraciones de 50 a $200 \mathrm{mM}$ (Fig. 22).

Se observó que el crecimiento en placa y la morfología del hongo no se vieron afectados por el empleo del TMTU (datos no mostrados), por lo que se desprende que el efecto sobre la lovastatina se debió al antioxidante.

Con el empleo de ambos antioxidantes y observando el efecto que tuvo sobre el crecimiento y la producción de lovastatina, se determinó emplear el antioxidante NAC en FL y FS para estudiar su efecto sobre la biosíntesis de lovastatina y la producción de ROS. 


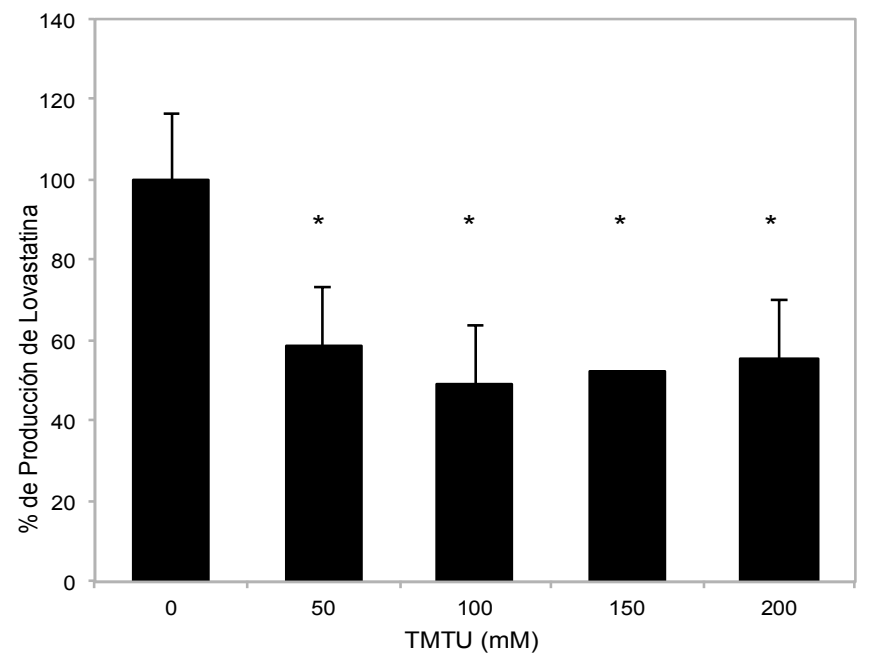

Fig. 22 Efecto del antioxidante TMTU sobre la biosíntesis de lovastatina al día 10 de cultivo en caja de Petri . Se observó un efecto negativo significativo $(\mathrm{p}<0.05)$ de acuerdo a la prueba de comparación de Dunnet.

\subsubsection{Efecto del NAC en FL.}

\subsubsection{Efecto de diferentes concentraciones de NAC.}

Con el objeto de analizar el efecto antioxidante sobre la producción específica de lovastatina y la generación de ROS al día 3, se suplementó NAC desde el tiempo 0 del cultivo a concentraciones finales de 1,10 y $50 \mathrm{mM}$. Al final del día 3, se tomaron muestras de cultivo para extracción de RNA, para analizar el perfil de expresión de los genes $l o v E$ y $l o v F$, que pertenecen a la vía biosintética de lovastatina.

A las 72 h de la FL, se observó un efecto negativo sobre la producción de lovastatina y sobre la acumulación de ROS al emplear concentraciones iniciales de 10 y $50 \mathrm{mM}$ del antioxidante NAC. La producción de lovastatina se redujo de $320.9 \mu \mathrm{g} / \mathrm{ml}$ (control, 0 mM NAC) a 192.5 y $119.7 \mu \mathrm{g} / \mathrm{ml}$, es decir, reducciones del 40 y $62 \%$ empleando 10 y $50 \mathrm{mM}$ respectivamente (Fig. 23, Tabla 4). Con respecto a la acumulación de ROS (la cual fue monitoreada por la oxidación de la sonda DCF-DA), de manera semejante a la lovastatina, se observaron reducciones significativas empleando 10 y $50 \mathrm{mM}$ del 64 y 71\% (Fig. 23, Tabla 4). Un análisis de regresión lineal simple, mostró una estrecha relación entre ambas variables (Lovastatina vs ROS), dando un índice de correlación $\mathrm{R}^{2}=0.93(\mathrm{p}<0.05)$. 


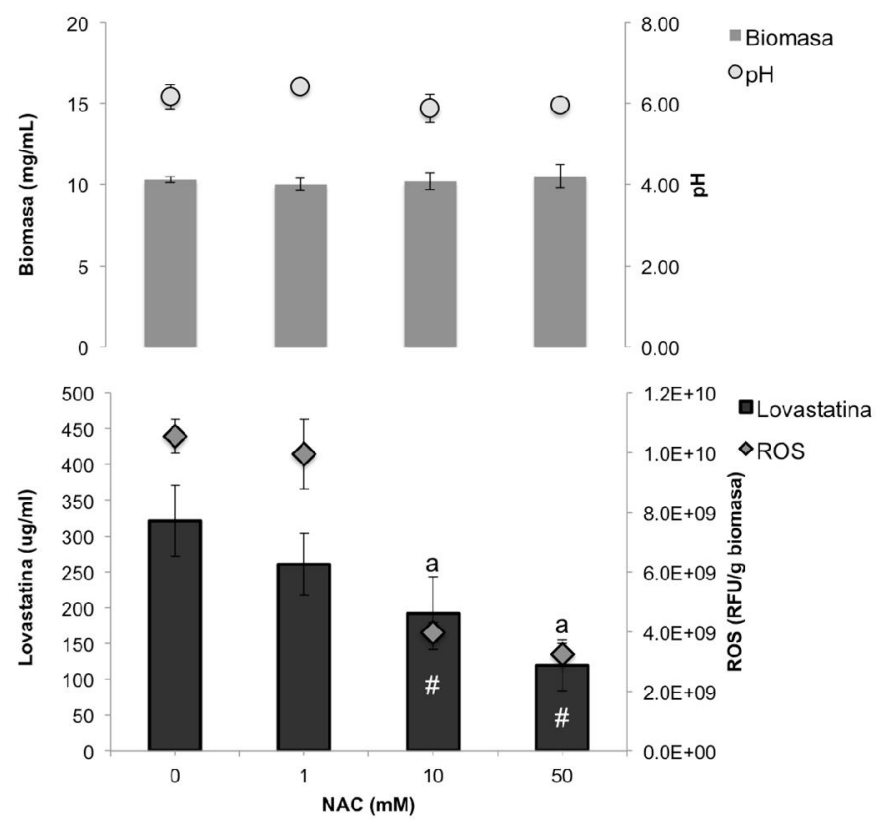

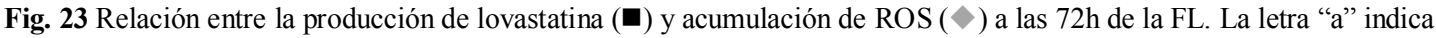
diferencia significativa con respecto al control en relación a la producción de lovastatina, mientras que el signo "\#” indica diferencias significativas en la acumulación de ROS, según la prueba de comparaciones múltiples de Dunnet $(\mathrm{p}<0.05)$. En la parte superior, se muestran los datos de biomasa $(\square)$ y el comportamiento del $\mathrm{pH}(\odot)$ donde no hubo diferencias significativas con respecto al control de acuerdo a la prueba de Dunnet $(\mathrm{p}<0.05)$.

Se descartó que la baja producción tanto de lovastatina como de ROS, se debiera a una disminución en la producción de biomasa, por lo que se midió este parámetro y se observó que no se alteró por el empleo del antioxidante (Fig. 23), de igual manera, para descartar que el comportamiento observado en lovastatina y ROS no estuviera influenciado por cambios de $\mathrm{pH}$, éste se midió al final de las 72 h y no se observaron cambios significativos (Fig. 23).

Tabla 4 Reducción de lovastatina (\%), y ROS por el empleo de diferentes concentraciones de NAC en FL. La letra "a" y el signo "\#” indican diferencias significativas con respecto a sus controles, de acuerdo a la prueba de Dunnet $(\mathrm{p}<0.05)$.

\begin{tabular}{|ccccc|}
\hline NAC & \multicolumn{2}{c}{ Lovastatina } & \multicolumn{2}{c|}{ ROS } \\
\hline $\mathbf{m M}$ & $\mu \mathrm{g} / \mathrm{ml}$ & \% Reducción & URF $/ \mathrm{g}$ & \% Reducción \\
\hline $\mathbf{0}$ & $320.9 \pm 49$ & 0 & $1.1 \mathrm{E}+10 \pm 5.7 \mathrm{E}+08$ & 0 \\
\hline $\mathbf{1}$ & $260.51 \pm 43$ & 18 & $1.0 \mathrm{E}+10 \pm 1.2 \mathrm{E}+09$ & 9 \\
\hline $\mathbf{1 0}$ & $\mathbf{1 9 2 . 4 8} \pm \mathbf{5 0} \mathbf{a}$ & $\mathbf{4 0}$ & $\mathbf{4 . 0 E}+\mathbf{0 9} \pm \mathbf{3 . 2 E}+\mathbf{0 8} \#$ & $\mathbf{6 4}$ \\
\hline $\mathbf{5 0}$ & $\mathbf{1 1 9 . 7 2} \pm \mathbf{3 5 a}$ & $\mathbf{6 2}$ & $\mathbf{3 . 2 E}+\mathbf{0 9} \pm \mathbf{3 . 6 E}+\mathbf{0 8} \#$ & $\mathbf{7 1}$ \\
\hline
\end{tabular}


Considerando la biomasa obtenida, se obtuvo la producción específica para cada uno de los tratamientos, y como se esperaba (por los datos anteriores), las disminuciones fueron significativas a partir de $10 \mathrm{mM}$ (39\% de reducción) (Fig. 23) .

\subsubsection{Efecto del tiempo de adición del NAC.}

Para analizar el efecto que tiene el antioxidante NAC sobre la producción de lovastatina, se suplementó NAC a una concentración final de $10 \mathrm{mM}$ a diferentes tiempos de la trofofase $(0$, 15 y 20h) y en la idiofase (36 y 48h). El resultado "control" mostrado en la Fig. 24, es aquel al que no se le suplementó NAC.

Los resultados mostraron que la adición de $10 \mathrm{mM}$ de NAC desde las 0, 15, 20 y $36 \mathrm{~h}$, redujeron significativamente la producción de lovastatina (Fig. 24, Tabla 5) desde un 50 a un $80 \%$. Y aunque la adición a las 48 h mostró una disminución del 30\%, este no fue significativo con respecto al control.

Se observó también que tanto como la biomasa y el $\mathrm{pH}$ no se vieron alterados por la adición del NAC (Fig. 24). 


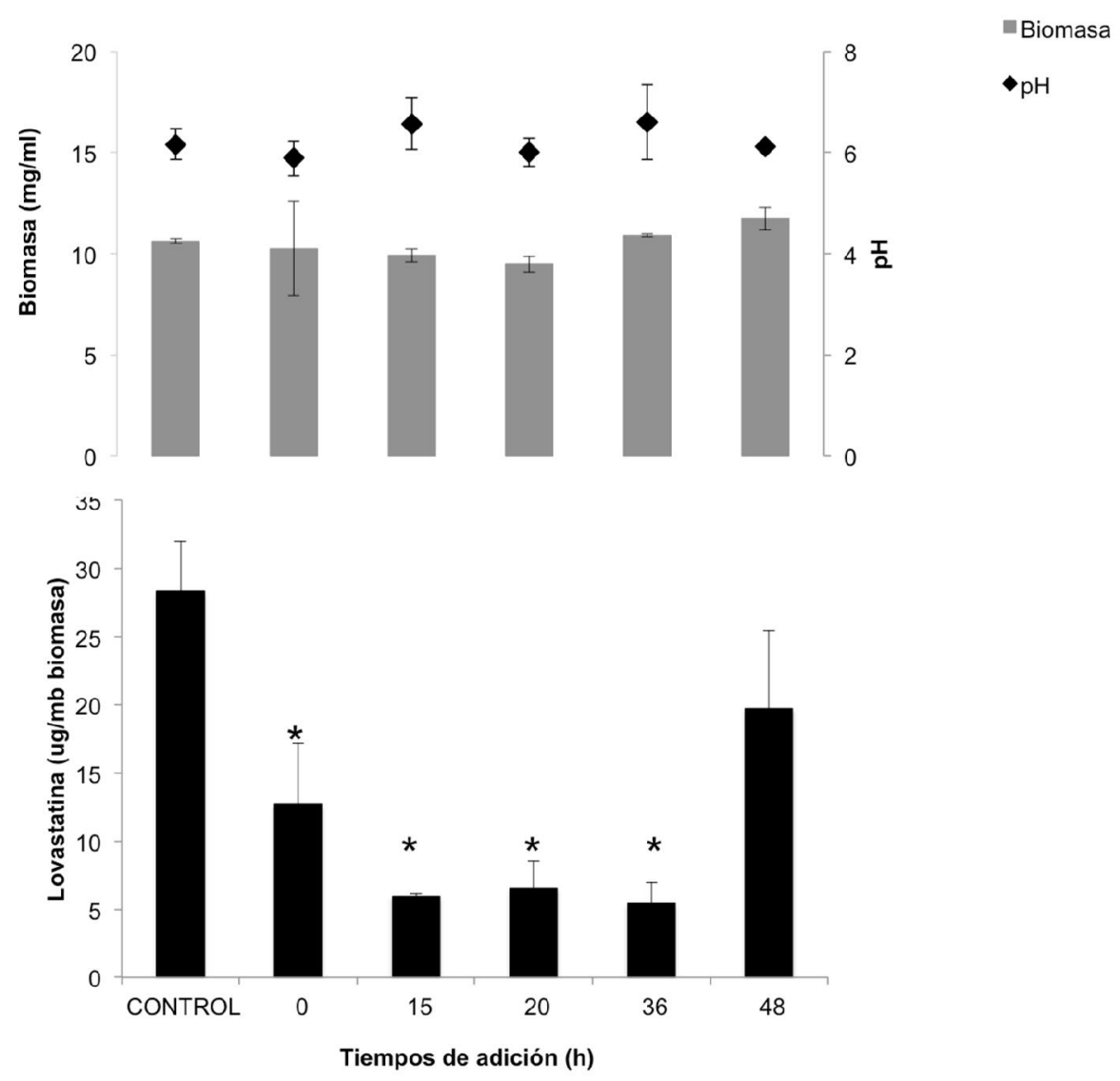

Fig. 24 Efecto de la adición de 10mM de NAC sobre la producción de lovastatina ( $\mathbf{\square})$ al final de las $72 \mathrm{~h}$ en FL. La adición se realizó independientemente a diferentes tiempos durante la trofofase $(0,15$ y $20 \mathrm{~h})$ e idiofase ( 36 y $48 \mathrm{~h})$. El CONTROL, es al que no se le adicionó NAC. En la parte superior, se muestra la producción final de biomasa (๒) y el pH $(\diamond)$ al final de las $72 \mathrm{~h}$ después de cada tratamiento. El símbolo “*” muestra diferencias significativas respecto al control de acuerdo a la prueba de Dunnet $(\mathrm{p}<0.05)$.

Tabla 5 Producción Específica de lovastatina en FL y \% de reducción debido a la adición del antioxidante NAC (10mM) a diferentes tiempos . La letra "a" indica diferencias significativas de acuerdo a la prueba de comparaciones múltiples Dunnet $(\mathrm{p}<0.05)$.

\begin{tabular}{|c|c|c|}
\hline Tiempo (h) & $\mu \mathrm{g}$ Lov/mg bms & $\%$ \\
\hline CONTROL & $28.4 \pm 3.6$ & 0 \\
\hline $\mathbf{0}$ & $12.7 \pm 4.4 \mathrm{a}$ & 55 \\
\hline 15 & $6.0 \pm 0.2 \mathrm{a}$ & 79 \\
\hline 20 & $6.6 \pm 1.9 a$ & 76 \\
\hline 36 & $5.4 \pm 1.5 \mathrm{a}$ & 80 \\
\hline 48 & $19.8 \pm 5.0$ & 30 \\
\hline
\end{tabular}




\subsubsection{Efecto del NAC en FS.}

Para estudiar el efecto antioxidante sobre la FS, se emplearon concentraciones finales de NAC de 1, 10, 50 y $100 \mathrm{mM}$. Los resultados mostraron que el NAC ejerció un efecto negativo tanto sobre la producción de ROS como de lovastatina (Fig. 25).

Se observó que sólo a concentraciones mayores se obtuvieron disminuciones en la producción de lovastatina significativas con respecto al control. Con 50 y $100 \mathrm{mM}$ se obtuvo disminuciones del 72 y $79 \%(p<0.05)$ respectivamente (Fig.25, Tabla 6).

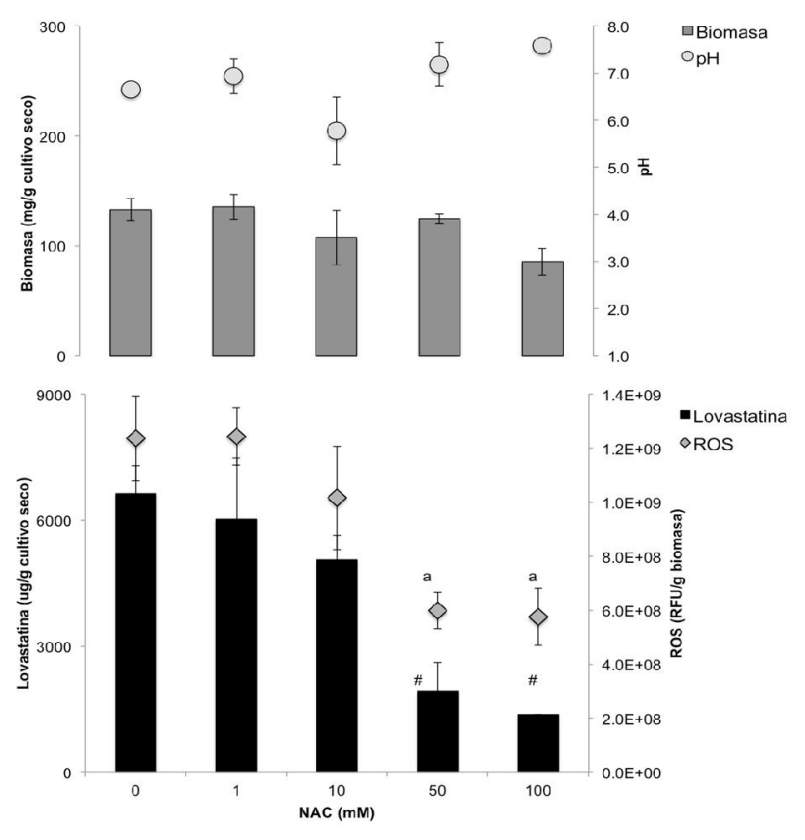

Fig. 25 Relación producción de lovastatina $(\boldsymbol{\square})$ vs acumulación de ROS $(\diamond)$ a las $72 \mathrm{~h}$ de la FS. La letra "a" indica diferencia significativa con respecto al control en relación a la producción de lovastatina, y el signo “\#”en la acumulación de ROS, según la prueba de comparaciones múltiples Dunnet $(\mathrm{p}<0.05)$. En la parte superior, se muestran los datos de biomasa $(\square)$ y el comportamiento del $\mathrm{pH}(\odot)$ donde no hubo diferencias significativas con respecto al control de acuerdo a la prueba de Dunnet $(\mathrm{p}<0.05)$.

La acumulación de ROS de igual manera se vio afectada por el empleo del antioxidante NAC, ya que al cuantificar éstas al final del día $3(72$ h), se observó una disminución con 50 y 100 $\mathrm{mM}$, del 52 y $53 \%(\mathrm{p}<0.05)$ respectivamente. Esto se relaciona estrechamente con la producción de lovastatina, según un Análisis de Regresión Simple, ya que se obtuvo un índice de correlación $\mathrm{R}^{2}=0.99(\mathrm{p}<0.05)$. 
Tabla 6 Reducción (\%) en la producción de lovastatina y ROS al emplear diferentes concentraciones de NAC. La letra "a" indica diferencias significativas según la prueba de comparaciones múltiples de Dunnet.

\begin{tabular}{|ccccc|}
\hline \multicolumn{4}{|c}{ Lovastatina } & \multicolumn{2}{c|}{ ROS } \\
\hline NAC $(\mathbf{m M})$ & $\mu \mathrm{g} / \mathrm{g}$ ms & \% reducción & URF/g biomasa & \%Reducción \\
\hline $\mathbf{0}$ & $6633 \pm 658$ & 0 & $1.24 \mathrm{e}+09 \pm 1.57 \mathrm{e}+08$ & 0 \\
\hline $\mathbf{1}$ & $6030 \pm 1453$ & 9 & $1.24 \mathrm{e}+09 \pm 1.07 \mathrm{e}+08$ & 0 \\
\hline $\mathbf{1 0}$ & $5062 \pm 585$ & 24 & $1.02 \mathrm{e}+09 \pm 1.91 \mathrm{e}+08$ & 18 \\
\hline $\mathbf{5 0}$ & $\mathbf{1 9 3 7 \pm \mathbf { 6 7 2 }} \mathbf{a}$ & $\mathbf{7 2}$ & $\mathbf{5 . 9 9 e}+\mathbf{0 8} \pm \mathbf{6 . 6 0 e}+\mathbf{0 7} \#$ & $\mathbf{5 2}$ \\
\hline $\mathbf{1 0 0}$ & $\mathbf{1 3 7 4} \pm \mathbf{1 0} \mathbf{a}$ & $\mathbf{7 9}$ & $\mathbf{5 . 7 6 e + 0 8} \pm \mathbf{1 . 0 6}+\mathbf{0 8} \#$ & $\mathbf{5 3}$ \\
\hline
\end{tabular}




\subsubsection{Efecto del NAC sobre la expresión de los genes de la ruta biosintética: lovE y}

lovF.

Para revisar si el efecto observado (de disminución) en la producción de lovastatina, se debió a una afectación del NAC sobre los genes de la ruta biosintética de la lovastatina, se realizó un análisis de Northern de los genes $l o v E$ y $l o v F$, (que codifican para el factor transcripcional de la vía y Policétido Sintasa respectivamente) tanto para FS como FL.

\subsubsection{Análisis de Northern de los genes $\quad$ lovE y lovF en FS.}

El análisis de Northern de los genes $\operatorname{lov} E$ y $\operatorname{lov} F$, indicó disminuciones en su nivel de acumulación de transcritos para ambos genes (Fig. 26). Y los resultados se detallan a continuación.

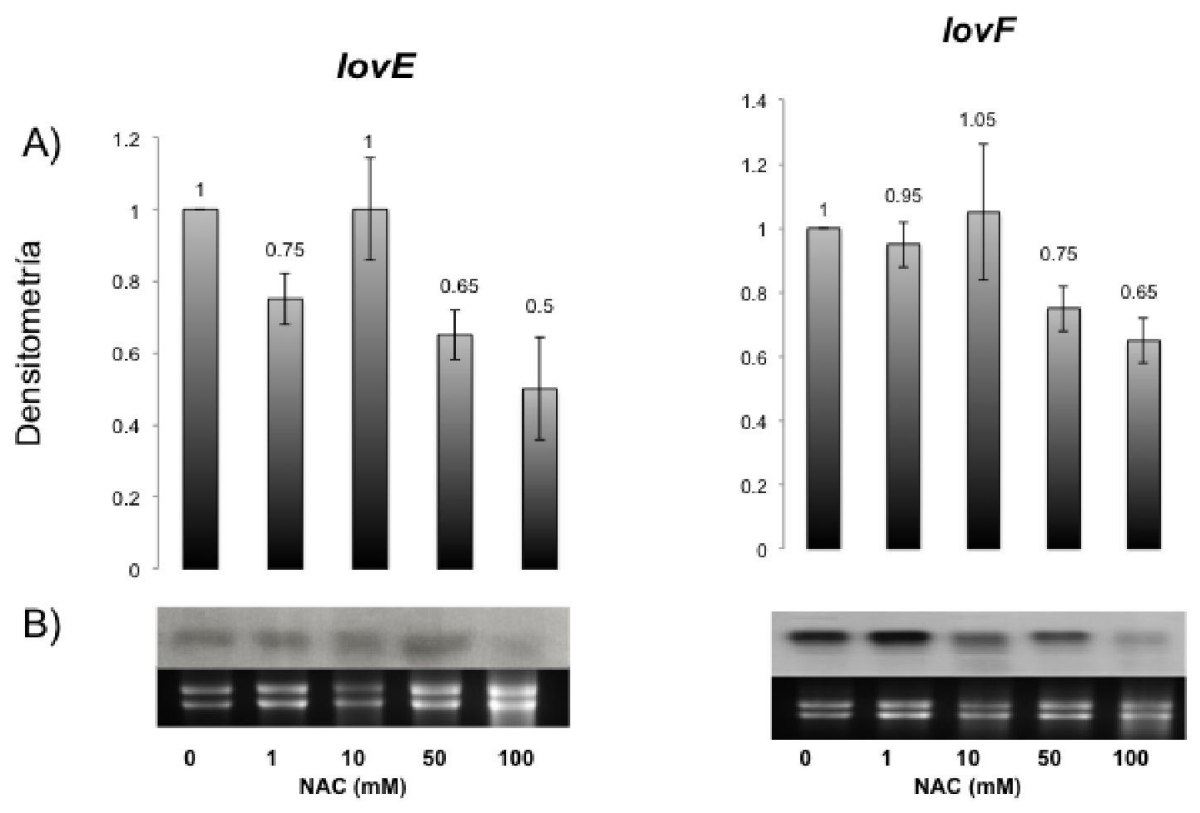

Fig. 26 Northern-blot de los genes $l o v E$ y lovF en FS. La intensidad de las bandas (señales) fueron cuantificadas por densitometría empleando el software ImageJ (versión 1.43u) y los resultados se normalizaron con la carga de rRNA (teñido con bromuro de etidio). A) Los resultados de la normalización de los tratamientos se presentan como fracción, considerando que la banda correspondiente a la muestra control (0) es 1 (es decir, el 100\%), se muestran los promedios de las densitometrías de 2 réplicas independientes. B) Se muestra el resultado de uno de los Northerns obtenidos de los genes lovE y $l o v F$. 


\subsection{Análisis de $l o v E$.}

Para el caso del gen $\operatorname{lovE}$ (Fig. 26) se observó un decaimiento en el nivel de transcritos del $25 \%$ con $1 \mathrm{mM}$ ( $9 \%$ de disminución en lovastatina), del 35\% con $50 \mathrm{mM}$ (72\% disminución de lovastatina) y de un 50\% con $100 \mathrm{mM}$ (79\% de disminución de lovastatina) (Ver Tabla 6). Cabe mencionar que según los datos de densitometría obtenidos, la muestra proveniente del tratamiento con $10 \mathrm{mM}$, no mostró cambios en el nivel de expresión, sin embargo se obtuvo un decremento del 24\% en el nivel de producción del metabolito (no significativo).

Estos resultados mostraron que con concentraciones altas de NAC (50 y $100 \mathrm{mM})$ se lograron disminuciones significativas en la producción de lovastatina (ver Tabla 6) y esto puede deberse a un decaimiento en el nivel de transcritos de $l o v E$ del 35 y $50 \%$ respectivamente.

\subsection{Análisis de $l o v F$.}

El gen $l o v F$ que codifica para la Policétido Sintasa (LDKS), se utilizó como un indicador del comportamiento de los genes biosintéticos de lovastatina. La expresión de este gen mostró un comportamiento a la baja con el empleo del NAC. Se obtuvo un ligero decremento del 5\% empleando1 $\mathrm{mM}$ del NAC, mientras que con $10 \mathrm{mM}$ no se mostraron cambios, empleando 50 mM se observó un decremento en el nivel de transcritos de un 25\% (con 72\% de disminución en lovastatina, que fue significativo) y el mínimo nivel de transcritos se observó con $100 \mathrm{mM}$ de NAC, ya que decayó un 35\% (y un 79\% de disminución en lovastatina) (ver Tabla 6 y Fig. 26). 


\subsubsection{Análisis de Northern de los genes $l o v E$ y $l o v F$ para FL.}

lovE

A)

A)

B)

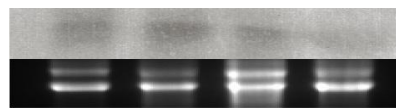

0

50

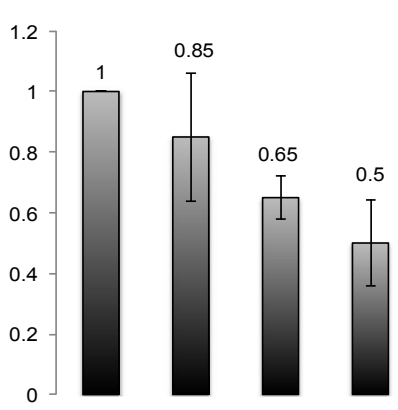

NAC (mM)

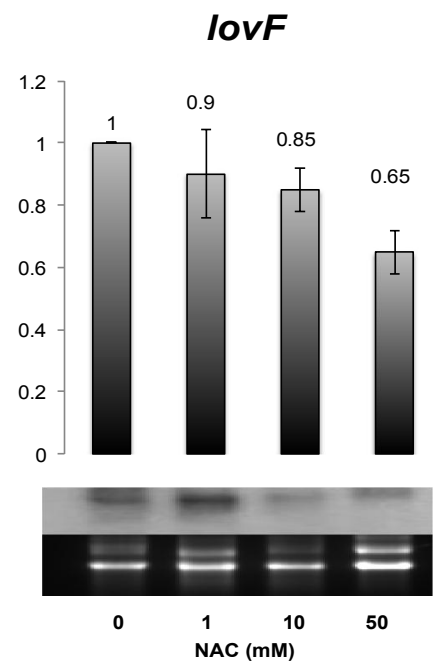

Fig. 27 Northern-blot de los genes $l o v E$ y lovF en FL. La intensidad de las bandas (señales) fueron cuantificadas por densitometría empleando el software ImageJ (versión 1.43u) y los resultados se normalizaron con la carga de rRNA (teñido con bromuro de etidio). Los resultados de la normalización de los tratamientos se presentan como fracción, considerando que

la banda correspondiente a la muestra control (0) es 1 (es decir, el 100\%). A) Los resultados de la normalización de los tratamientos se presentan como fracción, considerando que la banda correspondiente a la muestra control ( 0$)$ es 1 (es decir, el $100 \%$ ), se muestran los promedios de las densitometrías de dos réplicas independientes. B) Se muestra el resultado de uno de los Northerns obtenidos de los genes $l o v E$ y $l o v F$.

\subsection{Análisis de $\quad l o v E$.}

El perfil de acumulación de transcritos del gen $\operatorname{lovE}$, mostró una tendencia a la baja y se observó que, a mayor concentración de NAC, mayor decremento en el nivel de transcritos de este gen. Con el empleo de $1 \mathrm{mM}$ de NAC, se observó un decremento de un 15\%, y con el empleo de 10 y $50 \mathrm{mM}$, se obtuvieron decrementos del $35 \%$ y $50 \%$ en el nivel de transcritos de $l o v E$ respectivamente (Fig. 27).

El nivel de transcritos de este gen, influyó en el nivel de biosíntesis de lovastatina. Así que con los decrementos obtenidos, se logró disminuir la biosíntesis del metabolito en un 9, 64 y $71 \%$ para 1,10 y $50 \mathrm{mM}$ respectivamente (Tabla 4).

\subsection{Análisis de lovF .}

La expresión del gen lov $F$ mostró que el empleo de 1 y $10 \mathrm{mM}$ de NAC, resultaron en decrementos del 10 y $15 \%$ y con el empleo de $50 \mathrm{mM}$ se observó un decremento del $35 \%$ en el nivel de transcritos de este gen. 
De este modo, al realizar un Análisis de Regresión Lineal Simple relacionando en el nivel de transcritos de lov $F$ vs producción de lovastatina (Tabla 4), se obtuvo un índice de correlación $\mathrm{R}^{2}=0.94$, lo cual indica una estrecha relación entre ambas variables.

\subsection{Efecto de oxidantes exógenos sobre la producción de lovastatina.}

Para tener un panorama más amplio del papel de las ROS sobre la biosíntesis de lovastatina, se emplearon oxidantes exógenos como el $\mathrm{H}_{2} \mathrm{O}_{2}$ y el paraquat.

\subsubsection{Efecto de oxidantes en cultivo en caja de Petri.}

Se suplementó los oxidantes $\mathrm{H}_{2} \mathrm{O}_{2}$ y paraquat desde el inicio del cultivo, y se observó en general, que el empleo de estos oxidantes exógenos, aumentaron la producción de lovastatina en cultivo sólido realizado en caja de Petri.

La producción de lovastatina, se incrementó proporcionalmente de acuerdo a la concentración de $\mathrm{H}_{2} \mathrm{O}_{2}$ empleada, sin embargo, el aumento sólo fue significativo (de acuerdo a la prueba estadística de Dunnet $(\mathrm{p}<0.05))$ empleando $150 \mathrm{mM}$ en el medio, obteniéndose un incremento de $233.3 \%$ con respecto al control (Fig. 28).

Este efecto fue similar al emplear paraquat (generador de superóxidos), ya que con concentraciones de 1,10 y $25 \mathrm{mM}$, se lograron obtener aumentos con respecto al control, del 64,149 y $106 \%$ respectivamente (Fig. 28).

Sin embargo, el aumento de la producción fue sólo significativo con el empleo del 10 y 25 $\mathrm{mM}$ de paraquat (según la prueba estadística de Dunnet $(\mathrm{p}<0.05)$. 


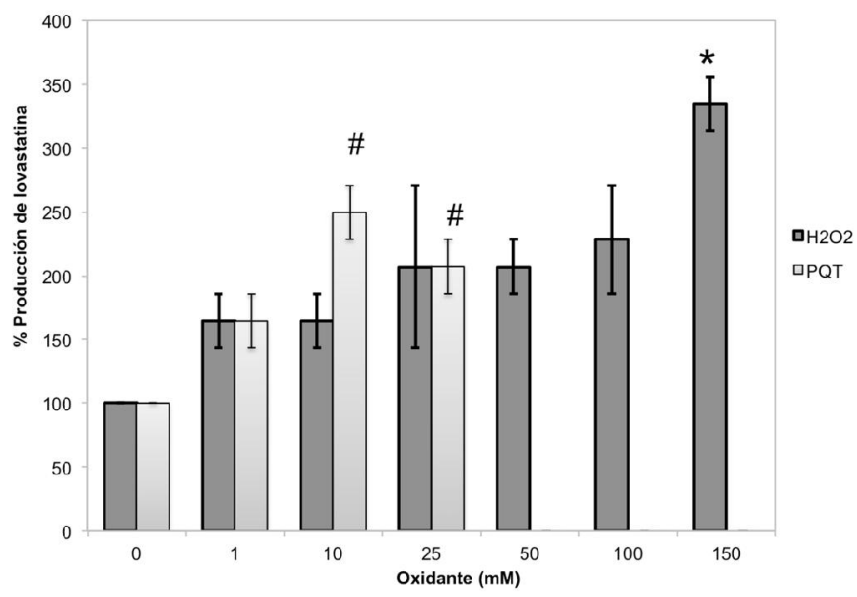

Fig. 28 Producción de lovastatina (en \%) en cultivo sólido en caja de Petri al día 10 al suplementar diferentes concentraciones de $\mathrm{H}_{2} \mathrm{O}_{2}$ y paraquat (PQT). Los símbolos “*” y “\#”, muestran diferencias significativas de muestras tratadas con $\mathrm{H}_{2} \mathrm{O}_{2}$ y paraquat respectivamente, comparado contra el control, esto de acuerdo a la prueba de comparaciones múltiples de Dunnet $(\mathrm{p}<0.05)$.

Cabe señalar, que el empleo del $\mathrm{H}_{2} \mathrm{O}_{2}$ no tuvo ningún efecto sobre el crecimiento y/o morfología del hongo, sin embargo, el empleo de paraquat alteró negativamente tanto el crecimiento como la morfología del hongo a partir de $10 \mathrm{mM}$ (Fig. 29).

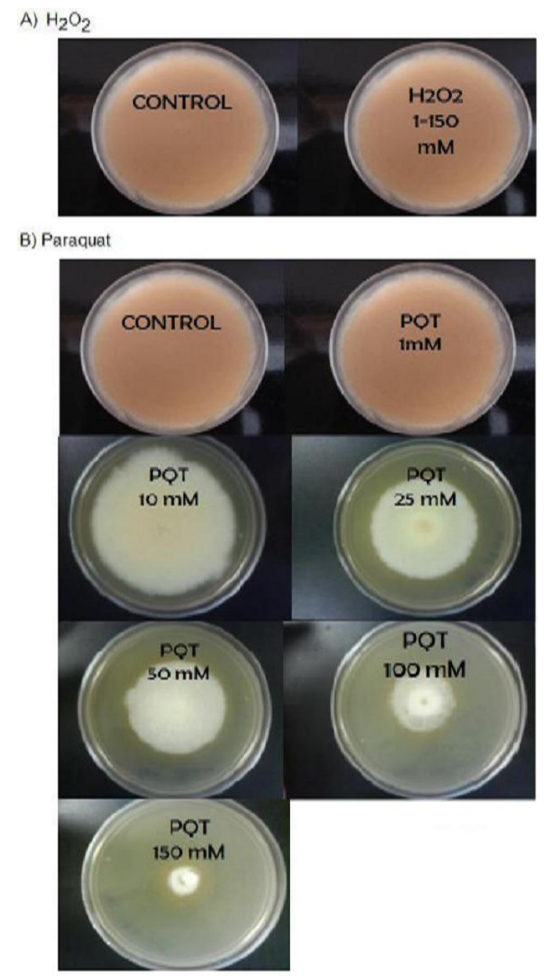

Fig. 29 Efecto de los oxidantes $\mathrm{H}_{2} \mathrm{O}_{2}$ y paraquat (PQT) sobre la morfología de Aspergillus terreus al día 10 en caja de Petri. 


\subsubsection{Efecto del $\mathrm{H}_{2} \mathrm{O}_{2}$ en FL.}

En un primer ensayo, se probaron 3 concentraciones distintas de $\mathrm{H}_{2} \mathrm{O}_{2}$ (ver métodos para medir concentración): 50, 150 y $200 \mathrm{mM}$, que fueron suplementados desde el tiempo 0.

Los resultados mostraron que el tratamiento por $\mathrm{H}_{2} \mathrm{O}_{2}$ no alteró la producción de lovastatina, ya que el análisis de varianza (ANOVA) no detectó cambios $(\mathrm{p}=0.2238)$. En cuanto a la producción de biomasa, de igual manera no se observaron cambios significativos por el tratamiento con el peróxido de hidrógeno, según el análisis de ANOVA ( $p=0.08$ ) (ver Fig. $30)$.

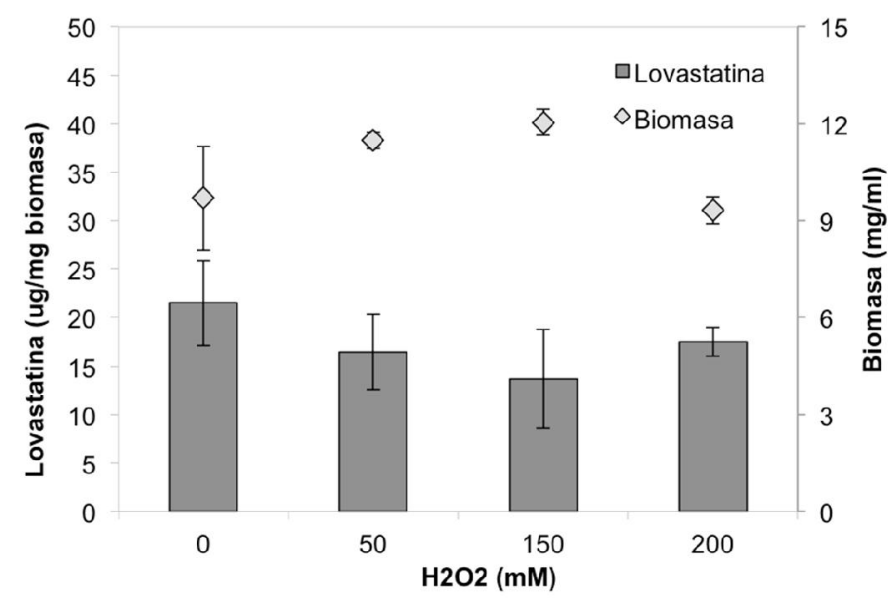

Fig. 30 Efecto de diferentes concentraciones de $\mathrm{H}_{2} \mathrm{O}_{2}$ al día 3 de la FL, sobre la producción específica de lovastatina ( $\square$ ) y sobre la producción de biomasa $(\diamond)$. En ambos parámetros, no se observaron cambios significativos.

En otro ensayo, se suplementó $\mathrm{H}_{2} \mathrm{O}_{2} 50 \mathrm{mM}$ a diferentes tiempos durante la trofofase de FL (a $0,15,20 \mathrm{~h}$ y una doble suplementación en un mismo cultivo a las $15 \mathrm{~h}$ y posteriormente a las 20h).

En los resultados mostrados en la Fig. 31 se observó que la adición de $\mathrm{H}_{2} \mathrm{O}_{2} 50$ mM desde las $0 \mathrm{~h}$ y a las $15 \mathrm{~h}$, ejerció un efecto negativo sobre la producción específica, también pudo observarse un aumento de aproximadamente el $20 \%$ en el nivel de producción cuando se añadió el oxidante a las 20h. Sin embargo, el Análisis de varianza (ANOVA) no detectó diferencias significativas en cuanto a los resultados obtenidos por el tratamiento, en cuanto a producción específica $(\mathrm{p}=0.1640)$ y biomasa $(\mathrm{p}=0.3577)$. 


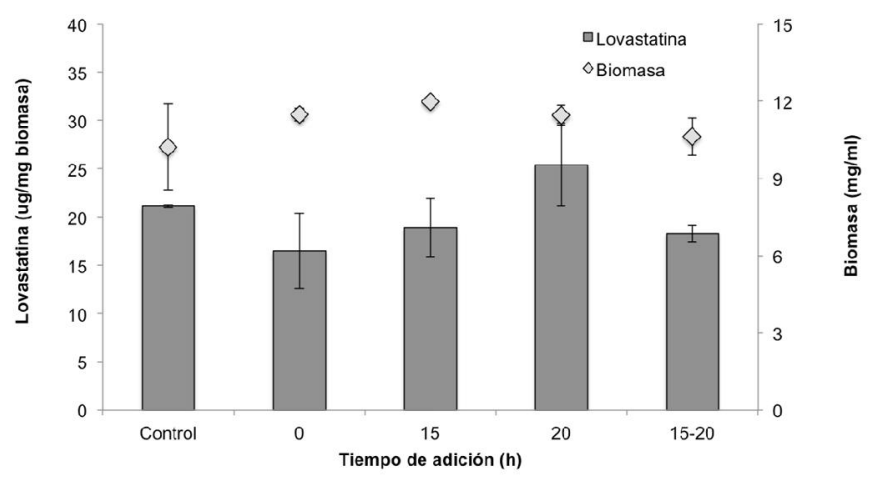

Fig. 31 Efecto de la adición de $\mathrm{H}_{2} \mathrm{O}_{2} 50 \mathrm{mM}$ a diferentes tiempos de la $\mathrm{FL}$ al día 3 sobre la producción específica de lovastatina $(\square)$ y sobre la producción de biomasa $(\diamond)$. En ambos parámetros, no se detectaron diferencias significativas al aplicar el Análisis de Varianza.

\subsubsection{Efecto del $\mathrm{H}_{2} \mathrm{O}_{2}$ sobre la biosíntesis de lovastatina en FS.}

El ensayo realizado en FS, suplementando el medio de producción con diferentes concentraciones de $\mathrm{H}_{2} \mathrm{O}_{2}$, mostró que el oxidante tuvo un efecto negativo sobre la biosíntesis de lovastatina y biomasa. Esto se observó al emplear concentraciones de 10 y $50 \mathrm{mM}$ del oxidante, donde la caída en la producción fue significativa (la disminución fue del 98\%, prácticamente se abolió) (Fig. 32).

Cabe mencionar que debido a que el sistema de FS es heterogéneo, no fue factible hacer un ensayo donde se pudiera aplicar a distintos tiempos del cultivo. 


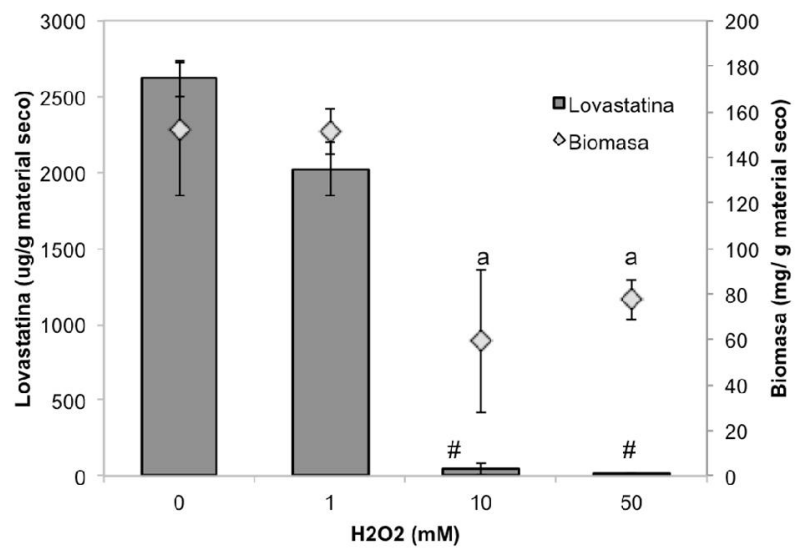

Fig. 32 Efecto de varias concentraciones de $\mathrm{H}_{2} \mathrm{O}_{2}$ sobre la biosíntesis de lovastatina y biomasa, al final del día 3 (72h) de FS. $\mathrm{El}$ análisis de ANOVA mostró que existen diferencias, y el análisis de Dunnet encontró diferencias significativas $(\mathrm{p}<0.05)$ en la producción de lovastatina con 10 y $50 \mathrm{mM}$ (\#) y la biomasa (a).

\subsection{Mecanismo que pueden regular la biosíntesis de lovastatina.}

Los estudios realizados con el antioxidante, demostraron que la biosíntesis de lovastatina está regulada al menos parcialmente por la acumulación de ROS.

Con el objeto de proponer el (los) posible(s) mecanismo(s) por el (los) cual(es) pueden las ROS influenciar la biosíntesis de lovastatina, se realizó un análisis in silico, de los promotores de los genes $\operatorname{lovE}$ (factor transcripcional de la ruta biosintética de lovastatina), $\operatorname{lov} F$ (LDKS o Policétido Sintasa).

Para realizar el análisis de cada uno de los promotores, se tomaron de cada uno, $1000 \mathrm{pb}$ corriente arriba del codón de inicio de traducción (ATG) de cada gen y se analizaron con los programas (software) descrito en la sección de MATERIALES Y MÉTODOS.

\subsubsection{Análisis in silico del promotor del gen lovE.}

El gen $\operatorname{lov} E$ codifica para un factor transcripcional del tipo dedos de zinc $\left(\mathrm{Zn}_{2} \mathrm{Cys}_{6}\right)$ que regula la expresión de genes, cuyos productos participan en la ruta de biosíntesis de lovastatina (Kennedy 1999; Bok \& Keller 2004). 
Para realizar el análisis de los promotores, estos se localizaron dentro del genoma publicado por el Broad Institute ${ }^{16}$. La ubicación de la secuencia codificadora del gen $l o v E$ dentro del genoma está descrita en la Tabla 7.

Tabla 7 Posición del gen lovE en el genoma de Aspergillus terreus obtenido del Broad Institute.

\begin{tabular}{|l|l|}
\hline Locus & ATEG_09966.1 \\
\hline Gene Name & hypothetical protein similar to polyketide \\
\hline Gene Product Names & hypothetical protein similar to polyketide \\
\hline Location & A. terreus: Supercontig 16:57546-59057+ \\
\hline Length & Gene: $1512 \mathrm{nt}$; Protein: 503 aa \\
\hline
\end{tabular}

Para localizar el promotor, se tomaron $1000 \mathrm{pb}$ corriente arriba de la posición del ATG (posición 57546), es decir, el promotor se consideró de la posición 56546 a la 57545 (Fig. $33)$.

\footnotetext{
${ }^{16}$ El proyecto de secuenciación de Aspergillus terreus NIH 2624 es parte del Broad Fungal Genome Initiative y fue fundado por el National Institute of Allergy and Infectious Disease (NIAID) a través del Broad's Sequencing Center (MSC). El acceso a la base de datos es: http://www.broadinstitute.org/annotation/genome/aspergillus_group/MultiHome.html).
} 


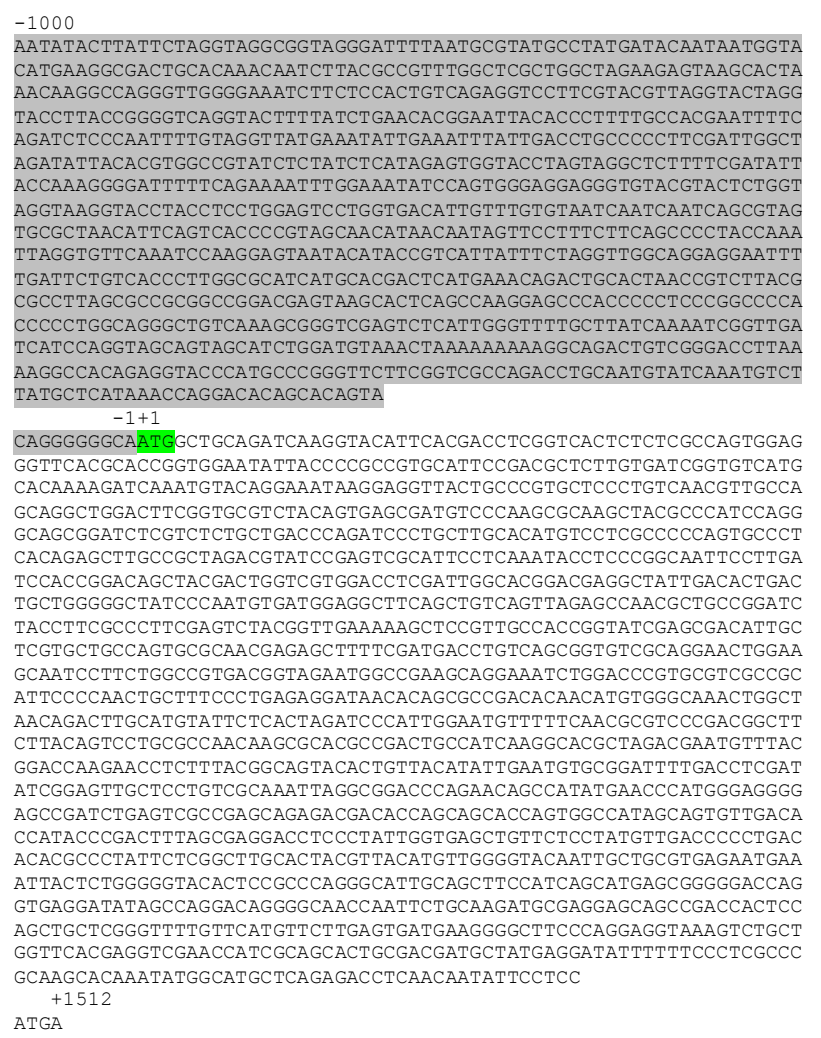

Fig. 33 Promotor (en gris) junto con la secuencia codificadora del gen lovE, ubicado en el supercontig 16: 56546-59057 (+).

Un análisis realizado por el programa MEME, encontró 3 motivos conservados dentro del promotor de estudio (Fig. 34).

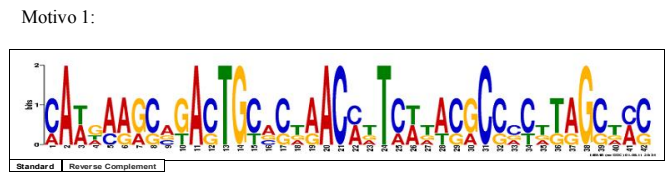

Motivo 2:

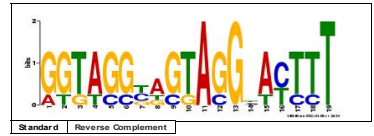

Motivo 3

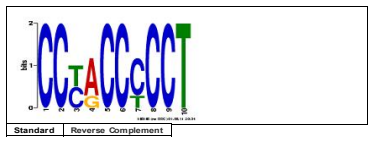

Fig. 34 Motivos conservados encontrados por el programa MEME en el promotor del gen lovE.

Posteriormente, se realizó un análisis con las herramientas GOMO y JASPAR, para poder pronosticar o predecir que Factores Transcripcionales pueden unirse a estos motivos o sitios de unión. 
La Fig. 35 muestra en resumen los posibles sitios de unión a Factores Transcripcionales putativos que responden a diferentes estímulos como EOX o estrés nutricional. Este resultado in silico mostró que el promotor es rico en posibles sitios de unión que en su mayoría responde a EOX como Skn7, Ap-1 (homólogo de Atyap1), Msn2/4, Nrf2 y NF-K-B (Factores Transcripcionales de respuesta a EOX en mamíferos), lo cual sugiere que este tipo de estrés puede regular a través de $l o v E$ la biosíntesis de lovastatina.

Un análisis más detallado se encuentra en el APÉNDICE I.

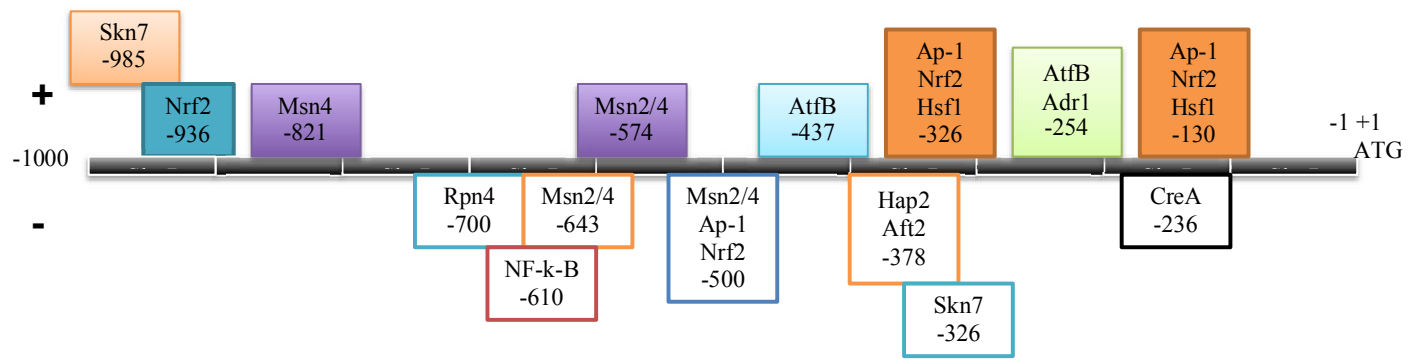

Fig. 35 Posibles sitios de unión de Factores Transcripcionales (que responden a diferentes tipos de estímulos. Nótese que en su mayoría, son Factores Transcripcionales que responden a EOX (Skn7, Nrf2, Msn2/4, AtfB, Ap-1, Aft2 y NF-kB) y algunos más que responden a estrés nutricional (CreA, Adr1, Rpn4). Algunos sitios de unión se encontraron sobre la cadena principal (+, sobre la línea) y algunos otros, se encontraron en la cadena antisentido (-, debajo de la cadena).

\subsubsection{Análisis in silico del promotor $l o v F$.}

De manera semejante al análisis del promotor de $l o v E$, se realizó el mismo procedimiento para el promotor de $\operatorname{lov} F$. La información para la localización del gen dentro del genoma de A. terreus mediante el genoma publicado por el Broad Institute, se presenta en la siguiente tabla.

Tabla 8 Localización del gen $l o v F$ dentro del genoma de A. terreus (Broad Institue).

\begin{tabular}{|l|l|}
\hline Locus & ATEG 09968.1 \\
\hline Gene Name & hypothetical protein similar to polyketide synthase \\
\hline Gene Product Names & hypothetical protein similar to polyketide synthase \\
\hline Location & A. terreus: Supercontig 16: 63664-71705+ \\
\hline Length & Gene: $8042 \mathrm{nt}$; Protein: 2452 aa \\
\hline
\end{tabular}


Para localizar el promotor, se tomaron $1000 \mathrm{pb}$ corriente arriba de la posición del ATG (posición 63664), es decir, el promotor se consideró de la posición 62664 a la 63664 (Fig. $36)$.

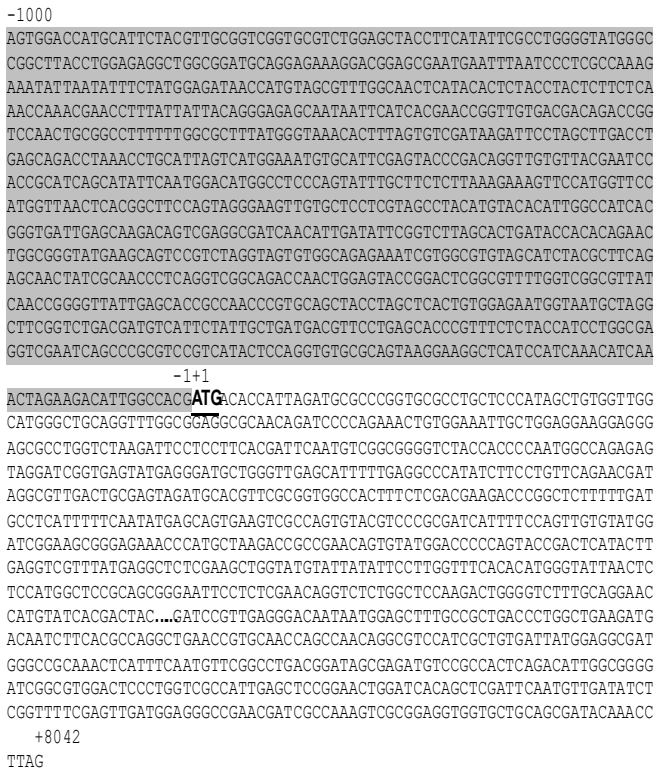

Fig. 36 Promotor (en gris) junto con la secuencia codificadora del gen $l o v F$, ubicado en el supercontig 16: 63664-71705(+)

El análisis del promotor de $l o v F$, con MEME y JASPAR, dio como resultado los sitios de unión a diferentes Factores Transcripcionales que responden a diferentes situaciones de estrés. En el caso de EOX, se encontraron al menos 10 sitios de unión para el Factor Transcripcional Skn7 (homólogo a SrrA, en hongos), 2 sitios de unión para Ap-1 (homólogo a Yap1 en levaduras), y un sitio para Nrf2 (ó NFE2L1::MafG), entre otros, como Msn2 y Yap5.

Se encontraron también putativos sitios de unión a Factores Transcripcionales que responden a otras situaciones, i.e. Gln3 responde a deprivación de nitrógeno mediante la vía TOR. Además se hallaron múltiples sitios para Factor Transcripcional que se relacionan con desarrollo como Mata1, Arr1, Hap1/2, etc.

La Fig. 37 muestra la posición de los posibles sitios de unión a diferentes Factores Transcripcionales que responden a EOX. Un análisis más detallado del promotor, se muestra en el APENDICE II. 


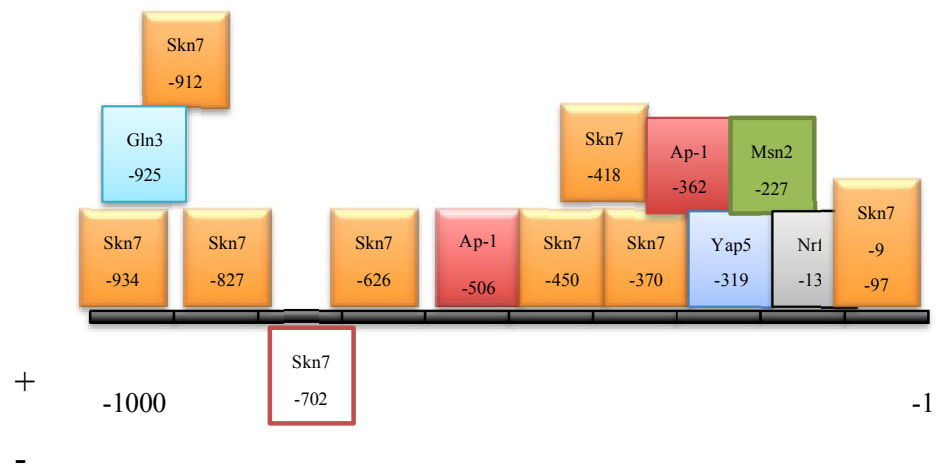

Fig. 37 Posibles sitios de unión a Factores Transcripcionales que responden a EOX en el promotor de lovF. Nótese que en su mayoría son sitios de unión a Skn7 (en levadura), homólogo a SrrA (en Aspergillus).

\subsubsection{Perfiles de expresión de genes que codifican para los Factores Transcripcionales : $\operatorname{srr} A$ y Atyap1.}

Con el objeto de sugerir un posible mecanismo de regulación de biosíntesis de lovastatina a través de ROS, y a partir del análisis in silico realizado anteriormente, se presume o sugiere que la biosíntesis de lovastatina puede ser regulada a través de algunos de estos Factores Transcripcionales, por lo que se decidió observar los perfiles de expresión de los genes que codifican para los factores transcripcionales $\operatorname{SrrA}^{17}$ (homólogo a Skn7, indicador de la ruta MAPK quinasas) y AtYap1 (homólogo a Yap1, ortólogo de AP-1), tanto en FS como en FL.

De manera semejante y para tener un panorama general, el perfil de expresión de los genes anteriores, se comparó con la expresión de los genes lovE y lov $F$ como indicadores del metabolismo secundario y sólo en el caso de FS, del gen $\operatorname{brlA}$, estos 3 genes como indicador de la conidiación, así mismo, también con la expresión del gen $\operatorname{sodl}$ y fadA, el primero como indicador del EOX y el segundo como indicador de la vía cAMP-PKA. La expresión de los genes fadA y brlA, se tomaron como referencia de los resultados de la tesis de maestría para efectos comparativos (Miranda et al. 2008).

${ }^{17}$ El análisis de Northern-blot fue realizado en conjunto con Mariel Mendoza Rico (ver tesis). 


\subsubsection{1. $\quad$ Expresión de $\operatorname{srr} A$ y Atyap1 en FS.}

La Fig. 38 mostró los siguientes resultados. El análisis de Northern realizado para el gen srrA, reveló que este se encendió poco antes de iniciarse la idiofase (observado por el inicio de expresión del gen $\operatorname{lovE}$ y $\operatorname{lov} F$ ) y permaneció así hasta el final del cultivo. No así el gen Atyap1, ya que este se encendió durante la trofofase.

Con respecto al gen $f a d A$, no se observaron cambios en sus niveles de expresión, ya que estos fueron constantes durante la trofofase e idiofase.

En relación al gen sod1, por su patrón de expresión, sugiere que este gen puede ser regulado por Atyapl (un análisis in silico en el promotor de sod1, mostró sitios putativos de unión a AP-1 o Yap1, datos no mostrados), ya que ambos tanto Atyapl como sodl están encendidos en los mismos puntos de tiempo y es más notable en trofofase.

En relación al inicio de expresión de los genes del metabolismo secundario (lovE, lov $F$ y brlA), coincidieron con el patrón de expresión del gen srrA. 
Trofofase $\boldsymbol{\Downarrow} \quad$ Idiofase

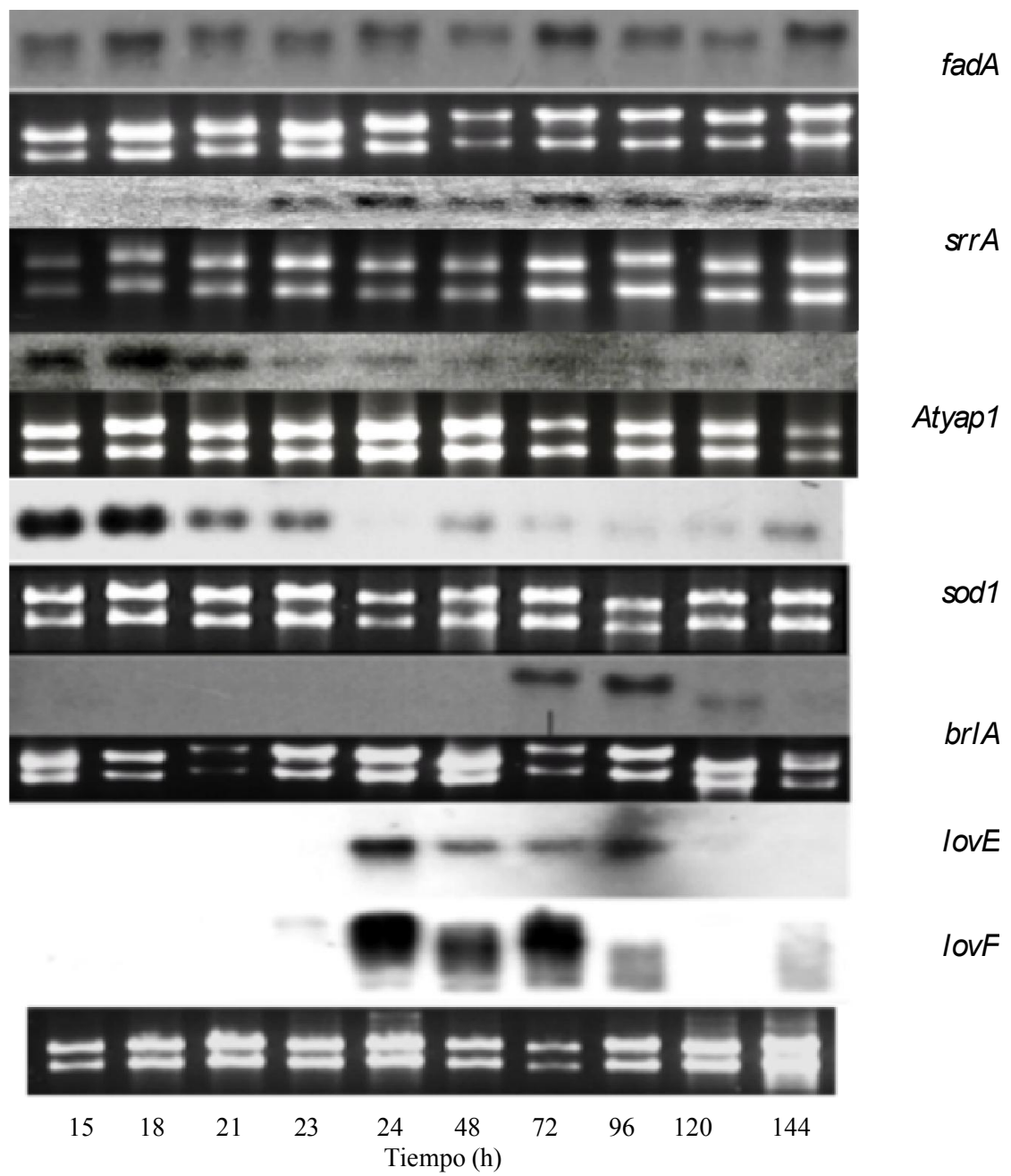

Fig. 38 Análisis de Northern de los genes srrA, Atyapl, fadA, sod1, brlA, lovE y lovF, a diferentes tiempos de trofo- $(15,18$, 21 y $23 \mathrm{~h}$ ) y de idiofase ( $24 \mathrm{~h}$ en adelante) de la FS. Para cada uno de los genes se muestra su rRNA empleado como control de carga para cada gen en particular. La flecha en la parte superior indica que las $24 \mathrm{~h}$ es el inicio de la idiofase, observado por el inicio de expresión de $\operatorname{lov} E$ y por medio de una cinética de producción de lovastatina. 


\subsubsection{2. $\quad$ Expresión de $\operatorname{srr} A$ y Atyap1 en FL.}

En la Fig. 39 se muestran los siguientes resultados. El análisis de Northern realizado para el gen $\operatorname{sr} A$, no mostró un patrón de comportamiento como en FS, dado que se observó que se expresó en diferentes tiempos de la trofofase, prácticamente se abolió en el inicio de la idiofase (a las 24h) y se encendió intermitentemente durante toda la idiofase, aunque no es muy claro.

Para el caso de la expresión del gen Atyap1, se observó que se encendió fuertemente hasta las $18 \mathrm{~h}$, horas antes del inicio del metabolismo secundario (observado por la expresión de los genes $l o v E$ y lov $F$ ) y decayó considerablemente después de las $18 \mathrm{~h}$ hasta el final del cultivo.

Por otra parte, el gen $f a d A$ mostró un comportamiento distinto al de FS. Se observó que éste se expresa fuertemente durante toda la trofofase (hasta las $24 \mathrm{~h}$ ), después de este tiempo, la expresión de este gen decayó considerablemente.

Para el caso de FL, se encontró que tanto los genes que codifican para Atyapl y fadA, tienen un comportamiento muy similar al de $\operatorname{sod} 1$, el cual también se enciende fuertemente durante la trofofase y decae considerablemente en la idiofase.

Por otra parte, el gen srrA no parece tener un comportamiento definido durante todo el cultivo, pero es claro que se encontró encendido durante la trofofase, y en puntos distintos de tiempo durante la idiofase. 


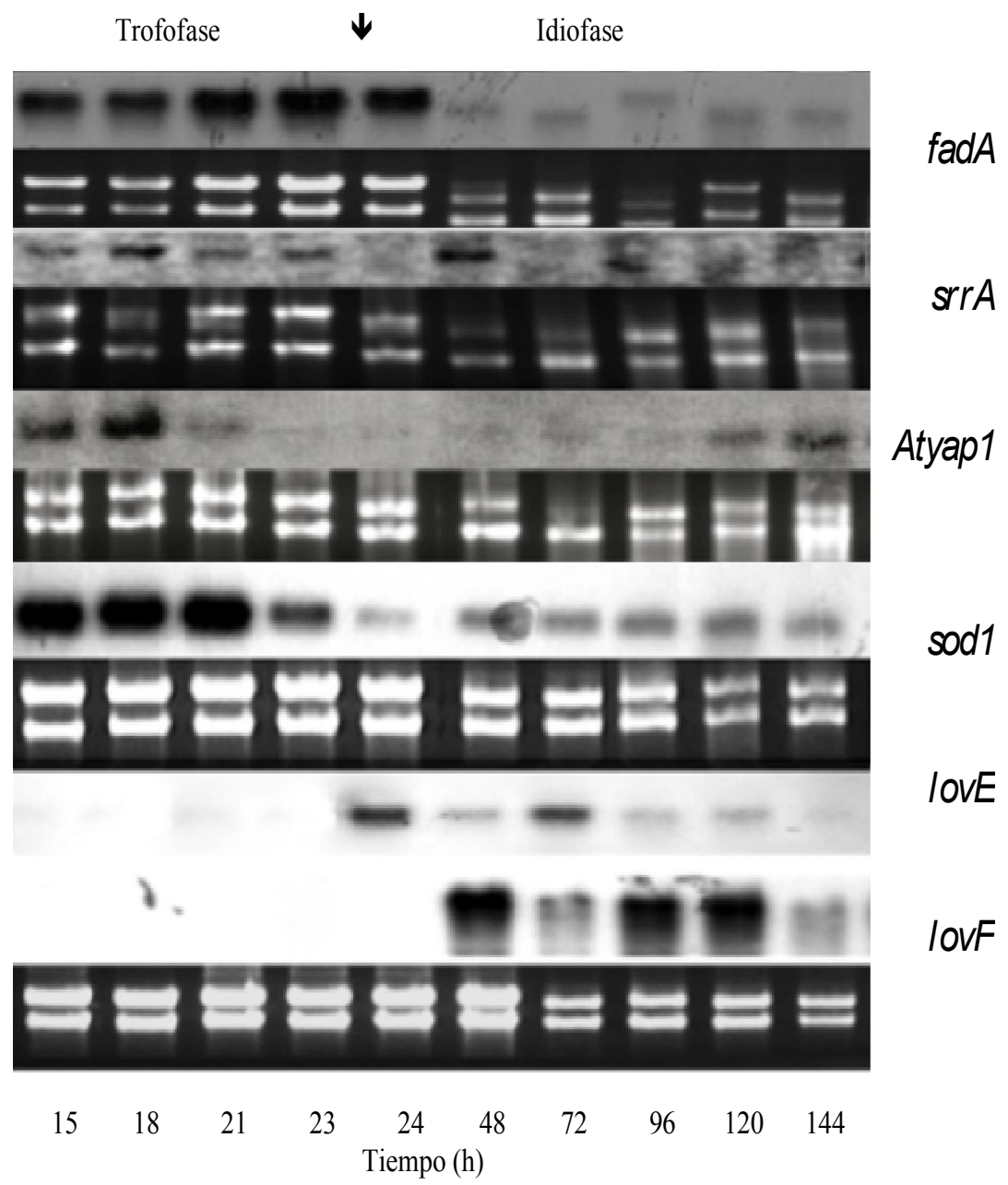

Fig. 39 Análisis de Northern de los genes srrA, Atyap1, fadA, $\operatorname{sod} 1$, lovE y lovF, a diferentes tiempos de la trofo-(de 15 a $23 \mathrm{~h}$ ) y de la idiofase (de $24 \mathrm{~h}$ en adelante) de la FL. Para cada uno de los genes se muestra el rRNA como control de carga empleado para cada gen en particular. La flecha en la parte superior indica que las $24 \mathrm{~h}$ es el inicio de la idiofase, observado por el inicio de expresión de $\operatorname{lov} E$ y por medio de una cinética de producción de lovastatina. 


\subsubsection{Efecto del silenciamiento de Atyap1.}

\subsubsection{Construcción del vector pGdpPkiRNAi-Atyap1.}

En colaboración con Ailed Pérez Sánchez, se logró la amplificación del fragmento del gen de Atyap1 con los oligos yap1RNAi-Fwd y yap1RNAi-Rev (Tabla 3). Se observó que la mejor temperatura de hibridación, fue a $68^{\circ} \mathrm{C}$ (al realizarlo en una prueba con empleando un gradiente con diferentes temperaturas de hibridación) (41-A). Dicho fragmento se clonó dentro del vector $\mathrm{pJET} /$ Blunt, para generar el vector $\mathrm{pJet}$-Atyap1RNAi.

El fragmento de Atyapl con extremos NcoI, se obtuvo de la construcción pJet-Atyap1RNAi después de la digestión con dicha enzima de restricción (Fig. 41-B). El fragmento purificado, se clonó dentro del vector pGpdPki-RNAi (Fig. 14) previamente digerido con NcoI y purificado (Fig. 40).

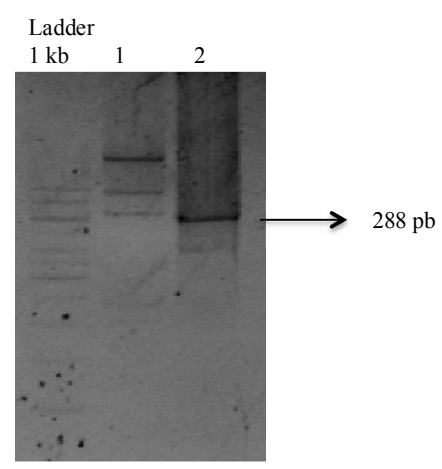

Fig. 40 Caracterización del plásmido pGpdPki-RNAi. Carril 1: plásmido sin digerir. Carril 2: plásmido digerido con NcoI. 
A)

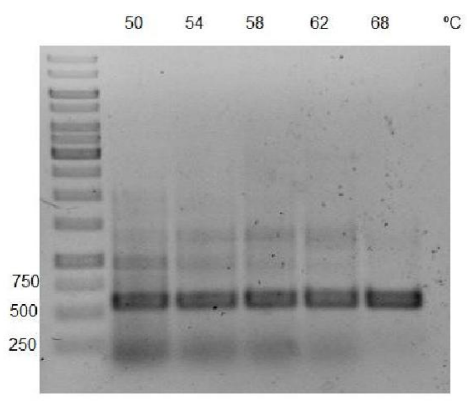

B)

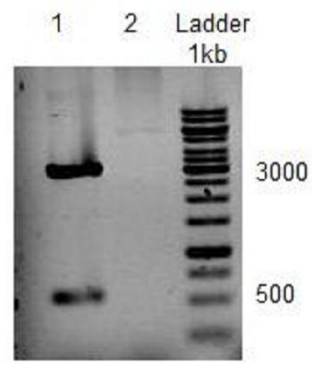

Fig. 41 A) Obtención del fragmento de 553 pb de Atyapl empleando un gradiente de temperaturas de hibridación; B) Caracterización de una de las clonas de $E$. coli DH5 $\alpha$ transformadas con la construcción pJET-Atyap1RNAi seleccionadas, tras una digestión con la enzima de restricción NcoI

De la construcción pJet-Atyap1RNAi, se obtuvo el fragmento del gen Atyap1 mediante la digestión con la enzima NcoI. El producto se clonó dentro del vector pGpdPki-RNAi para generar el vector pGpdPki-Atyap1RNAi. La construcción se verificó mediante la digestión de la enzima $N c o$, cuando generó 2 fragmentos, uno correspondiente al vector (6628 pb) y otro correspondiente al inserto (553 pb) (Fig. 42).

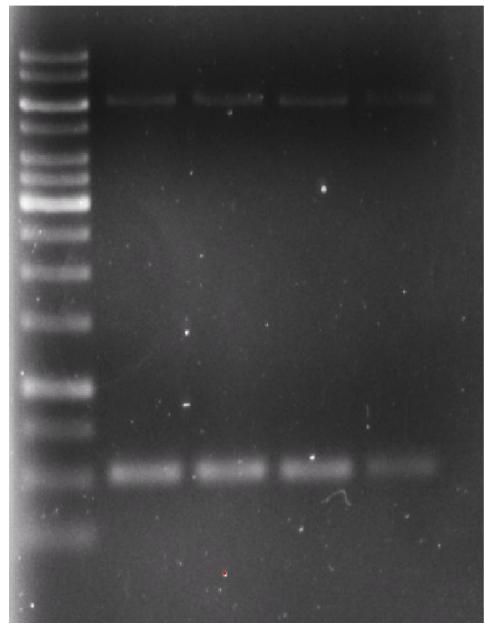

$6288 \mathrm{pb}$

$553 \mathrm{pb}$

Fig. 42 Caracterización de las clonas que poseen la construcción pGdpPkiRNAi-Atyap1 tras la digestión con la enzima $N c o I$.

Con la construcción ya comprobada, se transformó a $A$. terreus por el método de protoplastos generándose 8 transformantes. 


\subsubsection{Caracterización de las transformantes de $A$. terreus con la construcción pGdpPkiRNAi-Atyap1.}

\subsection{Sensibilidad al $\mathrm{H}_{2} \mathrm{O}_{2}$.}

De las transformantes obtenidas, se seleccionaron y analizaron las T1, T5, T7 y T8. De acuerdo a los resultados obtenidos, las transformantes con la construcción de silenciamiento, produjo sensibilidad en las esporas a diferentes concentraciones de $\mathrm{H}_{2} \mathrm{O}_{2}$. La Fig. 43 muestra que las transformantes mostraron marcada sensibilidad a concentraciones mayores de 140 $\mathrm{mM}$ de $\mathrm{H}_{2} \mathrm{O}_{2}$, además, con respecto a la parental, las 4 transformantes redujeron su viabilidad celular a concentraciones de 100 y $120 \mathrm{mM}$ de $\mathrm{H}_{2} \mathrm{O}_{2}$.

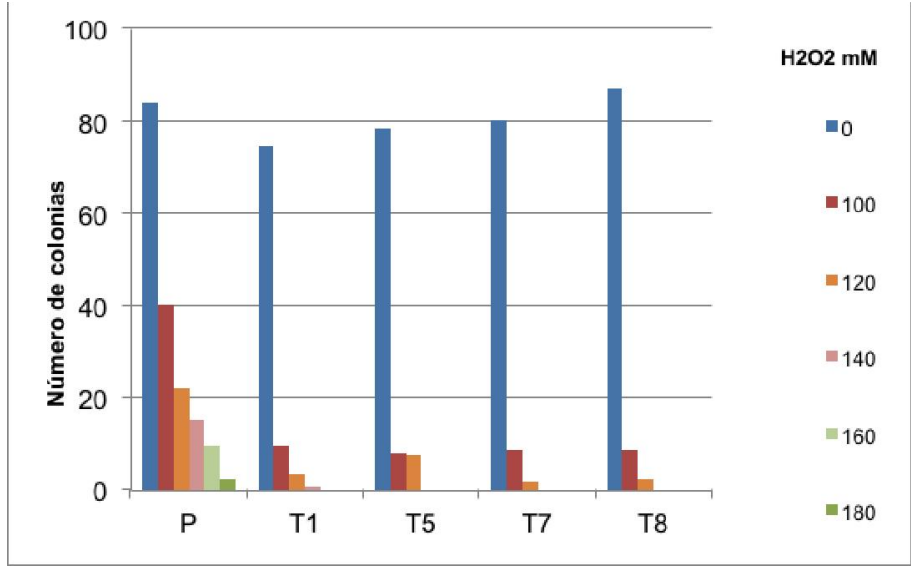

Fig. 43 Sensibilidad de las esporas de A. terreus a $\mathrm{H}_{2} \mathrm{O}_{2}$ : $\mathrm{P}$, cepa parental; $\mathrm{T} 1$ a $\mathrm{T} 8$, transformantes (con la construcción pGdpPkiRNAi-Atyapl) obtenidas de A. terreus. 


\subsection{Esporulación y producción de lovastatina de las transformantes de $A$.}

terreus.

Se realizó una cinética de esporulación de las transformantes de A. terreus, y se observó su comportamiento frente a la cepa parental Fig. 44. Los resultados mostraron que las cepas transformantes, tuvieron una marcada elevación en la producción de esporas, además de que se presentó una producción temprana de éstas. En la cepa parental se observó que la producción empezó entre las 120 y 144 h, mientras que en las transformantes analizadas, se observó que la producción empezó entre las 72 y 96 h. Todo esto se realizó en medio de cultivo en Caja de Petri con medio de producción de lovastatina $1 \mathrm{X}$.

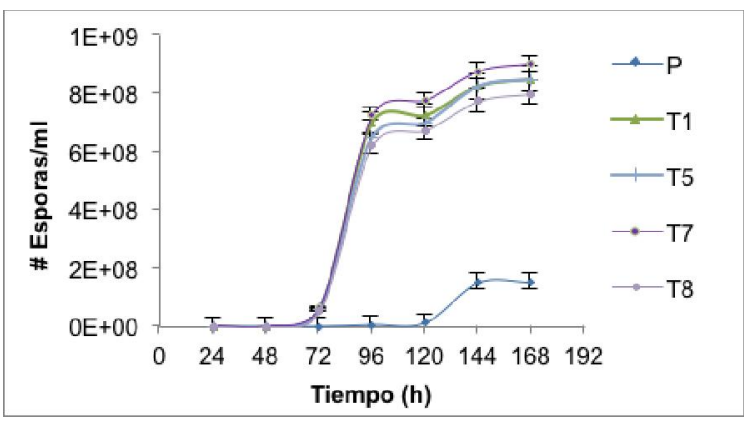

Fig. 44 Cinética de esporulación de las cepas transformantes y la parental (P) de A. terreus.

Es importante señalar que en experimentos preliminares, las transformantes tuvieron un inicio precoz en la biosíntesis de lovastatina (Pérez et al., 2013). Actualmente se está trabajando con una caracterización más profunda de las transformantes obtenidas (Pérez et al., tesis de maestría en desarrollo). 


\subsection{Diferencias entre FS y FL.}

En este trabajo se hizo un esfuerzo para detectar las diferencias entre FS y FL que nos podrían ayudar a tener un mejor entendimiento de las características propias de la fisiología del medio sólido. La primera diferencia inesperada, fue que sodl se expresó mayormente en FL. Por otra parte, cuando este gen se regula a la baja (justo en el inicio de la idiofase), la acumulación de ROS se incrementa considerablemente. En relación a esto, el balance redox (medido por el cociente GSH/GSSG) fue 4 veces mayor en FS con respecto a la FL, durante la trofofase (Tabla 9).

Tabla 9 Diferencias fisiológicas y a nivel de expresión de genes encontradas entre FS y FL

\begin{tabular}{|c|c|c|c|c|}
\hline \multicolumn{2}{|c|}{ PARÁMETRO } & FL & FS & COMENTARIOS \\
\hline \multirow{3}{*}{ 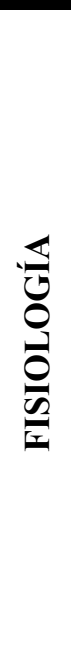 } & $\begin{array}{l}\text { Producción } \\
\text { específica de } \\
\text { lovastatina }\end{array}$ & $\begin{array}{l}38 \mu \mathrm{g} \mathrm{mg}^{-1} \\
\text { biomasa }\end{array}$ & $118.4 \mu \mathrm{g} \mathrm{mg}^{-1}$ biomasa & Al día 7 \\
\hline & $\begin{array}{l}\text { ROS en } \\
\text { idiofase } \\
\text { (valores } \\
\text { promedio) }\end{array}$ & $\begin{array}{l}1 \times 10^{10} \mathrm{URF} / \mathrm{g} \\
\text { biomasa. } \\
\text { Niveles fluctuantes }\end{array}$ & $\begin{array}{l}1.2 \times 10^{9} \mathrm{URF} / \mathrm{g} \text { biomasa. } \\
\text { Niveles constantes }\end{array}$ & $\begin{array}{c}\text { *En ambos, bajos } \\
\text { niveles en } \\
\text { trofofase. } \\
\approx 10 \text { veces menos } \\
\text { en FS. } \\
\text { Aumento } \\
\text { significativo a las } \\
\text { 24h (inicio } \\
\text { idiofase). }\end{array}$ \\
\hline & $\begin{array}{c}\text { GSH/GSSG en } \\
\text { trofofase }\end{array}$ & 5.1 & 22 & $\begin{array}{c}\approx 4 \text { veces mayor en } \\
\text { FS }\end{array}$ \\
\hline \multirow{5}{*}{ 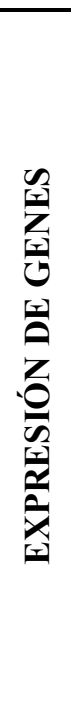 } & sod1 & $\begin{array}{l}\text { Fuerte expresión } \\
\text { en trofofase } \\
\text { ( } 2.5 \text { veces mayor } \\
\text { que en FS) }\end{array}$ & Fuerte expresión en trofofase & $\begin{array}{l}\text { En ambas, } \\
\text { regulación a la baja } \\
\text { en idiofase }\end{array}$ \\
\hline & Atyap 1 & $\begin{array}{l}\text { Expresión fuerte } \\
\text { en trofofase }\end{array}$ & Expresión fuerte en trofofase & $\begin{array}{l}\text { Regulación a la } \\
\text { baja en idiofase }\end{array}$ \\
\hline & $\operatorname{srr} A$ & $\begin{array}{l}\text { Expresión } \\
\text { intermitente en } \\
\text { trofo- e idiofase }\end{array}$ & $\begin{array}{l}\text { Expresión fuerte en trofofase, } \\
\text { regulación a la baja en idiofase }\end{array}$ & \\
\hline & fadA & $\begin{array}{l}\text { Fuerte expresión } \\
\text { en trofo-, baja en } \\
\text { idiofase }\end{array}$ & $\begin{array}{l}\text { Expresión constante durante } \\
\text { trofo- e idiofase }\end{array}$ & $\begin{array}{l}\text { Miranda et al., } \\
2008\end{array}$ \\
\hline & brlA & No se expresó & $\begin{array}{l}\text { Expresión en idiofase, entre } 36 \\
\text { y } 48 \text { h. }\end{array}$ & $\begin{array}{l}\text { Miranda et al., } \\
2008\end{array}$ \\
\hline
\end{tabular}




\section{DISCUSIÓN.}

En los últimos años varios autores han encontrado evidencia de una estrecha asociación entre el estrés oxidante y el desarrollo y la diferenciación de hongos (Aguirre et al. 2006). Además, la diferenciación se ha asociado con el metabolismo secundario (Calvo et al. 2002).

Son pocos los estudios que han relacionado el metabolismo secundario con el EOX, y esto se ha centrado en la biosíntesis de AT (Jayashree \& Subramanyam 2000; Narasaiah et al. 2006), por lo que este trabajo se enfocó en encontrar por primera vez, una relación entre la biosíntesis de lovastatina y el EOX o la producción de ROS.

La lovastatina es un metabolito secundario de importante interés farmacéutico y comercial por sus propiedades anticolesterolémicas, además, se han asociado efectos pleiotrópicos con el empleo de esta y otras estatinas (Barrios-González \& R. Miranda 2010).

Se ha reportado que la producción de este metabolito secundario por $A$. terreus puede llegar a ser hasta 30 veces mayor mediante FS con respecto a la FL (Baños et al. 2009). Estudios moleculares previos, indicaron que una mayor expresión de los genes de la vía de biosíntesis en FS, puede ser responsable de esta alta producción (Barrios-González et al. 2008). A su vez, esto se debe a estímulos ambientales que en FL no están presentes. De hecho, se han logrado identificar varios de estos estímulos (Barrios-González 2012)

Uno de estos estímulos que influye de forma muy importante en una mejor producción en FS, es que el micelio está en contacto directo con el aire, lo cual a su vez genera EOX a través de la formación de ROS.

En estudios anteriores (Miranda et al., 2008), se encontró que el gen sod1 estaba fuertemente expresado durante la trofofase de FS y FL. Inesperadamente, se encontró también que la expresión de sod 1 fue 2.5 veces mayor en FL que en FS.

En ese momento los resultados parecían indicar la existencia de un Periodo de Estrés Oxidativo (PEO) debido a una teórica elevada concentración de ROS que resultaba en un estado más oxidante, el cual antecedía el inicio de la biosíntesis de lovastatina. Esto, pensando en lo reportado por Toledo et al. (1991), quienes encontraron un estado hiperoxidante que precede justamente los procesos de diferenciación en Neurospora crassa (el paso de germinación y el de hifa a hifa aérea-espora). Consideramos que si el paso de trofo- a idiofase se puede entender como un proceso de diferenciación metabólica o bioquímica (Calvo et al. 2002), esperaríamos algo similar: un estado hiperoxidante precediendo el cambio. 
Entonces, la hipótesis original se estructuró en función de los hallazgos en cuanto al perfil de expresión de sod1. Se pensó inicialmente la existencia de un PEO durante la trofofase, en el cual se encontrarían concentraciones elevadas de ROS, y por consiguiente, un estado más oxidante; todo esto justo antes de iniciarse la idiofase de lovastatina en FS y FL. Por lo que la demostración de esta hipótesis se inició realizando a la par FS y FL y la caracterización del PEO.

\subsection{Diferencias de producción de lovastatina en FS y FL: Fisiología especial del medio sólido.}

Rara vez se realizan comparaciones precisas entre FL y FS. Una razón importante de esto es porque la FS generalmente se realiza utilizando sustratos naturales (agroindustriales), por lo que el medio de la FL correspondiente, puede diferir considerablemente (Barrios-González et al. 2005). El sistema FS utilizado en este trabajo (FS sobre soporte inerte) permitió el uso del mismo medio líquido que en FL, impregnado en un soporte inerte (espuma de poliuretano). Este es también un sistema más limpio en el que se pueden hacer comparaciones precisas. De esta manera, el cultivo para la producción de lovastatina en FS y FL se realizó el mismo medio de cultivo (aunque una versión 2.5x se utilizó en FS, ver sección Medios de Cultivo, y ambos presentaron cinéticas de $\mathrm{pH}$ muy similares. Por otra parte, el inicio de la idiofase ocurrió en tiempos similares (aproximadamente a las $24 \mathrm{~h}$ ) en ambos sistemas de cultivo, alcanzado los máximos de producción de lovastatina en los mismos tiempos de cultivo en general (144 h).

La diferencia en la fisiología del medio sólido, fue representado por una mayor producción de lovastatina en FS, así como la esporulación. En FS se produjeron $22.57 \mathrm{mg} / \mathrm{g}$ cultivo seco vs $0.65 \mathrm{mg} / \mathrm{ml}$ de FL (Fig. 15). A menudo se reporta, en estudios comparativos FS vs FL, una mayor producción y productividad de enzimas y de metabolitos en FS (Robinson et al. 2001).

Para poder corroborar la existencia del PEO en trofofase e idiofase de lovastatina, se identificaron ambas fases a nivel fisiológico (Fig. 15) y a nivel molecular (inicio de transcripción de los genes lovE y lovF, ver Fig. 38 y Fig. 39). En ambos sistemas de cultivo, se observó que la idiofase inició a las 24 h, por lo que se tomaron muestras de micelio de diferentes puntos de trofofase y otros tantos de idiofase para iniciar la caracterización del PEO. 


\subsection{Caracterización del PEO: Cuantificación de ROS y balance redox.}

Como ya se mencionó anteriormente, se pensó en la existencia de un PEO que precedía la biosíntesis de lovastatina, por lo que se procedió a caracterizarlo en función de 2 parámetros principales: 1) Cantidad de ROS y 2) Balance REDOX; ambos parámetros nos ayudarían a aclarar si un estado hiperoxidante precede el inicio de idiofase de lovastatina.

Si la inducción de la sodl se interpreta como un indicador de altas concentraciones de ROS, estos resultados parecían indicar la presencia de un estado transitorio hiper-oxidante que estrechamente precede la aparición de la idiofase de lovastatina; aún más cercano que la misma esporulación, ya que la expresión del gen brlA se detectó a las $48 \mathrm{~h}$. Esto sería consistente con el hecho de que el cambio entre las fases de desarrollo (ontogénesis hongos) se produce a través de un estado inestable hiper-oxidante determinado por un aumento en el nivel de ROS en las células (Belozerskaya \& Gessler 2007).

Sin embargo, la medición directa de ROS en el micelio no lo confirmó. Por el contrario, los resultados mostraron que no existía un estado hiperoxidante en la trofofase. En su lugar, se puso de manifiesto un estado oxidante en la idiofase en ambos sistemas de cultivo, el cual continuó durante la mayor parte de la fase de producción. Esto sugiere que las ROS influyen directamente sobre la biosíntesis de la lovastatina.

Estudios realizados por otros autores, habían indicado una correlación positiva entre la acumulación de ROS y la producción de otro metabolito secundario: aflatoxinas (AT). Jayashree y Subramanyam (2000) encontraron mayores niveles de ROS en una cepa toxigénica de Aspergillus parasiticus, en relación con una cepa toxigénica. Por otra parte, las actividades de las enzimas antioxidantes, tales como SOD y GPX, así como los niveles de $\mathrm{GSH}$, fueron todos aumentados durante la progresión de la cepa toxigénica de trofofase a idiofase. Los autores discutieron que las AT son policétidos altamente oxigenados con actividad antioxidante, cuya producción puede ser sometido a la regulación redox. Por otra parte, proponen que las AT junto con las enzimas antioxidantes, regresan el estado redox intracelular de nuevo a su estado normal (Narasaiah et al. 2006, Belozerskaya \& Gessler 2007).

Sin embargo, debido a que la lovastatina es un policétido más bien reducido, y no se ha reportado para éste actividad antioxidante, nuestros resultados sugieren que la relación entre el metabolismo secundario y la formación de ROS puede ser más general. El presente trabajo 
constituye el primer reporte de un estado oxidante relacionado con la producción de lovastatina en $A$. terreus, ya que es un metabolito secundario diferente de AT, sugiriendo que las ROS podría estar implicado en la regulación de otros MS.

En contraste con el caso de AT, en los cultivos de lovastatina estudiados aquí, la transcripción de la enzima antioxidante sodl (y probablemente otros) se reguló a la baja en idiofase, aparentemente propiciando un aumento de ROS y posiblemente induciendo el metabolismo secundario. Los resultados sugieren que, durante la fase de crecimiento rápido (trofofase), la alta expresión sodl contribuye a contener los niveles de ROS con el fin de generar un entorno intracelular conveniente para el crecimiento. Recientes investigaciones denotan que las vías de señalización celular implicados en la proliferación, el crecimiento, y la diferenciación de diversos eucariotas están regulados por su estado redox intracelular (Kamata \& Hirata 1999).

Además, nuestros resultados mostraron que durante la fase de crecimiento rápido los cultivos de lovastatina, tuvieron altas expresiones de Atyap1 y sod1 (Fig. 26 y Fig. 27) y niveles contenidos de ROS (Fig. 16). Esto sugiere que en A. terreus, AtYap1 regula a Sod1. Se ha señalado que en levadura, la expresión de sod1 es inducida por ROS, posiblemente a través de Yap1 (Jamieson 1998; Cyrne et al. 2003).

Las células tiene una serie de mecanismos para mantener bajos los niveles intracelulares de ROS que en conjunto constituyen la respuesta antioxidante(Aguirre et al. 2006). Esto es debido a que el EOX al que se enfrentan los hongos, afectan principalmente a las estructuras celulares y macromoléculas, principalmente lípidos, proteínas y ácidos nucleicos, que si se someten a cambios estructurales pueden dañar su función poniendo en peligro su desarrollo (Folch-Mallol et al. 2004). El control de ROS en la célula puede ser realizado enzimáticamente por la SOD que transforma los iones superóxido $\left(\mathrm{O}_{2}{ }^{\circ-}\right)$ en peróxido de hidrógeno $\left(\mathrm{H}_{2} \mathrm{O}_{2}\right)$. Dado que esta es también una molécula peligrosa, se transforma en $\mathrm{H}_{2} \mathrm{O}$ por la catalasa y/o por la glutatión peroxidasa GSH dependiente, al mismo tiempo la conversión a GSH a su forma oxidada GSSG (Pocsi et al. 2004).

El glutatión, es el tiol más prevalente que contiene en la célula y juega un papel clave en equilibrio redox. El equilibrio entre la formación y disolución de los enlaces disulfuro entre las moléculas de GSH impulsadas por el potencial redox de un estado celular, crea un tampón de alta capacidad oxidorreductivo dentro de la célula (Pocsi et al. 2004).

La célula debe ser capaz de detectar la alteración del equilibrio redox, modular la actividad de los reguladores transcripcionales apropiados y, a continuación inducir la expresión de los 
genes blanco relevantes. Mientras que los hongos utilizan varios medios diferentes para controlar la expresión de productos génicos activos por redox, una característica común es la necesidad de una respuesta transcripcional rápida al desafío oxidante (Moye-Rowley 2003).

En el presente trabajo, la acumulación de ROS en la idiofase, fue apoyado además por los datos del estado redox. En ambos sistemas de cultivo, los resultados mostraron un equilibrio redox bastante alto en trofofase (es decir, un entorno relativo de reducción intracelular). Este equilibrio comenzó a disminuir alrededor de las $24 \mathrm{~h}$ para llegar a un nivel bajo y estable en 48 y se extendió al resto de idiofase. Es decir, un entorno relativamente oxidante se observó en idiofase (alrededor de 4 veces menos que en fase de crecimiento). Al parecer, la oxidación de GSH se utiliza en parte para contrarrestar el alto nivel de ROS (además de ser utilizado para la biosíntesis de lovastatina y otros procesos celulares).

\subsection{Las ROS son necesarias para la biosíntesis de lovastatina.}

Debido a que se encontró una coincidencia en el inicio de biosíntesis de lovastatina y la acumulación de ROS, fue necesario establecer (o descartar) una relación entre ambas. Para realizarlo, se emplearon oxidantes y antioxidantes que fueron suplementados de manera exógena a los medios de cultivo empleados en FS y FL.

Inicialmente se realizaron ensayos con NAC y TMTU sobre cultivos en caja de Petri, donde se encontraron reducciones significativas en la producción de lovastatina, con el empleo de estos antioxidantes, además de que se determinaron los rangos efectivos para cada molécula (Fig. 19 y Fig. 22).

Interesantemente, el empleo del antioxidante NAC en FS y FL, redujo significativamente el nivel de producción de lovastatina en ambos sistemas, así como el nivel de producción/acumulación de ROS; ambas reducciones fueron dependientes de la dosis empleadas, de tal modo, que al realizar un Análisis de Regresión Simple, se obtuvieron índices de correlación $\mathrm{R}^{2}=0.93$ para $\mathrm{FL}$ y para $\mathrm{FS}$ un $\mathrm{R}^{2}=0.99$ (ambos $\mathrm{p}<0.05$ ) entre las variables lovastatina vs ROS.

El análisis a nivel transcripcional, reveló que la acumulación de transcritos de $\operatorname{lov} E$ y lov $F$ en FS y FL se redujeron con el empleo de NAC, y como ya se ha señalado anteriormente, el nivel de producción del metabolito, es consecuencia del nivel de expresión de los genes de la vía (Barrios-González et al. 2008; Sorrentino et al. 2010). 
El resultado de estos experimentos demuestran que las ROS contribuyen a la señalización sobre la regulación de la biosíntesis de lovastatina, a través del gen regulador lovE, y los genes de biosíntesis, representados aquí por el gen $l o v F$.

Ahora bien, el empleo de antioxidantes redujo la producción del metabolito con la concomitante reducción de ROS y a nivel transcripcional, redujo la expresión de los genes $\operatorname{lovE}$ y $l o v F$. Entonces, surgió la pregunta ¿qué pasará al emplear oxidantes?

Inicialmente, se pensó que con el empleo de oxidantes, se obtendría el efecto contrario a los antioxidantes, esto debido a que el uso tanto de $\mathrm{H}_{2} \mathrm{O}_{2}$ como de paraquat, indujeron incrementos importantes del metabolito en cultivo sólido en caja de Petri (Fig. 28), y con ello se pensó que se podría manipular fisiológicamente al hongo mediante los cultivos para mejorar los niveles de producción. Esto, aunado a los experimentos realizados con $A$. parasiticus, donde se lograron incrementos en la producción de AT, los cuales fueron dosisdependientes a diferentes concentraciones de $\mathrm{H}_{2} \mathrm{O}_{2}$ exógeno (Narasaiah et al. 2006).

Sin embargo, en nuestros sistemas de estudio (FS y FL), el empleo de $\mathrm{H}_{2} \mathrm{O}_{2}$ a diferentes concentraciones, redujeron el nivel de producción en FS, mientras que en FL no se mostraron diferencias importantes. Esto sugiere que existe una línea fina entre el nivel de ROS (niveles bajos y fisiológicos para poder señalizar (Reverberi et al. 2008), puede inducir el metabolismo secundario y/o otros procesos) y el EOX. En este sentido, en FS, concentraciones de 10 y 50 $\mathrm{mM}$ de $\mathrm{H}_{2} \mathrm{O}_{2}$ afectaron negativamente el crecimiento, aboliendo prácticamente la biosíntesis de lovastatina (Fig. 32), suponemos por un incremento en el nivel de EOX inducido por la adición de $\mathrm{H}_{2} \mathrm{O}_{2}$ exógeno, produciendo daño celular y consecuente muerte (Belozerskaya \& Gessler 2007).

\subsection{El mecanismo de regulación de ROS sobre la biosíntesis de lovastatina, puede ser a través de Factores Transcripcionales que responden a EOX.}

Debido a que el empleo del NAC redujo el nivel de transcritos de los genes de la vía (lovE y lovF), y como consecuencia una reducción en el nivel de lovastatina, se analizó in silico el promotor del gen $\operatorname{lovE}$ (Factor Transcripcional de la ruta biosintética de lovastatina). La presencia de sitios probables para CreA sugiere que es a través de este Factor Transcripcional que se regula la biosíntesis de lovastatina por represión catabólica (Hajjaj et al. 2001). Un análisis más a detalle del promotor de $\operatorname{lov} E$ puede aportar información importante sobre su regulación. 
La presencia de múltiples sitios de unión para Factores Transcripcionales que responden a diferentes tipos de estrés, (nutricional, térmico y oxidante), sugiere que la biosíntesis de lovastatina puede ser consecuencia de la respuesta a estímulos ambientales que generan estos tipos de estrés, generando una Respuesta General a Estrés (Folch-Mallol et al. 2004). Particularmente se encontraron en su mayoría Factores Transcripcionales que responden a EOX (AP-1, Skn7, Msn2/4, NF-kB y Nrf2, algunos en humanos y otros en levadura, Fig. 35), por lo que se sugiere que el EOX a través de las ROS, puede regular más particularmente este gen.

En forma análoga a $\operatorname{lovE}$, se encontraron sitios putativos de unión de AP-1 en el promotor del regulador AflR (factor transcripcional del cluster biosintético de AT, (Reverberi et al. 2008). Para poder tener un panorama que nos permita entender si es a través de AtYap1 que la biosíntesis de lovastatina pueda ser regulada, se realizó un análisis de Northern para el gen que codifica a este Factor Transcripcional.

Los resultados sugieren que en A. terreus, Atyapl puede regular a sod1, ya que ambos tienen patrones de expresión similares, i.e. se expresan fuertemente en trofofase. En S. pombe, donde Yap1p actúa como un sensor de equilibrio redox, regulando la activación de diferentes antioxidantes relacionadas con la defensa de los genes, como SOD, CAT y GPX (Lee et al. 1999).

La hipótesis de que la biosíntesis de AT es regulada por medio de Yap1p es interesante y podría ser el mismo mecanismo que para la lovastatina. Esto por que Yaplp es un Factor Transcripcional (paralelo a la cascada MAPK cinasas) que funciona como un sensor de ROS o estado redox de la célula; y que en caso de incremento de ROS, la proteína entra al núcleo y participa en la transcripción de cientos de genes cuyos productos van a contender o neutralizar este brote oxidante (Reverberi et al. 2008). Sin embargo, cuando Reverberi et al., (2008) construyeron una cepa $\triangle$ Apyapl sólo encontraron una acumulación precoz de ROS en el cultivo de AT y una producción adelantada de AT. Incluso la esporulación se presentó en forma precoz. Los autores propusieron que ApYap1 podría estar regulando en forma negativa los genes del metabolismo secundario, también es posible que los ROS estén regulando estos genes por otro mecanismo. Esto se relaciona por el hecho de que encontramos que Atyapl no se expresó durante la idiofase de FS y FL.

La hipótesis de que la regulación de lovastatina a través de AtYap1, no se descarta, por ello se empezó a trabajar en el silenciamiento de este gen en A. terreus. Nuestros resultados mostraron que el silenciamiento de este gen (además de que produjo una marcada sensibilidad 
al $\mathrm{H}_{2} \mathrm{O}_{2}$ como la reportado por Reverberi et al. (2008)), produjo una temprana y elevada producción de esporas. También, resultados preliminares mostraron un incremento importante en la biosíntesis de lovastatina, sin embargo, faltó una caracterización más profunda de las transformantes obtenidas, lo cual nos podrá en un futuro dar información valiosa sobre si es o no importante AtYap1 para la biosíntesis de lovastatina por A. terreus, y si se corrobora la alta producción de lovastatina por el silenciamiento de este, podría proponerse como una herramienta de mejoramiento genético.

Aunque AtYap1 podría ser el Factores Transcripcionales implicado, el mecanismo podría ser a través de algún otro Factor Transcripcional. Es importante notar que se encontraron varios sitios de unión para el Factor Transcripcional Skn7 (en S. cerevisiae) o SrrA (en A. nidulans). Por tal razón, se analizó el perfil de expresión de $\operatorname{srr} A$ de $A$. terreus en FS y FL por la técnica de Northern-blot en conjunto con Mariel Mendoza Rico (Mendoza-Rico et al., tesis en revisión).

Los resultados mostraron que en FS el gen srrA se expresó durante toda la idiofase, comenzando justo cuando el gen Atyapl es regulado a la baja. Así, se ve un patrón donde Atyapl es expresado durante la trofofase, junto con sodl, sugiriendo que son responsables del mantenimiento de bajos niveles ROS. Después, ambos disminuyen su expresión y es en ese momento donde empieza la acumulación de ROS. También es ese el momento en el que $\operatorname{sr} A$ se "enciende", y su expresión dura toda la idiofase (Mendoza-Rico et al., tesis en revisión).

Esto significa que el mecanismo por medio del cual los ROS regulan a los genes de lovastatina bien puede ser por medio de SrrA. Es decir, la acumulación de ROS estaría induciendo $\operatorname{sr} A$, cuyo producto va al promotor de $\operatorname{lovE}$ y quizás otros genes de la vía para facilitar su transcripción, como es el caso del promotor del gen $l o v F$, donde se encontraron hasta 10 sitios probables de unión para este Factor Transcripcional (Fig. 37).

Es importante notar que se ha demostrado que Skn7 (homólogo de SrrA) puede actuar en conjunto con Yap1, o sólo en la regulación de otros genes, i.e. de esporulación (Delaunay et al., 2000).

Por otra parte, los resultados obtenidos en FL fueron muy diferentes. En FL, srrA se expresó también durante parte de la trofofase (coincidiendo con Atyapl en 15, 18 y 21 h). Después, ya en idiofase, se expresó intermitentemente, de hecho, parece haber una correlación entre las ROS (debido a fluctuaciones en su contenido) y expresión de srrA durante la idiofase. Es 
posible que la variabilidad de ROS encontrada en FL esté relacionada con la expresión intermitente de $\operatorname{srr} A$ (Fig. 16 y Fig. 27).

Por otro lado, también se sabe que SrrA (y Skn7) participan en el ensamble, síntesis y mantenimiento de la pared celular, incluyendo respuesta a pérdida de turgor o estrés de pared en levadura (Fassler 2011). Esto parece importante, ya que nuestro grupo han encontrado que el micelio crecido en FS es diferente al crecido en FL, i.e. produce más. Además, es lógico pensar que un micelio de FS necesita explorar, colonizar, etc., por lo que se propuso que el micelio de FS es diferente (Barrios-González 2012). Así, también es posible que la diferencia de expresión de $\operatorname{sr} A$ en FS y en FL este señalando también la diferencia en las características del micelio de medio sólido.

\subsection{Diferencias en el control de ROS en FS y FL: ¿Causa de una mayor producción de lovastatina?}

Debido a que las concentraciones de ROS en idiofase fueron 10 veces más altos en el FL en relación con la FS, se podría pensar que se estaría induciendo EOX que a su vez podría dañar enzimas que podrían ser importantes para la biosíntesis de lovastatina. Por lo tanto, se podría pensar, que tal vez sea importante que los ROS se mantengan a un nivel mucho más estable, como lo encontrado en la idiofase de FS, ya que niveles bajos y fisiológicos, son importantes para que las ROS actúen como moléculas señalizadoras (Reverberi et al. 2008).

Otra de las diferencias encontradas, fueron los valores de equilibrio redox, los cuales también mostraron diferencias notables. En FS se mostró 4 veces mayor equilibrio redox que en FL. Al parecer, en FS las condiciones generadas permiten un medio ambiente intracelular más reductor en el cultivo. Este equilibrio más reductor podría ser necesario para un crecimiento más rápido en un ambiente más estresante o exigente.

Por otro lado, además de indicar que la acumulación de ROS y/o equilibrio redox en idiofase contribuye a regular la biosíntesis de lovastatina, nuestros resultados sugieren que los niveles más bajos y constantes de ROS encontrados en FS representan mejores señales para inducir los genes biosintéticos de lovastatina, que los mayores niveles observados en FL.

En relación con los niveles de ROS constantes y convenientes para las cascadas de señalización, un análisis proteómico de cepas de Penicillium chrysogenum con diferentes niveles de producción, incluida la de tipo silvestre y cepas sobreproductoras de penicilina, indicó que la reorganización metabólica global ocurrió durante el mejoramiento genético de la 
cepa, incluida una mejora en la respuesta al estrés oxidante, lo cual incluyó un aumento de las proteínas de respuesta a este tipo de estrés (Jami et al. 2010).

Hay evidencias de que en la FS los hongos crecen en un entorno con diferentes tipos de estrés, como el osmótico, oxidante, y posiblemente nutricional. En un trabajo anterior que mostró que el gen gldB está fuertemente inducido en FS de lovastatina, aunque no en FL. Como se trata de un gen del estrés osmótico de defensa, los resultados mostraron que el hongo está sometido a este estrés (Aw baja) durante la FS (Barrios-González et al. 2008). Es posible que este ambiente estresante active la "Protección Cruzada". De esta forma el micelio crecido en cultivo sólido estaría más apto para hacer frente a acumulaciones de ROS en cualquier momento, que el micelio de FL y por lo tanto, para mantener ROS a un nivel más bajo y más constante.

En levadura, la Respuesta General al Estrés, se da mediante la vía de señalización cAMPPKA, mediada por proteínas G heterotriméricas, cuya subunidad a (gen gpa2), en condiciones normales para el crecimiento, activa la adenilato ciclasa, incrementando así la concentración de cAMP (Thevelein, 1994). En A. nidulans, el gen de dicha subunidad se conoce como fadA, y ha sido empleado como un indicador de la vía (Hicks et al. 1997). En este punto es importante retomar el resultado obtenido en la tesis de maestría (Miranda et al., 2008), donde se observó que el gen $f a d A$ se comporta de manera distinta en FS y en FL. En FS el gen se trascribe de manera constante durante la trofofase e idiofase, no así en FL, donde pareció comportarse de acuerdo al modelo propuesto por Shimizu \& Keller (2001): cuando hay glucosa en el medio, la vía cAMP-PKA está activa, y al entrar en estrés nutricional (por agotamiento del nutriente clave), la vía baja su actividad para activar genes blanco que le ayudarán al hongo a ser frente a las nuevas condiciones. Así, se inicia el metabolismo secundario, la esporulación y se incrementa la resistencia a estrés.

En nuestro trabajo, además de encontrar diferencias en la expresión de fadA en FS y FL, otro de los hallazgos fue que fadA se regula a nivel transcripcional, lo cual hasta la fecha no se ha reportado.

El hallazgo de que las ROS se encontraron a niveles bajos y constantes, podría ser consecuencia de una regulación que podría correlacionarse por la actividad de la vía cAMPPKA, la cual hoy en día es una línea de investigación en nuestro grupo (Pérez-Aguirre T., Tesis Doctoral en desarrollo). 


\section{CONCLUSIONES}

(1) No existe un estado hiperoxidante durante la trofofase, sino reductor. Bajos niveles de ROS, resultado de un estado reductor (medido por el balance GSH/GSSG) y/o expresión de enzimas antioxidantes i.e. sodl, se encontraron presentes en la trofofase de ambos sistemas de cultivo.

(2) AtYap1 parece regular a Sod1 en A. terreus. Se encontraron patrones de expresión similares entre los genes que codifican a estas proteínas. Además, estos se expresaron fuertemente en la trofofase de FS y FL, por lo que se sugiere que contribuyen a mantener bajos niveles de ROS, apropiados para llevar a cabo el desarrollo celular. Su regulación a la baja, induce la acumulación de ROS en idiofase.

(3) Las ROS contribuyen en la señalización para iniciar la idiofase de FS y FL. El empleo del antioxidante NAC redujo niveles de ROS y lovastatina, este último como consecuencia de una disminución en el nivel de transcritos de los genes de la vía por efecto del antioxidante.

(4) Existe una alta probabilidad de que el mecanismo por el cual las ROS pueden señalizar la biosíntesis de lovastatina sea a través de Factores Transcripcionales que responden a EOX. Se encontraron varios sitios de unión a elementos como Ap-1 (Yap1 en hongos), Nrf2, Skn7 (homólogo a SrrA), etc., en el promotor de lovE y lovF. En particular, SrrA se correlacionó con el comportamiento de acumulación de ROS. Mientras que AtYap1 parece regular a Sod1 para que a su vez regule niveles de ROS. El silenciamiento de Atyapl (mediante RNAi), produjo una desregulación en el metabolismo de producción de esporas, ya que estas se produjeron más tempranamente y en número elevado, y al parecer también, el silenciamiento estimuló una elevación en la biosíntesis de lovastatina en FS y FL.

(5) Los niveles bajos y controlados de ROS parecen ser importantes para un buen nivel de producción (como loe encontrados en FS). 


\section{PERSPECTIVAS.}

El presente proyecto abre una vía importante en la investigación de los mecanismos que pueden regular el metabolismo secundario (particularmente lovastatina en A. terreus). Estos conocimientos podrían aplicarse para mejorar el proceso de producción biotecnológica de este MS, ya sea por manipulación fisiológica o por el mejoramiento genético de la cepa.

El presente trabajo ha establecido una relación entre la producción de ROS y la biosíntesis de lovastatina, y se propone que es a través de Factores Transcripcionales que responden a EOX donde está la clave de regulación.

Particularmente, para conocer cual es la porción del promotor importante para la regulación por ROS y cual es el factor o factores transcripcionales clave en esta regulación, se propone analizar in vitro el promotor del gen $\operatorname{lovE}$. Partiendo del análisis in silico de este gen, se podría analizar por fragmentos el promotor el cual estaría fusionado con algún gen reportero como GUS o EGFP, con el objeto de encontrar la zona del promotor que está sujeta a regulación.

Por otra parte, el silenciamiento de genes mediante el mecanismo de RNAi parece ser un modo fácil y efectivo de reducir considerablemente la expresión de genes blanco, por lo que otra manera de observar cual o cuales son los Factores Transcripcionales que influyen sobre la biosíntesis de lovastatina, sería mediante el silenciamiento de Factores Transcripcionales que responden a EOX, i.e. SrrA, AtfB, etc.

Ejemplo claro, es el silenciamiento del gen Atyapl a través del mecanismo de RNAi, que potencialmente parece tener implicaciones positivas en el metabolismo secundario de $A$. terreus, ya que se lograron altas producciones de esporas y al parecer, de lovastatina (por corroborar). Esta puede ser una estrategia de mejoramiento genético de la cepa que podría tener implicaciones biotecnológicas.

El tratar de comprender aun mejor la físiología del medio sólido para aprovechar ese conocimiento en el mejoramiento del proceso de producción de lovastatina, parece una labor difícil, pero en nuestro grupo los avances parecen ser muy importantes, y queda claro que en el área del EOX-metabolismo secundario queda mucho por investigar. 


\section{REFERENCIAS}

Adibhatla, R.M. \& Hatcher, J.F., 2008. Altered lipid metabolism in brain injury and disorders. Subcellular Biochemistry. 49, pp.241-268.

Aguirre, J. et al., 2005. Reactive oxygen species and development in microbial eukaryotes. Trends in microbiology, 13(3), pp.111-118.

Aguirre, J., Hansberg, W. \& Navarro, R., 2006. Fungal responses to reactive oxygen species. Medical Mycology, 44(s1), pp.101-107.

Alberts, A. et al., 1980. Mevinolin: a highly potent competitive inhibitor of hydroxymethylglutaryl-coenzyme A reductase and a cholesterol-lowering agent. Proceedings of the National Academy of Sciences of the United States of America, 77(7), p.3957.

Apel, K. \& Hirt, H., 2004. REACTIVE OXYGEN SPECIES: Metabolism, Oxidative Stress, and Signal Transduction. Annual Review of Plant Biology, 55(1), pp.373-399.

Ávila N., Mejía A., Garay-Arroyo y Barrios-González J. 2009. Efecto del contacto con el aire, el estrés osmótico y el estímulo de exploración del micelio sobre la producción de lovastatina en Aspergillus terreus. Tesis (Maestría en Biotecnología). México, D.F. Universidad Autónoma Metropolitana.

Babior, B.M. 2000. The NADPH oxidase of endothelial cells. IUBMB Life 50. Pp. 267-9.

Babior, B.M. 2002. The leukocyte NADPH oxidase. Isr Med Assoc J 4: 1023-4.

Baños, J.G. et al., 2009. High lovastatin production by Aspergillus terreus in solid-state fermentation on polyurethane foam: an artificial inert support. Journal of Bioscience and Bioengineering, 108(2), pp.105-110.

Baños J., Mejía A., Garay-Arroyo A \& Barrios-González J. 2010. Producción de lovastatina en fermentación sólida sobre soporte inerte artificial, por una cepa silvestre de Aspergillus terreus (TUB F-514) y por sus mutantes resistentes a estrés osmótico y oxidativo. Tesis (Doctorado en Biotecnología). México, D.F., Universidad Autónoma Metropolitana.

Barrios-González, J., 2012. Solid-state fermentation: Physiology of solid medium, its molecular basis and applications. Process Biochemistry, 47(2), pp.175-185.

Barrios-González, J. \& Miranda, R., 2010. Biotechnological production and applications of statins. Applied Microbiology and Biotechnology, 85(4), pp.869-883.

Barrios-González, J, Tomasini A., Viniegra-González G \& López J. 1988. Penicillin production by solid state fermentation. Biotechnology Letters, 10(11), pp. 793-798.

Barrios-González, J. et al., 2008. Lovastatin biosynthetic genes of Aspergillus terreus are expressed differentially in solid-state and in liquid submerged fermentation. Applied Microbiology and Biotechnology, 79(2), pp.179-186.

Barrios-González, J. et al., 2005. Secondary metabolites production by solid state fermentation. Malaysian J Microbiol, 1, pp.1-6.

Barrios-González, J., Fernández, F.J. \& Tomasini, A., 2003. Microbial secondary metabolites production and strain improvement. Indian Journal of Biotechnology, 2(3), pp.322-333.

Belozerskaya, T.A. \& Gessler, N.N., 2007. Reactive oxygen species and the strategy of antioxidant defense in fungi: A review. Applied Biochemistry and Microbiology, 43(5), pp.506-515.

Bermingham-McDonogh, O., Gralla, E. \& Valentine, J., 1988. The copper, zinc-superoxide dismutase gene of Saccharomyces cerevisiae: cloning, sequencing, and biological activity. Proceedings of the National Academy of Sciences of the United States of America, 85(13), p.4789.

Bok, J. \& Keller, N., 2004. LaeA, a regulator of secondary metabolism in Aspergillus spp. 
Eukaryotic Cell, 3(2), p.527.

Bokoch, G.M. \& Knaus, U.G., 2003. NADPH oxidases: not just for leukocytes anymore! Trends in biochemical sciences, 28(9), pp.502-508.

Bonovas, S. et al., 2006. Statins and Cancer Risk: A Literature-Based Meta-Analysis and Meta-Regression Analysis of 35 Randomized Controlled Trials. Journal of Clinical Oncology, 24(30), pp.4808-4817.

Cadenas, E. and K.J. Davies. 2000. Mitochondrial free radical generation, oxidative stress, and aging. Free Radic Biol Med 29: 222-30.

Calvo, A. et al., 2002. Relationship between secondary metabolism and fungal development. Microbiology and Molecular Biology Reviews, 66(3), p.447.

Cano-Dominguez, N. et al., 2008. NADPH Oxidases NOX-1 and NOX-2 Require the Regulatory Subunit NOR-1 To Control Cell Differentiation and Growth in Neurospora crassa. Eukaryotic Cell, 7(8), pp.1352-1361.

Casas López, J. et al., 2004. Fermentation optimization for the production of lovastatin by Aspergillus terreus: use of response surface methodology. Journal of Chemical Technology \& Biotechnology, 79(10), pp.1119-1126.

Chance, B., B. Schoener, R. Oshino, F. Itshak, and Y. Nakase. 1979. Oxidation-reduction ratio studies of mitochondria in freeze-trapped samples. NADH and flavoprotein fluorescence signals. J Biol Chem 254: 4764-71.

Cyrne, L. et al., 2003. Regulation of antioxidant enzymes gene expression in the yeast Saccharomyces cerevisiae during stationary phase. Free Radical Biology and Medicine, 34(3), pp.385-393.

Delaunay, A., Isnard, A.D., \& M.B. Toledano. 2000. H2O2 sensing through oxidation of the Yap1 transcription factor. EMBO J. 19(19), pp. 5157-66..

Drahota, Z., S.K. Chowdhury, D. Floryk, T. Mracek, J. Wilhelm, H. Rauchova, G. Lenaz, and J. Houstek. 2002. Glycerophosphate- dependent hydrogen peroxide production by brown adipose tissue mitochondria and its activation by ferricyanide. J Bioenerg Biomembr 34: $105-13$.

Dulak, J. \& Józkowicz, A., 2005. Anti-angiogenic and anti-inflammatory effects of statins: relevance to anti-cancer therapy. Current Cancer Drug Targets, 5(8), p.579.

Endo, A., 2008. A gift from nature: the birth of the statins. Nature Medicine, 14(10), pp.1050-1052.

Endo, A. et al., 1985. Biosynthesis of ML-236B (compactin) and monacolin K. The Journal of antibiotics, 38(3), pp.444-448.

Fassbender, K. et al., 2001. Simvastatin strongly reduces levels of Alzheimer's disease $\beta$ amyloid peptides $\mathrm{A} \beta 42$ and $\mathrm{A} \beta 40$ in vitro and in vivo. Proceedings of the National Academy of Sciences of the United States of America, 98(10), p.5856.

Fassler, J., 2011. Fungal Skn7 Stress Responses and Their Relationship to Virulence. Eukaryotic Cell.

Finkel, T., 2003. Oxidant signals and oxidative stress. Current Opinion in Cell Biology, 15(2), pp.247-254.

Folch-Mallol, J. et al., 2004. La respuesta a estrés en la levadura Saccharomyces cerevisiae. Latinoamericana de Microbiología, 46(1-2), pp.24-46.

Garay-Arroyo, A. et al., 2003. Cu, Zn-superoxide dismutase of Saccharomyces cerevisiae is required for resistance to hyperosmosis. FEBS letters, 539(1-3), pp.68-72.

Glynn, S.A. et al., 2008. The 3-hydroxy-3-methylglutaryl-coenzyme A reductase inhibitors, simvastatin, lovastatin and mevastatin inhibit proliferation and invasion of melanoma cells. BMC Cancer, 8(1), p.9.

Guijarro, C., 2001. Statins: effects beyond cholesterol lowering. Nephrology Dialysis Transplantation. 
Hajjaj, H., Niederberger, P. \& Duboc, P., 2001. Lovastatin biosynthesis by Aspergillus terreus in a chemically defined medium. Applied and Environmental Microbiology, 67(6), pp.2596-2602.

Hauptmann, N., J. Grimsby, J.C. Shih, and E. Cadenas. 1996. The metabolism of tyramine by monoamine oxidase A/B causes oxidative damage to mitochondrial DNA. Arch Biochem Biophys 335: 295-304.

Hendrickson, L. et al., 1999. Lovastatin biosynthesis in Aspergillus terreus: characterization of blocked mutants, enzyme activities and a multifunctional polyketide synthase gene. Chemistry \& biology, 6(7), pp.429-439.

Hisada, H. et al., 2005. Cloning and expression analysis of two catalase genes from Aspergillus oryzae. Journal of Bioscience and Bioengineering, 99(6), pp.562-568.

Jami, M.-S. et al., 2010. Proteome Analysis of the Penicillin Producer Penicillium chrysogenum. Molecular \& Cellular Proteomics, 9, pp. 1182-1198.

Jamieson, D., 1998. Oxidative stress responses of the yeast Saccharomyces cerevisiae. Yeast, 14(16), pp.1511-1527.

Jayashree, T. \& Subramanyam, C., 2000. Oxidative stress as a prerequisite for aflatoxin production by Aspergillus parasiticus. Free Radical Biology and Medicine, 29(10), pp.981-985.

Jia, Z. et al., 2010. Enhancement of lovastatin production by supplementing polyketide antibiotics to the submerged culture of Aspergillus terreus. Applied Biochemistry and Biotechnology, 160(7), pp.2014-2025.

Jones, A.M., 1994. Surprising signals in plant cells. Science, 263(5144), pp.183-184.

Kamata, H. \& Hirata, H., 1999. Redox Regulation of Cellular Signalling. Cellular Signalling, $11(1)$, pp.1-14.

Kapur, N. \& Musunuru, K., 2008. Clinical efficacy and safety of statins in managing cardiovascular risk. Vascular Health and Risk Management, 4(2), p.341.

Kawasaki, L., Wysong, D. \& Diamond, R., 1997. Two divergent catalase genes are differentially regulated during Aspergillus nidulans development and oxidative stress. Journal of Bacteriology. 179(10), pp. 3284-3292.

Keller, N.P., Turner, G. \& Bennett, J.W., 2005. Fungal secondary metabolism-from biochemistry to genomics. Nature Reviews Microbiology, 3(12), pp.937-947.

Kennedy, J., 1999. Modulation of Polyketide Synthase Activity by Accessory Proteins During Lovastatin Biosynthesis. Science, 284(5418), pp.1368-1372.

Kidd, J., 2006. Life after statin patent expiries. Nature reviews. Drug discovery, 5(10), pp.813-814.

Kodaman, P. \& Duleba, A., 2008. Statins in the treatment of polycystic ovary syndrome. Seminars in reproductive medicine, 26(1), p.127.

Kreiner, M., McNeil, B. \& Harvey, L., 2000. "Oxidative stress" response in submerged cultures of a recombinant Aspergillus niger (B1-D). Biotechnology and Bioengineering, $70(6)$, pp.662-669.

Kumar, M.S. et al., 2000. A rapid technique for screening of lovastatin-producing strains of Aspergillus terreus by agar plug and Neurospora crassa bioassay. Journal of microbiological methods, 40(1), pp.99-104.

Lara, A. et al., 2004. Hipercolesterolemia e hipertensión arterial en México. Consolidación urbana actual con obesidad, diabetes y tabaquismo. Arch Cardiol Mex, 74(3), pp.231245.

Lara-Ortíz, T., Riveros-Rosas, H. \& Aguirre, J., 2003. Reactive oxygen species generated by microbial NADPH oxidase NoxA regulate sexual development in Aspergillus nidulans. Molecular Microbiology, 50(4), pp.1241-1255.

Lee, J. et al., 1999. Yap1 and Skn7 control two specialized oxidative stress response regulons 
in yeast. Journal of Biological Chemistry, 274(23), p.16040.

Lee BN, Kroken S, Chou DY, et al. 2005. Functional analysis of all nonribosomal peptide synthetases in Cochliobolus heterostrophus reveals a factor, NPS6, involved in virulence and resistance to oxidative stress. Eukaryot Cell 2005; 4, pp. 545-555.

Lledías, F., Rangel, P. \& Hansberg, W., 1998. Oxidation of catalase by singlet oxygen. The Journal of biological chemistry, 273(17), pp.10630-10637.

Maiques Galán, A., Franch Taix, M. \& Fluixá Carrascosa, C., 2004. Estatinas: eficacia, seguridad e indicaciones. Información Terapéutica del Sistema Nacional de Salud, 28(4), pp.89-100.

Manzoni, M. et al., 1998. Production and purification of statins from Aspergillus terreus strains. Biotechnology Techniques, 12(7), pp.529-532.

Manzoni, M. et al., 1999. Production of statins by filamentous fungi. Biotechnology Letters, 21(3), pp.253-257.

Marcial J., Montiel M, Tomasini A. \& Fernández FJ. 2011. Identificación de una aspartato proteasa producida por Amylomyces rouxii, silenciamiento del gen que la codifica y efecto sobre la actividad tirosinasa. Tesis (Doctorado en Biotecnología), México, D.F. Universidad Autónoma Metropolitana.

McCarey, D., Sattar, N. \& McInnes, I., 2005. Do the pleiotropic effects of statins in the vasculature predict a role in inflammatory diseases. Arthritis Research \& Therapy, 7(2), p.55.

Miranda RU., Garay-Arroyo A., Mejía A \& Barrios-González J. 2008. Expresión del gen sodl durante la trofofase e idiofase de Aspergillus terreus en fermentación sólida y líquida para la producción de lovastatina. Tesis (Maestría en Biotecnología). México, D.F. Universidad Autónoma Metropolitana.

Miranda, R.U. et al., 2013. Oxidative state in idiophase links reactive oxygen species (ROS) and lovastatin biosynthesis: Differences and similarities in submerged- and solid-state fermentations. Fungal Biology, pp.1-9.

Montoya, C.J. et al., 2012. Randomized clinical trial of lovastatin in HIV-infected, HAART naIve patients (NCT00721305). Journal of Infection, 65(6), pp.549-558.

Moye-Rowley, W., 2003. Regulation of the transcriptional response to oxidative stress in fungi: similarities and differences. Eukaryotic Cell, 2(3), p.381.

Narasaiah, K., Sashidhar, R. \& Subramanyam, C., 2006. Biochemical analysis of oxidative stress in the production of aflatoxin and its precursor intermediates. Mycopathologia, 162(3), pp.179-189.

Ooijkaas, L.P., Tramper, J. \& Buitelaar, R.M., 1998. Biomass estimation of Coniothyrium minitans in solid-state fermentation. T2 - T3 . Enzyme and Microbial Technology, 22(6), pp.480-486.

Pahan, K., 2006. Lipid-lowering drugs. Cellular and Molecular Life Sciences, 63(10), pp.1165-1178.

Pandey, A., Larroche, C. \& Soccol, C.R., 2008. Current Developments in Solid-state Fermentation, Springer Science+Business Media.

Pei-lian, W., et al., 2006. Comparison of three biomass estimation methods in Solid State Fermentation . Journal of Food Science and Biotechnology, 25(1), pp. 1673-1689.

Pérez-Aguirre T., Fierro F., Mejía A. \& Barrios-González J. 2009. Clonación y sobreexpresión del gen regulador global laeA en Aspergillus terreus TUB F-514: Efecto sobre la producción de lovastatina en fermentación sólida y líquida. Tesis (Maestría en Biotecnología). México, D.F. Universidad Autónoma Metropolitana.

Pérez-Sánchez A., Miranda RU \& Barrios-González J. 2013. Effect of sillencing gene yapl in Aspergillus terreus. 12th International Symposium on the Genetics of Industrial Microorganisms. Cancún, Quintana Roo, México. Junio 23-28. 
Pocsi, I., Prade, R. \& Penninckx, M., 2004. Glutathione, altruistic metabolite in fungi. Advances in microbial physiology, 49, pp.1-76.

Pócsi, I. et al., 2005. Comparison of gene expression signatures of diamide, $\mathrm{H}_{2} \mathrm{O}_{2}$ and menadione exposed Aspergillus nidulans cultures--linking genome-wide transcriptional changes to cellular physiology. BMC genomics, 6, p.182.

Reverberi, M. et al., 2008. Modulation of antioxidant defense in Aspergillus parasiticus is involved in aflatoxin biosynthesis: a role for the ApyapA gene. Eukaryotic Cell, 7(6), pp.988-1000.

Rhee, S.G., 2006. Cell signaling. $\mathrm{H}_{2} \mathrm{O}_{2}$, a necessary evil for cell signaling. Science, 312(5782), pp.1882-1883.

Robinson, T., Singh, D. \& Nigam, P., 2001. Solid-state fermentation: a promising microbial technology for secondary metabolite production. Applied Microbiology and Biotechnology, 55(3), pp.284-289.

Rollini, M.M.M., 2002. Biosynthesis and biotechnological production of statins by filamentous fungi and application of these cholesterol-lowering drugs. Applied Microbiology and Biotechnology, 58(5), pp.555-564.

Roze, L.V. et al., 2011. Stress-related transcription factor AtfB integrates secondary metabolism with oxidative stress response in aspergilli. Journal of Biological Chemistry, 286(40), pp.35137-35148.

Sorrentino, F., Roy, I. \& Keshavarz, T., 2010. Impact of linoleic acid supplementation on lovastatin production in Aspergillus terreus cultures. Applied Microbiology and Biotechnology, 88(1), pp.65-73.

Suryanarayan, S. \& Mazumdar, K., 2003. Patent US6664095 - Solid state fermentation .

Szakács, G., Morovján, G. \& Tengerdy, R.P., 1998. Production of lovastatin by a wild strain of Aspergillus terreus. Biotechnology Letters, 20(4), pp.411-415.

Thevelein, J. M. 1994. Signal transduction in yeast. Yeast. 10, pp. 109-130.

Tobert, J.A., 2003. Lovastatin and beyond: the history of the HMG-CoA reductase inhibitors. Nature reviews. Drug discovery, 2(7), pp.517-526.

Tomasini, A., Fajardo, C. \& Barrios-Gonza lez, J., 1997. Gibberellic acid production using different solid-state fermentation systems. World Journal of Microbiology and Biotechnology, 13(2), pp.203-206.

Turrens, J.F. 2003. Mitochondrial formation of reactive oxygen species. J Physiol 552: 33544.

Ullán, R.V. et al., 2008. RNA-silencing in Penicillium chrysogenum and Acremonium chrysogenum: Validation studies using $\beta$-lactam genes expression. Journal of microbiological methods, 75(2), pp.209-218.

Varghese, S., Y. Tang, and J.A. Imlay. 2003. Contrasting sensitivities of Escherichia coli aconitases A and B to oxidation and iron depletion. J Bacteriol 185: 221-30.

Valera, H.R. et al., 2005. Lovastatin production by solid state fermentation using Aspergillus flavipes. Enzyme and Microbial Technology, 37(5), pp.521-526.

Veal, E.A., Day, A.M. \& Morgan, B.A., 2007. Hydrogen Peroxide Sensing and Signaling. Molecular Cell, 26(1), pp.1-14.

Vignais, P.V. 2002. The superoxide-generating NADPH oxidase: structural aspects and activation mechanism. Cell Mol Life Sci 59: 1428-59.

Wang, C., Liu, P. \& Liao, J., 2008. Pleiotropic effects of statin therapy: molecular mechanisms and clinical results. Trends in Molecular Medicine, 14(1), pp.37-44.

Wei, P. \& Xu, Z., 2007. Lovastatin production by Aspergillus terreus in solid-state fermentation. Journal of Zhejiang University-Science A.

Woloshuk, C.P. et al., 1994. Molecular characterization of aflR, a regulatory locus for aflatoxin biosynthesis. Applied and Environmental Microbiology, 60(7), pp.2408-2414. 
Yang, D.-J. \& Hwang, L.S., 2006. Study on the conversion of three natural statins from lactone forms to their corresponding hydroxy acid forms and their determination in $\mathrm{Pu}-$ Erh tea. Journal of chromatography. A, 1119(1-2), pp.277-284.

Yoshizawa, Y. et al., 1994. Revision of the biosynthetic origin of oxygens in mevinolin (lovastatin), a hypocholesterolemic drug from Aspergillus terreus MF 4845. Journal of the American Chemical Society, 116(6), pp.2693-2694. 


\section{APÉNDICE 1: Análisis in silico de lovE.}

Un análisis detallado de estos putativos o posibles sitios de unión (o motivos), se presenta en la Tabla 10.

Tabla 10 Posición y valor del p-value de cada uno de los motivos encontrados en el promotor del gen lovE por el programa MEME. Los motivos o sitios de unión señalados en color VERDE, muestra las secuencias consenso conservadas pertenecientes al motivo 1, en ROSA, se presentan las secuencias consenso para el motivo 2 y en AMARILLO las secuencias consenso para el motivo 3 (ubicadas en Fig. 45).

\begin{tabular}{|c|c|c|c|}
\hline MOTIVO & POSICION & $p$-value & DIAGRAMA DE BLOQUES \\
\hline $1-A$ & -326 & $2.93 \mathrm{e}-20$ & CATGAAACAGACT CCACTAACCGTCTTACGCGCCTTAGCGCC \\
\hline 1-B & -936 & $1.68 \mathrm{e}-17$ & CATGAAGGCGACTCCACAAACAATCTTACGCCGTTTGCCTCG \\
\hline $1-C$ & -500 & $2.80 \mathrm{e}-16$ & CAATCACCGTAGTCCCTAACATTCAGTCACCCCGTAGCAAC \\
\hline 1-D & -130 & $6.33 \mathrm{e}-15$ & AAAAAGCCAGACT GTCGGGACCTTAAAAGCCCACAGAGGTAC \\
\hline $2-\mathrm{A}$ & -985 & $5.64 \mathrm{e}-10$ & GGTAGCCGGTAGGCATTTT \\
\hline 2-B & -378 & $6.45 \mathrm{e}-09$ & GGTTGCCAGCAGCAATTTT \\
\hline $2-\mathrm{C}$ & -821 & $1.11 \mathrm{e}-08$ & GTTAGGTACTAGGTACCTT \\
\hline 2-D & -643 & $2.10 \mathrm{e}-08$ & GGTACCTAGTAGCCTCTTT \\
\hline 2-E & -574 & $1.48 \mathrm{e}-07$ & AGCAGGGTGTACGTACTCT \\
\hline $3-A$ & -236 & $7.20 \mathrm{e}-07$ & СССАСССССТ \\
\hline $3-B$ & -252 & $7.20 \mathrm{e}-07$ & СССАСССССТ \\
\hline $3-C$ & -700 & $2.84 \mathrm{e}-06$ & ССТ GCCСССТ \\
\hline 3-D & -542 & $4.52 \mathrm{e}-06$ & ССТАССТССТ \\
\hline
\end{tabular}

Posteriormente, se realizó un análisis para poder pronosticar o predecir que Factores Transcripcionales pueden unirse a estos motivos o sitios de unión. 
prom_love 1
-900
G GCTCGCTGGC

prom_love

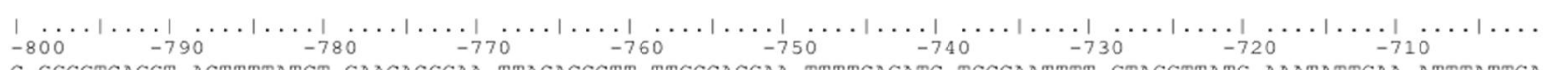

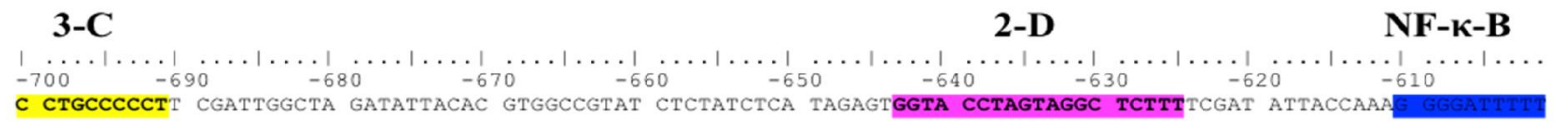

\section{2-E}

\section{3-D}

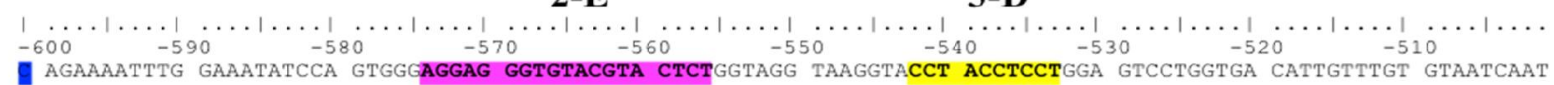

prom_love

$$
\text { 1-C }
$$

AtfB

prom_love

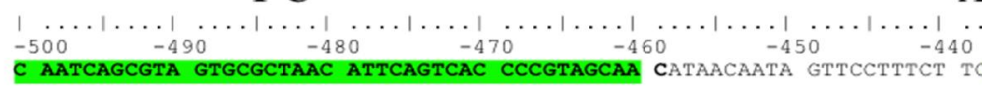

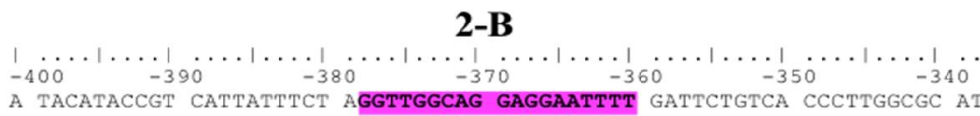

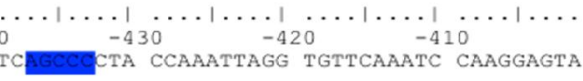

prom_love a tacataccGt CattattTet

\section{AtfB/ 3-B}

$\cdots+\cdots+\frac{1}{330}$

$\mathbf{1 - A}$

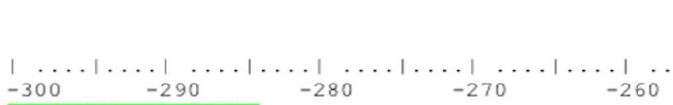

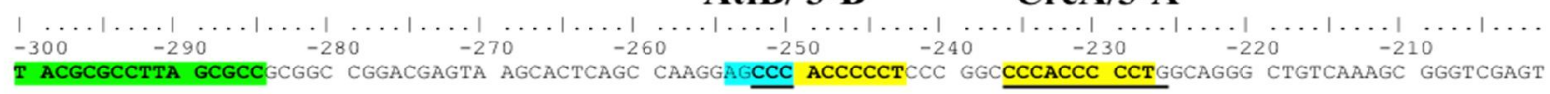

CreA/3-A

prom_love

1-D

prom_love

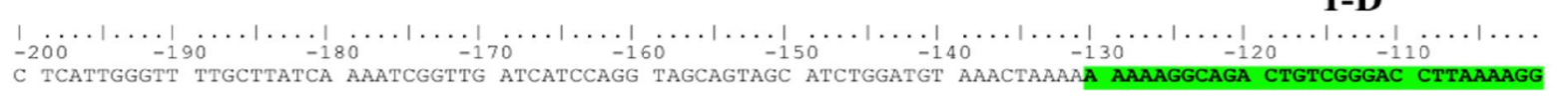

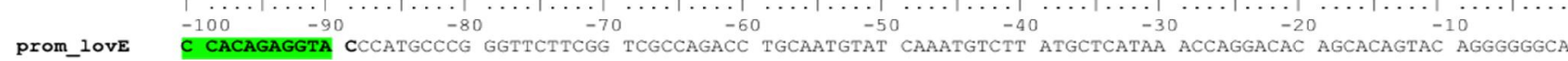

Fig. 45 Distribución de los motivos o posibles sitios de unión de factores transcripcionales en el promotor del gen lovE. En verde el motivo1, en rosa el motivo2, en amarillo el motivo 3, en azul rey, sitios encontrados por NSITE o por búsqueda dirigida, en verde agua sitio de unión compartido por motivo 3 y AtfB y en la secuencia 3-A (amarillo y subrayado) es el mismo sitio probable para el factor CreA. 
Un análisis realizado con el programa N_SITE, reconoció los probables motivos regulatorios, al comparar contra los 8458 motivos funcionales contenidos en Ghosh Database y Animal Database, con un nivel de significancia del 95\% y una homología del $80 \%$ como criterios de comparación.

Los resultados obtenidos, mostraron que en el promotor del gen $l o v E$ se encuentran presentes diversos elementos regulatorios (58 en total), entre los cuales existen similitudes con aquellos reconocidos por algunos Factores Transcripcionales de respuesta a EOX en humanos, tales como AP-1, AP-2, HSFT, NF-Y, NF- $\kappa-B$, entre otras diversas funciones.

El análisis también se soportó con el programa JASPAR, ya que este programa posee matrices de comparación con Factores Transcripcionales descritos para hongos (específicamente, para la levadura Saccharomyces cerevisiae) y para vertebrados.

El análisis arrojó que el promotor posee diferentes sitios de unión que responden a diferentes actividades celulares, sin embargo, sólo se detallan los probables sitios de unión que responden a EOX, debido al enfoque de este trabajo.

Los resultados de éste análisis se detallan en la Tabla 11. 
Tabla 11 Posibles Factores Transcripcionales que pueden unirse a los motivos encontrados.

\begin{tabular}{|c|c|c|c|c|c|c|}
\hline MOTIVO & Factor Transcripcional & Relative score & CADENA & \multicolumn{2}{|c|}{ POSIBLE SITIO DE UNIÓN } & OBSERVACIONES \\
\hline \multirow[t]{5}{*}{$1-\mathrm{A}$} & HSF 1 & 0.84 & 1 & \multicolumn{2}{|l|}{ ATGAAACA } & HEAT SHOCK FACTOR \\
\hline & SKN7 & 0.85 & -1 & \multicolumn{2}{|l|}{ GGCGCG } & HOMÓLOGO A srrA \\
\hline & SKN7 & 0.86 & -1 & \multicolumn{2}{|l|}{ GGCGCT } & \\
\hline & NFE2L1::MafG & 0.82 & 1 & \multicolumn{2}{|l|}{ CATGAA } & EN HUMANOS NRF-2 (ARE) \\
\hline & AP1 & 0.89 & 1 & \multicolumn{2}{|l|}{ TGAAACA } & HOMOLOGO A YAP1 \\
\hline \multirow[t]{2}{*}{ 1-B } & SKN7 & 0.89 & 1 & \multicolumn{2}{|l|}{ GGCGAC } & \\
\hline & NFE2L1::MafG & 0.82 & 1 & \multicolumn{2}{|l|}{ CATGAA } & \\
\hline \multirow[t]{4}{*}{$1-\mathrm{C}$} & MSN2 & 0.90 & -1 & \multicolumn{2}{|l|}{ CGGGG } & \\
\hline & MSN4 & 0.81 & -1 & \multicolumn{2}{|l|}{ CGGGG } & \\
\hline & AP1 & 0.93 & -1 & \multicolumn{2}{|l|}{ TGACTGA } & \\
\hline & NFE2L1::MafG & 0.87 & -1 & \multicolumn{2}{|l|}{ GGTGAC } & \\
\hline \multirow[t]{2}{*}{ 1-D } & SKN7 & 0.83 & -1 & \multicolumn{2}{|l|}{ GGCCTT } & \\
\hline & SKN7 & 0.97 & 1 & \multicolumn{2}{|l|}{ GGCCAC } & \\
\hline $2-\mathrm{A}$ & SKN7 & 0.90 & 1 & \multicolumn{2}{|l|}{ GGCGGT } & \\
\hline \multirow[t]{2}{*}{ 2-B } & HAP2 & 0.99 & 1 & \multicolumn{2}{|l|}{ TTGGC } & Resp. A Estrés Nutricional \\
\hline & AFT2 & 0.94 & -1 & \multicolumn{2}{|l|}{ TACACCCT } & Homeostasis al hierro y Resp. a EOX \\
\hline $2-\mathrm{C}$ & MSN4 & 0.82 & 1 & \multicolumn{2}{|l|}{ AGGGT } & Resp. A EOX \\
\hline \multirow[t]{7}{*}{ 3-A, 3-B } & AFT2 & 0.86 & 1 & \multicolumn{2}{|l|}{ CCCACCCC } & \\
\hline & AFT2 & 0.82 & 1 & \multicolumn{2}{|l|}{ CACCCCCT } & \\
\hline & ADR1 & 0.82 & 1 & \multicolumn{2}{|l|}{ ACCCCCT } & Resp. Estrés Nutricional \\
\hline & MSN2 & 0.97 & -1 & \multicolumn{2}{|l|}{ GGGGG } & \\
\hline & MSN4 & 0.92 & -1 & GGGGG & & \\
\hline & MSN2 & 1.00 & -1 & AGGGG & & \\
\hline & MSN4 & 1.00 & -1 & AGGGG & & \\
\hline $3-\mathrm{C}$ & RPN4 & 0.86 & -1 & GGGGGCA & & Resp. A varios tipos de estrés \\
\hline & MSN2 & 0.97 & -1 & GGGGG & & \\
\hline & MSN4 & 0.92 & -1 & GGGGG & & \\
\hline & MSN2 & 1.00 & -1 & AGGGG & & \\
\hline & MSN4 & 1.00 & -1 & AGGGG & & \\
\hline Otros posil & es motivos encontrados $\mathrm{c}$ & de Respuesta a E & & & & \\
\hline Factor Tra & scripcional & Posición & Cadena & Posible sitio de unión & & \\
\hline NF-K-B & & -610 & -1 & GGGGATTTTTC & Res & p. A EOX \\
\hline CREA & & -236 & -1 & CCССACСCСCTG & Rep & resión Catabólica \\
\hline ATFB & & -437 & 1 & AGCCC & & \\
\hline & & -254 & 1 & AGCCC & & \\
\hline
\end{tabular}


APÉNDICE 2. Análisis del promotor de lovF.

Siguiendo la misma lógica que para el análisis del promotor $l o v E$, se obtuvieron los resultados descritos en la Fig. 46 para el promotor del gen lovF. Así mismo se detallan las posiciones o sitios de unión probables encontrados para cada uno de los Factores Transcripcionales en la Tabla 12.

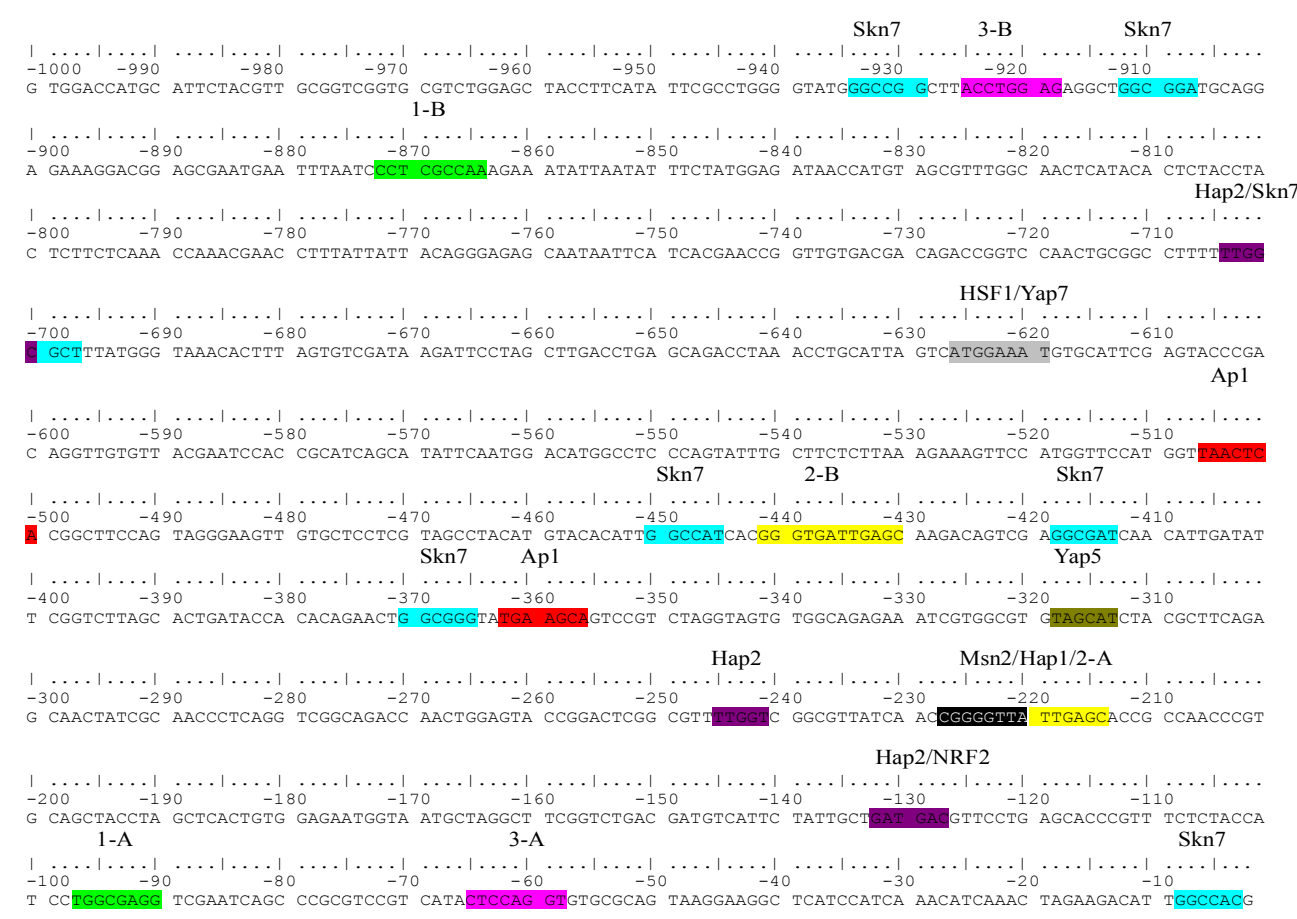

Fig. 46 Análisis in silico del promotor del gen lovF de Aspergillus terreus. 
Tabla 12 Factores Transcripcionales encontrados y sus probables sitios de unión en el promotor del gen lovF de Aspergillus terreus.

\begin{tabular}{l}
\multicolumn{6}{l}{ ANÁLISIS REALIZADO CON MEME Y JASPAR } \\
\begin{tabular}{|l|l|l|l|l|l|l}
\hline Motivo & Cadena & Inicio & p-value & Sitio probable & Secuencia en & POSIBLE FT QUE SE UNE AL \\
\hline $1-A$ & - & -97 & $1.50 \mathrm{E}-05$ & CCTCGCCA & TGGCGAGG & SKN7 \\
\hline $1-\mathrm{B}$ & + & -872 & $1.50 \mathrm{E}-05$ & CCTCGCCA & & \\
\hline 2-A & + & -225 & $1.19 \mathrm{E}-07$ & GGGTTATTGA & & MATA1 \\
\hline 2-B & + & -441 & $1.19 \mathrm{E}-07$ & GGGTGATTGA & & \\
\hline 3-A & - & -64 & $1.51 \mathrm{E}-05$ & ACCTGGAG & CTCCAGGT & ARR1 \\
\hline 3-B & + & -925 & $1.51 \mathrm{E}-05$ & ACCTGGAG & & GLN3 \\
\hline
\end{tabular}
\end{tabular}

\begin{tabular}{l|l|l|l|l|l|}
\hline \multicolumn{7}{|l}{ ANÁLISIS REALIZADO CON JASPAR } & SCOR & RELATIVE & POSICION & CADENA & POSIBLE SECUENCIA DE \\
\hline FACTOR & 8.02 & 0.98 & -934 & 1 & GGCCGG \\
\hline SKN7 & 5.42 & 0.88 & -912 & 1 & GGCGGA \\
\hline SKN7 & 8.50 & 0.99 & -704 & 1 & TTGGC \\
\hline HAP2 & 4.80 & 0.86 & -702 & 1 & GGCGCT \\
\hline SKN7 & 10.53 & 0.90 & -626 & 1 & ATTAGTCATGG \\
\hline YAP7 & 8.30 & 0.88 & -626 & 1 & ATGGAAAT \\
\hline HSF1 & 8.58 & 1.00 & -450 & 1 & GGCCAT \\
\hline SKN7 & 6.36 & 0.92 & -418 & 1 & GGCGAT \\
\hline SKN7 & 5.79 & 0.89 & -370 & 1 & GGCGGG \\
\hline SKN7 & 7.69 & 0.95 & -319 & 1 & TAGCAT \\
\hline YAP5 & 8.68 & 1.00 & -245 & 1 & TTGGT \\
\hline HAP2 & 9.17 & 0.91 & -227 & 1 & CGGGGTTA \\
\hline HAP1 & 6.07 & 0.90 & -227 & 1 & CGGGG \\
\hline MSN2 & 7.83 & 0.97 & -9 & 1 & GGCCAC \\
\hline SKN7 & 6.74 & 0.86 & -506 & 1 & TAACTCA \\
\hline AP1 & 6.69 & 0.85 & -362 & 1 & TGAAGCA \\
\hline AP1 & 8.69 & 0.99 & -132 & 1 & GATGAC \\
\hline NFE2L1::MafG (NRF2) & & & & & \\
\hline
\end{tabular}




\section{El jurado designado por la}

División de Ciencias Biológicas y de la Salud de la Unidad Iztapalapa aprobó la tesis

\section{“RELACIÓN DEL ESTRÉS OXIDANTE CON LA BIOSÍNTESIS DE LOVASTATINA POR Aspergillus terreus EN FERMENTACIÓN SÓLIDA Y LÍQUIDA"}

que presentó la

M. en B. Roxana Uri Miranda Labra

Comité Tutoral:

Director: Dr. Javier Barrios González

Asesor: Dr. Francisco Fierro Fierro

Asesor: Dr. Luis Enrique Gómez Quiroz

Jurado:

Presidente: Dr. Francisco Fierro Fierro

Secretario: Dr. Armando Mejía Álvarez

Vocal: Dr. Luis Enrique Gómez Quiroz

Vocal: Dr. Armando Luna López

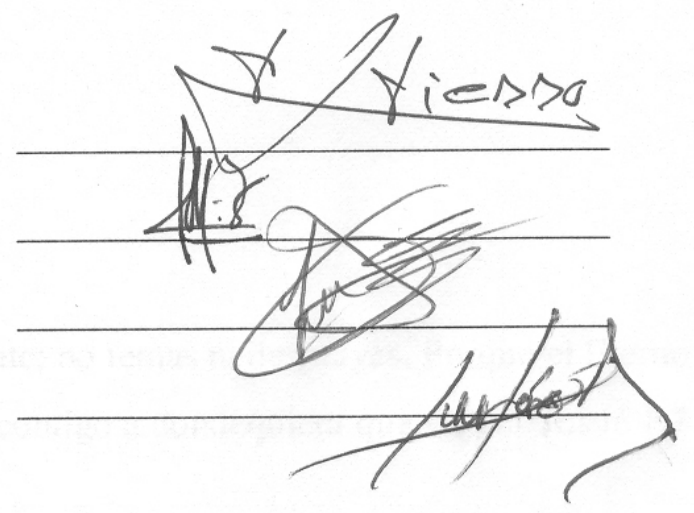

